\title{
Psychosocial interventions to reduce alcohol consumption in concurrent problem alcohol and illicit drug users (Review)
}

Klimas J, Fairgrieve C, Tobin H, Field CA, O'Gorman CSM, Glynn LG, Keenan E, Saunders J, Bury G, Dunne C, Cullen W

Klimas J, Fairgrieve C, Tobin H, Field CA, O'Gorman CSM, Glynn LG, Keenan E, Saunders J, Bury G, Dunne C, Cullen W. Psychosocial interventions to reduce alcohol consumption in concurrent problem alcohol and illicit drug users.

Cochrane Database of Systematic Reviews 2018, Issue 12. Art. No.: CD009269.

DOI: 10.1002/14651858.CD009269.pub4.

www.cochranelibrary.com

Psychosocial interventions to reduce alcohol consumption in concurrent problem alcohol and illicit drug users 
TABLE OF CONTENTS

HEADER 1

ABSTRACT

PLAIN LANGUAGE SUMMARY

SUMMARY OF FINDINGS

BACKGROUND

OBJECTIVES

METHODS

RESULTS

Figure 1.

Figure 2.

Figure 3.

DISCUSSION

AUTHORS' CONCLUSIONS

ACKNOWLEDGEMENTS

REFERENCES

CHARACTERISTICS OF STUDIES

DATA AND ANALYSES

Analysis 1.1. Comparison 1 Cognitive-behavioural coping skills training (CBCST) versus twelve-step facilitation (TSF) programme, Outcome 1 Alcohol abstinence as number achieving 3 or more weeks of consecutive alcohol abstinence during treatment.

Analysis 1.2. Comparison 1 Cognitive-behavioural coping skills training (CBCST) versus twelve-step facilitation (TSF) programme, Outcome 2 Alcohol abstinence as maximum number of weeks of consecutive alcohol abstinence during treatment.

Analysis 1.3. Comparison 1 Cognitive-behavioural coping skills training (CBCST) versus twelve-step facilitation (TSF) programme, Outcome 3 Alcohol abstinence during follow-up year.

Analysis 1.4. Comparison 1 Cognitive-behavioural coping skills training (CBCST) versus twelve-step facilitation (TSF) programme, Outcome 4 Retention - end of treatment (unpublished).

Analysis 1.5. Comparison 1 Cognitive-behavioural coping skills training (CBCST) versus twelve-step facilitation (TSF) programme, Outcome 5 Illicit drug abstinence as maximum number of weeks of consecutive abstinence from cocaine during treatment.

Analysis 1.6. Comparison 1 Cognitive-behavioural coping skills training (CBCST) versus twelve-step facilitation (TSF) programme, Outcome 6 Illicit drug abstinence as number achieving 3 or more weeks of consecutive abstinence from cocaine during treatment.

Analysis 1.7. Comparison 1 Cognitive-behavioural coping skills training (CBCST) versus twelve-step facilitation (TSF) programme, Outcome 7 Illicit drug abstinence as abstinence from cocaine during follow-up year.

Analysis 2.1. Comparison 2 Brief intervention (BI) versus treatment as usual (TAU), Outcome 1 Alcohol use as AUDIT or ASSIST scores at 3 months.

Analysis 2.2. Comparison 2 Brief intervention (BI) versus treatment as usual (TAU), Outcome 2 Alcohol use as AUDIT scores at 9 months.

Analysis 2.3. Comparison 2 Brief intervention (BI) versus treatment as usual (TAU), Outcome 3 Alcohol use as decreased alcohol use at 3 months.

Analysis 2.4. Comparison 2 Brief intervention (BI) versus treatment as usual (TAU), Outcome 4 Alcohol use as number of drinks per week at 3 months.

Analysis 2.5. Comparison 2 Brief intervention (BI) versus treatment as usual (TAU), Outcome 5 Alcohol use as number of drinks per week at 9 months.

Analysis 2.6. Comparison 2 Brief intervention (BI) versus treatment as usual (TAU), Outcome 6 Alcohol use as decreased alcohol use at 9 months.

Analysis 2.7. Comparison 2 Brief intervention (BI) versus treatment as usual (TAU), Outcome 7 Retention at 3 months (unpublished and published data).

Analysis 3.1. Comparison 3 Motivational interviewing (MI) versus treatment as usual (TAU) or educational intervention only, Outcome 1 Alcohol use as AUDIT or ASSIST scores at 3 months.

Analysis 3.2. Comparison 3 Motivational interviewing (MI) versus treatment as usual (TAU) or educational intervention only, Outcome 2 Alcohol use as AUDIT scores at 9 months. 
Analysis 3.3. Comparison 3 Motivational interviewing (MI) versus treatment as usual (TAU) or educational intervention only, Outcome 3 Alcohol use as number of standard drinks consumed per day over the last 30 days.

Analysis 3.4. Comparison 3 Motivational interviewing (MI) versus treatment as usual (TAU) or educational intervention only, Outcome 4 Alcohol use as number of drinks per week at 3 months.

Analysis 3.5. Comparison 3 Motivational interviewing (MI) versus treatment as usual (TAU) or educational intervention only, Outcome 5 Alcohol use as number of drinks per week at 9 months.

Analysis 3.6. Comparison 3 Motivational interviewing (MI) versus treatment as usual (TAU) or educational intervention only, Outcome 6 Alcohol use as greater than $50 \%$ reduction in number of standard drinks consumed per day over the last 30 days. ..

Analysis 3.7. Comparison 3 Motivational interviewing (MI) versus treatment as usual (TAU) or educational intervention only, Outcome 7 Alcohol abstinence as abstinence from alcohol over the last 30 days.

Analysis 3.8. Comparison 3 Motivational interviewing (MI) versus treatment as usual (TAU) or educational intervention only, Outcome 8 Alcohol use as decreased alcohol use at 3 months.

Analysis 3.9. Comparison 3 Motivational interviewing (MI) versus treatment as usual (TAU) or educational intervention only, Outcome 9 Alcohol use as decreased alcohol use at 9 months.

Analysis 3.10. Comparison 3 Motivational interviewing (MI) versus treatment as usual (TAU) or educational intervention only, Outcome 10 Retention - end of treatment.

Analysis 3.11. Comparison 3 Motivational interviewing (MI) versus treatment as usual (TAU) or educational intervention only, Outcome 11 Retention at 3 months (unpublished and published data).

Analysis 3.12. Comparison 3 Motivational interviewing (MI) versus treatment as usual (TAU) or educational intervention only, Outcome 12 Illicit drug use as frequency of drug use (as measured by Addiction Severity Index - ASI drug).

Analysis 3.13. Comparison 3 Motivational interviewing (MI) versus treatment as usual (TAU) or educational intervention only, Outcome 13 Illicit drug use as a composite drug score (frequency*severity for all drugs taken).

Analysis 4.1. Comparison 4 Brief motivational interviewing (BMI) versus assessment-only, Outcome 1 Alcohol use as number of days in the past 30 days with alcohol use at 1 month.

Analysis 4.2. Comparison 4 Brief motivational interviewing (BMI) versus assessment-only, Outcome 2 Alcohol use as number of days in the past 30 days with alcohol use at 6 months.

Analysis 4.3. Comparison 4 Brief motivational interviewing (BMI) versus assessment-only, Outcome 3 Alcohol use as $25 \%$ reduction of drinking days in the past 30 days.

Analysis 4.4. Comparison 4 Brief motivational interviewing (BMI) versus assessment-only, Outcome 4 Alcohol use as $50 \%$ reduction of drinking days in the past 30 days.

Analysis 4.5. Comparison 4 Brief motivational interviewing (BMI) versus assessment-only, Outcome 5 Alcohol use as $75 \%$ reduction of drinking days in the past 30 days.

Analysis 4.6. Comparison 4 Brief motivational interviewing (BMI) versus assessment-only, Outcome 6 Alcohol use as 1 or more drinking days' reduction in the past 30 days.

Analysis 4.7. Comparison 4 Brief motivational interviewing (BMI) versus assessment-only, Outcome 7 Alcohol use as 7 or more drinking days' reduction in the past 30 days.

Analysis 4.8. Comparison 4 Brief motivational interviewing (BMI) versus assessment-only, Outcome 8 Retention - end of treatment.

Analysis 5.1. Comparison 5 Motivational interviewing intensive (MII) versus motivational interviewing (MI), Outcome 1 Alcohol addiction severity as ASI alcohol score at 2 months.

Analysis 5.2. Comparison 5 Motivational interviewing intensive (MII) versus motivational interviewing (MI), Outcome 2 Alcohol addiction severity as ASI alcohol score at 4 months.

Analysis 5.3. Comparison 5 Motivational interviewing intensive (MII) versus motivational interviewing (MI), Outcome 3 Alcohol addiction severity as ASI alcohol score at 6 months.

Analysis 5.4. Comparison 5 Motivational interviewing intensive (MII) versus motivational interviewing (MI), Outcome 4 Retention - end of treatment (unpublished).

Analysis 5.5. Comparison 5 Motivational interviewing intensive (MII) versus motivational interviewing (MI), Outcome 5 Drug abstinence as \% days methamphetamine abstinent in the last 6 months (TLFB).

APPENDICES

WHAT'S NEW

HISTORY

CONTRIBUTIONS OF AUTHORS

DECLARATIONS OF INTEREST

SOURCES OF SUPPORT

DIFFERENCES BETWEEN PROTOCOL AND REVIEW

INDEX TERMS 
[Intervention Review]

\section{Psychosocial interventions to reduce alcohol consumption in concurrent problem alcohol and illicit drug users}

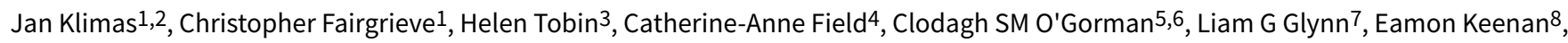
Jean Saunders 9 , Gerard Bury ${ }^{3}$, Colum Dunne 5,10 , Walter Cullen 3

1BC Centre on Substance Use, BC Centre for Excellence in HIV/AIDS, Vancouver, Canada. 2School of Medicine, University College Dublin, Dublin, Ireland. ${ }^{3}$ School of Medicine, University College Dublin, Dublin, Ireland. ${ }^{4}$ National University of Ireland Galway, Galway, Ireland. 5 Graduate Entry Medical School, Faculty of Education and Health Sciences, University of Limerick, Limerick, Ireland. ${ }^{6}$ Department of Paediatrics, Graduate Entry Medical School, University of Limerick, Limerick, Ireland. ${ }^{7}$ General Practice, Graduate Entry Medical School, University of Limerick, Limerick, Ireland. ${ }^{8}$ Addiction Services, Health Service Executive, Dublin, Ireland. ${ }^{9}$ Statistical Consulting Unit/ Applied Biostatistics Consulting Centre /CSTAR, Graduate Entry Medical School, University of Limerick, Limerick, Ireland. ${ }^{10}$ Centre for Interventions in Infection, Inflammation \& Immunity (4i), Faculty of Education and Health Sciences, University of Limerick, Limerick, Ireland

Contact address: Jan Klimas, BC Centre on Substance Use, BC Centre for Excellence in HIV/AIDS, 611 Powell Street, Vancouver, BC, V6A 1H2, Canada.jan.klimas@bccsu.ubc.ca.

Editorial group: Cochrane Drugs and Alcohol Group.

Publication status and date: New search for studies and content updated (no change to conclusions), published in Issue 12, 2018.

Citation: Klimas J, Fairgrieve C, Tobin H, Field CA, O'Gorman CSM, Glynn LG, Keenan E, Saunders J, Bury G, Dunne C, Cullen W. Psychosocial interventions to reduce alcohol consumption in concurrent problem alcohol and illicit drug users. Cochrane Database of Systematic Reviews 2018, Issue 12. Art. No.: CD009269. DOI: 10.1002/14651858.CD009269.pub4.

Copyright @ 2018 The Cochrane Collaboration. Published by John Wiley \& Sons, Ltd.

\section{A B S T R A C T}

\section{Background}

Problem alcohol use is common among people who use illicit drugs (PWID) and is associated with adverse health outcomes. It is also an important factor contributing to a poor prognosis among drug users with hepatitis $\mathrm{C}$ virus (HCV) as it impacts on progression to hepatic cirrhosis or opioid overdose in PWID.

\section{Objectives}

To assess the effectiveness of psychosocial interventions to reduce alcohol consumption in PWID (users of opioids and stimulants).

\section{Search methods}

We searched the Cochrane Drugs and Alcohol Group trials register, the Cochrane Central Register of Controlled Trials (CENTRAL), MEDLINE, Embase, CINAHL, and PsycINFO, from inception up to August 2017, and the reference lists of eligible articles. We also searched: 1) conference proceedings (online archives only) of the Society for the Study of Addiction, International Harm Reduction Association, International Conference on Alcohol Harm Reduction and American Association for the Treatment of Opioid Dependence; and 2) online registers of clinical trials: Current Controlled Trials, ClinicalTrials.gov, Center Watch and the World Health Organization International Clinical Trials Registry Platform.

\section{Selection criteria}

We included randomised controlled trials comparing psychosocial interventions with other psychosocial treatment, or treatment as usual, in adult PWIDs (aged at least 18 years) with concurrent problem alcohol use.

\section{Data collection and analysis}

We used the standard methodological procedures expected by Cochrane.

Psychosocial interventions to reduce alcohol consumption in concurrent problem alcohol and illicit drug users (Review) 


\section{Main results}

We included seven trials (825 participants). We judged the majority of the trials to have a high or unclear risk of bias.

The psychosocial interventions considered in the studies were: cognitive-behavioural coping skills training (one study), twelve-step programme (one study), brief intervention (three studies), motivational interviewing (two studies), and brief motivational interviewing (one study). Two studies were considered in two comparisons. There were no data for the secondary outcome, alcohol-related harm. The results were as follows.

\section{Comparison 1: cognitive-behavioural coping skills training versus twelve-step programme (one study, 41 participants)}

There was no significant difference between groups for either of the primary outcomes (alcohol abstinence assessed with Substance Abuse Calendar and breathalyser at one year: risk ratio (RR) 2.38 (95\% confidence interval [Cl] 0.10 to 55.06); and retention in treatment, measured at end of treatment: RR 0.89 ( $95 \% \mathrm{Cl} 0.62$ to 1.29), or for any of the secondary outcomes reported. The quality of evidence for the primary outcomes was very low.

\section{Comparison 2: brief intervention versus treatment as usual (three studies, 197 participants)}

There was no significant difference between groups for either of the primary outcomes (alcohol use, measured as scores on the Alcohol Use Disorders Identification Test (AUDIT) or Alcohol, Smoking and Substance Involvement Screening Test (ASSIST) at three months: standardised mean difference (SMD) 0.07 ( $95 \% \mathrm{Cl}-0.24$ to 0.37 ); and retention in treatment, measured at three months: RR 0.94 (95\% $\mathrm{Cl}$ 0.78 to 1.13$)$, or for any of the secondary outcomes reported. The quality of evidence for the primary outcomes was low.

Comparison 3: motivational interviewing versus treatment as usual or educational intervention only (three studies, 462 participants)

There was no significant difference between groups for either of the primary outcomes (alcohol use, measured as scores on the AUDIT or ASSIST at three months: SMD 0.04 ( $95 \% \mathrm{Cl}-0.29$ to 0.37$)$; and retention in treatment, measured at three months: $\mathrm{RR} 0.93$ ( $95 \% \mathrm{Cl} 0.60$ to 1.43), or for any of the secondary outcomes reported. The quality of evidence for the primary outcomes was low.

\section{Comparison 4: brief motivational intervention (BMI) versus assessment only (one study, 187 participants)}

More people reduced alcohol use (by seven or more days in the past month, measured at six months) in the BMI group than in the control group (RR 1.67; $95 \% \mathrm{Cl} 1.08$ to 2.60). There was no difference between groups for the other primary outcome, retention in treatment, measured at end of treatment: RR 0.98 ( $95 \% \mathrm{Cl} 0.94$ to 1.02), or for any of the secondary outcomes reported. The quality of evidence for the primary outcomes was moderate.

\section{Comparison 5: motivational interviewing (intensive) versus motivational interviewing (one study, 163 participants)}

There was no significant difference between groups for either of the primary outcomes (alcohol use, measured using the Addiction Severity Index-alcohol score (ASI) at two months: MD 0.03 (95\% $\mathrm{Cl} 0.02$ to 0.08 ); and retention in treatment, measured at end of treatment: RR 17.63 $(95 \% \mathrm{Cl} 1.03$ to 300.48$)$, or for any of the secondary outcomes reported. The quality of evidence for the primary outcomes was low.

\section{Authors' conclusions}

We found low to very low-quality evidence to suggest that there is no difference in effectiveness between different types of psychosocial interventions to reduce alcohol consumption among people who use illicit drugs, and that brief interventions are not superior to assessment-only or to treatment as usual. No firm conclusions can be made because of the paucity of the data and the low quality of the retrieved studies.

\section{PLAIN LANGUAGE SUMMARY}

Which talking therapies work for people who use drugs and also have alcohol problems?

\section{Review question}

We wanted to see whether talking therapies reduce drinking in adult users of illicit drugs (mainly opioids and stimulants). We also wanted to find out whether one type of therapy is more effective than another.

\section{Background}

Drinking alcohol above the low-risk drinking limits can lead to serious alcohol use problems or disorders. Drinking above those limits is common in people who also have problems with other drugs. It worsens their physical and mental health. Talking therapies aim to identify an alcohol problem and motivate an individual to do something about it. Talking therapies can be given by trained doctors, nurses, counsellors, psychologists, etc. Talking therapies may help reduce alcohol use but we wanted to find out if they can help people who also have problems with other drugs. 
Search date: the evidence is current to August 2017.

\section{Study characteristics}

We found seven studies that examined five talking therapies among 825 people with drug problems.

Cognitive-behavioural coping skills training (CBCST) is a talking therapy that focuses on changing the way people think and act.

The twelve-step programme is based on theories from Alcoholics Anonymous and aims to motivate the person to develop a desire to stop using drugs or alcohol.

Motivational interviewing (MI) helps people to explore and resolve doubts about changing their behaviour. It can be delivered in group, individual and intensive formats.

Brief motivational interviewing (BMI) is a shorter MI that takes 45 minutes to three hours.

Brief interventions are based on MI but they take only five to 30 minutes and are often delivered by a non-specialist.

Six of the studies were funded by the National Institutes for Health or by the Health Research Board; one study did not report its funding source.

\section{Key results}

We found that the talking therapies led to no differences, or only small differences, for the outcomes assessed. These included abstinence, reduced drinking, and substance use.

One study found that there may be no difference between CBCST and the twelve-step programme.

Three studies found that there may be no difference between brief intervention and usual treatment.

Three studies found that there may be no difference between MI and usual treatment or education only.

One study found that BMI is probably better at reducing alcohol use than usual treatment (needle exchange), but found no differences in other outcomes.

One study found that intensive MI may be somewhat better than standard MI at reducing severity of alcohol use disorder among women, but not among men and found no differences in other outcomes.

It remains uncertain whether talking therapies reduce alcohol and drug use in people who also have problems with other drugs. Highquality studies are missing and are needed.

\section{Quality of evidence}

The quality of the evidence was moderate for brief and intensive motivational interviewing, but low for brief interventions and standard motivational interviewing, and very low for CBCST versus twelve-step programme. 


\section{SUMMARY OF FINDINGS}

Summary of findings for the main comparison. Cognitive-behavioural coping skills training (CBCST) compared to twelve-step facilitation (TSF) programme to reduce alcohol consumption in people who use illicit drugs (PWID)

Cognitive-behavioural coping skills training (CBCST) compared to twelve-step facilitation (TSF) programme to reduce alcohol consumption in PWID

Patient or population: concurrent problem alcohol and illicit drug users

Setting: substance use treatment centre

Intervention: cognitive-behavioural coping skills training (CBCST)

Comparison: twelve-step facilitation (TSF) programme

\begin{tabular}{|c|c|c|c|c|c|c|}
\hline \multirow[t]{2}{*}{ Outcomes } & \multicolumn{2}{|c|}{ Anticipated absolute effects ${ }^{*}(95 \% \mathrm{Cl})$} & \multirow{2}{*}{$\begin{array}{l}\text { Relative effect } \\
(95 \% \mathrm{CI})\end{array}$} & \multirow{2}{*}{$\begin{array}{l}\text { № of partici- } \\
\text { pants } \\
\text { (studies) }\end{array}$} & \multirow{2}{*}{$\begin{array}{l}\text { Quality of the } \\
\text { evidence } \\
\text { (GRADE) }\end{array}$} & \multirow[t]{2}{*}{ Comments } \\
\hline & $\begin{array}{l}\text { Risk with twelve- } \\
\text { step facilitation } \\
\text { (TSF) programme }\end{array}$ & $\begin{array}{l}\text { Risk with cogni- } \\
\text { tive-behavioural } \\
\text { coping skills train- } \\
\text { ing (CBCST) }\end{array}$ & & & & \\
\hline $\begin{array}{l}\text { Maximum number of weeks of consecutive al- } \\
\text { cohol abstinence during treatment } \\
\text { assessed with: Substance abuse calendar } \\
\text { and breathalyser } \\
\text { Scale from: } 0 \text { to } 12 \\
\text { Follow-up: } 12 \text { weeks }\end{array}$ & $\begin{array}{l}\text { The mean maximum } \\
\text { number of weeks of } \\
\text { consecutive alcohol } \\
\text { abstinence during } \\
\text { treatment was } 1.8 \\
\text { weeks }\end{array}$ & $\begin{array}{l}\text { MD } 0.4 \text { weeks higher } \\
\text { (1.14 lower to } 1.94 \\
\text { higher) }\end{array}$ & - & $\begin{array}{l}41 \\
(1 \mathrm{RCT})\end{array}$ & $\begin{array}{l}\oplus \ominus \Theta \Theta \\
\text { VERY LOW } 12\end{array}$ & \\
\hline \multirow{2}{*}{$\begin{array}{l}\text { Number of participants achieving } 3 \text { or more } \\
\text { weeks of consecutive alcohol abstinence dur- } \\
\text { ing treatment } \\
\text { assessed with: Substance abuse calendar } \\
\text { and breathalyser } \\
\text { Follow-up: } 1 \text { year }\end{array}$} & \multicolumn{2}{|l|}{ Study population } & \multirow{2}{*}{$\begin{array}{l}\text { RR } 1.96 \\
\text { (0.43 to } 8.94)\end{array}$} & \multirow{2}{*}{$\begin{array}{l}41 \\
(1 \mathrm{RCT})\end{array}$} & \multirow{2}{*}{$\begin{array}{l}\oplus \ominus \Theta \Theta \\
\text { VERY LOW } 12\end{array}$} & \\
\hline & 111 per 1,000 & $\begin{array}{l}218 \text { per } 1,000 \\
\text { (48 to } 993 \text { ) }\end{array}$ & & & & \\
\hline \multirow{2}{*}{$\begin{array}{l}\text { Alcohol abstinence } \\
\text { assessed with: Substance abuse calendar } \\
\text { and breathalyser } \\
\text { Follow-up: } 1 \text { year }\end{array}$} & \multicolumn{2}{|l|}{ Study population } & \multirow{2}{*}{$\begin{array}{l}\text { RR } 2.38 \\
\text { (0.10 to } 55.06)\end{array}$} & \multirow{2}{*}{$\begin{array}{l}41 \\
(1 \mathrm{RCT})\end{array}$} & \multirow{2}{*}{$\begin{array}{l}\oplus \ominus \ominus \ominus \\
\text { VERY LOW } 12\end{array}$} & \\
\hline & 0 per 1,000 & $\begin{array}{l}0 \text { per } 1,000 \\
(0 \text { to } 0)\end{array}$ & & & & \\
\hline \multirow{2}{*}{$\begin{array}{l}\text { Retention - end of treatment } \\
\text { Assessed with: number of participants com- } \\
\text { pleting all treatment sessions }\end{array}$} & \multicolumn{2}{|l|}{ Study population } & \multirow{2}{*}{$\begin{array}{l}\text { RR } 0.89 \\
\text { (0.62 to } 1.29)\end{array}$} & \multirow{2}{*}{$\begin{array}{l}41 \\
(1 \mathrm{RCT})\end{array}$} & \multirow{2}{*}{$\begin{array}{l}\oplus \ominus \ominus \ominus \\
\text { VERY LOW } 12\end{array}$} & \\
\hline & 778 per 1,000 & $\begin{array}{l}692 \text { per } 1,000 \\
\text { (482 to } 1,000 \text { ) }\end{array}$ & & & & \\
\hline
\end{tabular}




\begin{tabular}{|c|c|c|c|c|c|c|c|}
\hline \multirow{10}{*}{ 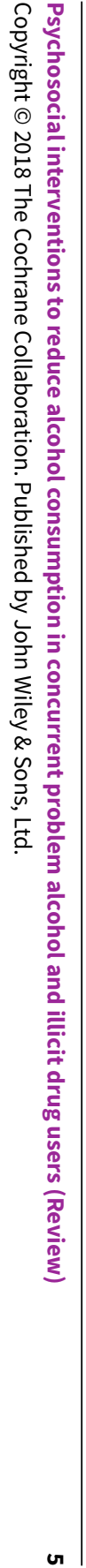 } & \multicolumn{7}{|c|}{$\begin{array}{l}{ }^{*} \text { The risk in the intervention group (and its } 95 \% \text { confidence interval) is based on the assumed } \\
\text { its } 95 \% \mathrm{Cl} \text { ). } \\
\text { Cl: Confidence interval; RR: Risk ratio; MD: mean difference; PWID: people who use illicit drugs }\end{array}$} \\
\hline & \multicolumn{7}{|c|}{$\begin{array}{l}\text { GRADE Working Group grades of evidence } \\
\text { High quality: We are very confident that the true effect lies close to that of the estimate of the effect } \\
\text { Moderate quality: We are moderately confident in the effect estimate: The true effect is likely to be close to the estimate of the effect, but there is a possibility that it is sub- } \\
\text { stantially different } \\
\text { Low quality: Our confidence in the effect estimate is limited: The true effect may be substantially different from the estimate of the effect } \\
\text { Very low quality: We have very little confidence in the effect estimate: The true effect is likely to be substantially different from the estimate of effect }\end{array}$} \\
\hline & \multicolumn{7}{|c|}{$\begin{array}{l}1 \text { Downgraded one level for risk of bias: incomplete outcome data. } \\
2 \text { Downgraded two levels for imprecision: only one study with very few participants included in comparison. }\end{array}$} \\
\hline & \multicolumn{7}{|c|}{ Brief intervention (BI) compared to treatment as usual (TAU) to reduce alcohol consumption in PWID } \\
\hline & \multicolumn{7}{|c|}{$\begin{array}{l}\text { Patient or population: concurrent problem alcohol and illicit drug users } \\
\text { Setting: opioid agonist treatment clinic, outpatient clinic with/without opioid agonist treatment, and primary care setting } \\
\text { Intervention: brief intervention (BI) } \\
\text { Comparison: treatment as usual (TAU) }\end{array}$} \\
\hline & \multirow[t]{2}{*}{ Outcomes } & \multicolumn{2}{|c|}{ Anticipated absolute effects ${ }^{\star}(95 \% \mathrm{Cl})$} & \multirow{2}{*}{$\begin{array}{l}\text { Relative effect } \\
(95 \% \mathrm{CI})\end{array}$} & \multirow{2}{*}{$\begin{array}{l}\text { № of partici- } \\
\text { pants } \\
\text { (studies) }\end{array}$} & \multirow{2}{*}{$\begin{array}{l}\text { Quality of the } \\
\text { evidence } \\
\text { (GRADE) }\end{array}$} & \multirow[t]{2}{*}{ Comments } \\
\hline & & $\begin{array}{l}\text { Risk with treatment as } \\
\text { usual (TAU) }\end{array}$ & $\begin{array}{l}\text { Risk with Brief in- } \\
\text { tervention (BI) }\end{array}$ & & & & \\
\hline & $\begin{array}{l}\text { Alcohol Use Disorders Identification Test } \\
\text { (AUDIT) or Alcohol, Smoking and Substance } \\
\text { Involvement Screening Test (ASSIST) scores } \\
\text { Follow-up: } 3 \text { months }\end{array}$ & $\begin{array}{l}\text { The mean alcohol Use } \\
\text { Disorders Identification } \\
\text { Test (AUDIT) or Alcohol, } \\
\text { Smoking and Substance } \\
\text { Involvement Screening } \\
\text { Test (ASSIST) score was } 0\end{array}$ & $\begin{array}{l}\text { SMD } 0.07 \text { higher } \\
(0.24 \text { lower to } 0.37 \\
\text { higher })^{4}\end{array}$ & - & $\begin{array}{l}170 \\
(3 \mathrm{RCTs})\end{array}$ & $\begin{array}{l}\oplus \oplus \Theta \ominus \\
\mathrm{LOW} 12\end{array}$ & \\
\hline & $\begin{array}{l}\text { Alcohol Use Disorders Identification Test } \\
\text { (AUDIT) scores } \\
\text { Follow-up: } 9 \text { months }\end{array}$ & $\begin{array}{l}\text { The mean alcohol Use } \\
\text { Disorders Identification } \\
\text { Test (AUDIT) scores was } \\
11.6\end{array}$ & $\begin{array}{l}\text { MD } 2.3 \text { higher } \\
\text { ( } 0.58 \text { lower to } 5.18 \\
\text { higher) }\end{array}$ & - & $\begin{array}{l}110 \\
(1 \mathrm{RCT})\end{array}$ & $\begin{array}{l}\oplus \oplus \odot \odot \\
\text { LOW } 13\end{array}$ & \\
\hline & $\begin{array}{l}\text { Number of drinks per week } \\
\text { Assessed with: unreported }\end{array}$ & $\begin{array}{l}\text { The mean number of } \\
\text { drinks per week was } 16.3\end{array}$ & MD 0.7 higher & - & $\begin{array}{l}110 \\
(1 \mathrm{RCT})\end{array}$ & $\begin{array}{l}\oplus \oplus \odot \odot \\
\text { LOW } 13\end{array}$ & \\
\hline
\end{tabular}




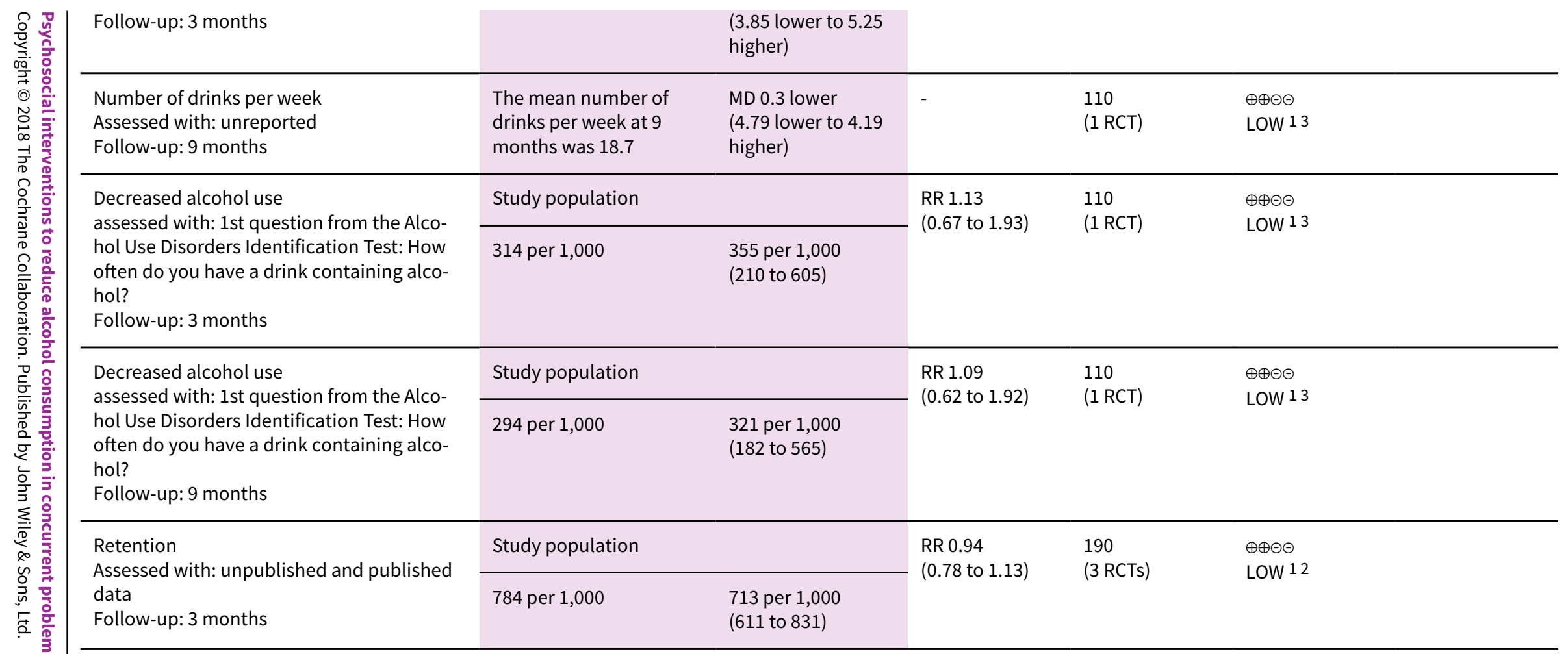

${ }^{*}$ The risk in the intervention group (and its $95 \%$ confidence interval) is based on the assumed risk in the comparison group and the relative effect of the intervention (and its $95 \% \mathrm{Cl})$.

CI: Confidence interval; RR: Risk ratio; MD: mean difference;SMD: standardised mean difference; PWID: people who use illicit drugs

\section{GRADE Working Group grades of evidence}

High quality: We are very confident that the true effect lies close to that of the estimate of the effect

Moderate quality: We are moderately confident in the effect estimate: The true effect is likely to be close to the estimate of the effect, but there is a possibility that it is substantially different

Low quality: Our confidence in the effect estimate is limited: The true effect may be substantially different from the estimate of the effect

Very low quality: We have very little confidence in the effect estimate: The true effect is likely to be substantially different from the estimate of effect

1 Downgraded one level for risk of bias: high risk of detection bias (no blinding of outcome assessor, subjective outcomes).

2 Downgraded one level for imprecision: only three studies with relatively few participants included in comparison.

3 Downgraded one level for imprecision: only one study with relatively few participants included in comparison.

4 The result corresponds to a small, statistically insignificant difference. 


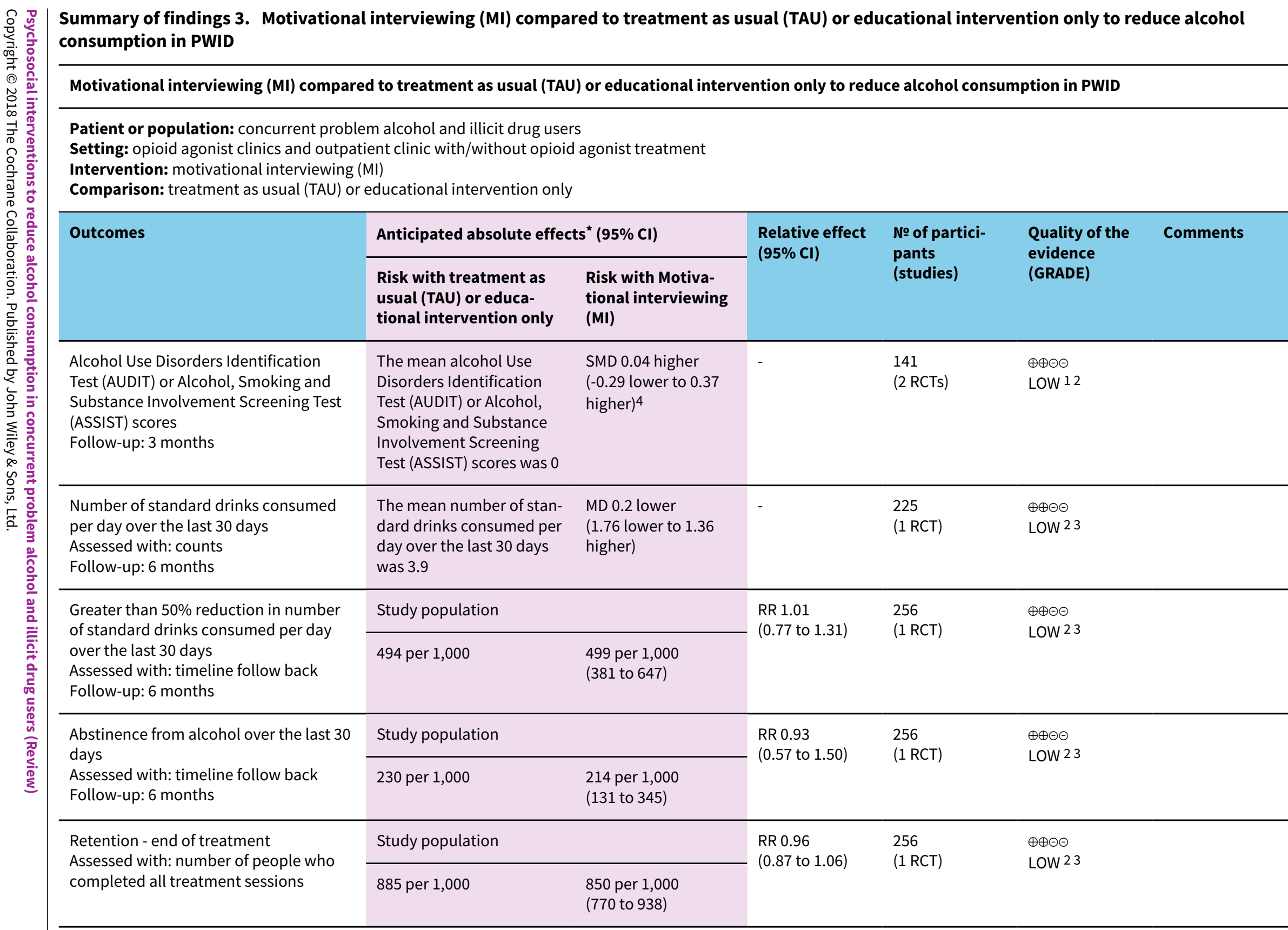

Setting: opioid agonist clinics and outpatient clinic with/without opioid agonist treatment

Intervention: motivational interviewing (MI)

Test (AUDIT) or Alcohol, Smoking an

Substance Involvement Screening Test

(ASSIST) scores

SMD 0.04 higher

$(-0.29$ lower to 0.37

Test (AUDIT) or Alcohol, higher) 4

Smoking and Substance

Involvement Screening

Test (ASSIST) scores was 0

Number of standard drinks consumed

The mean number of standard drinks consumed per day over the last 30 days

0.2 lower

(1.76 lower to 1.36

vas 3.9 


\begin{tabular}{|c|c|c|c|c|c|c|c|}
\hline \multirow{2}{*}{\multicolumn{2}{|c|}{ 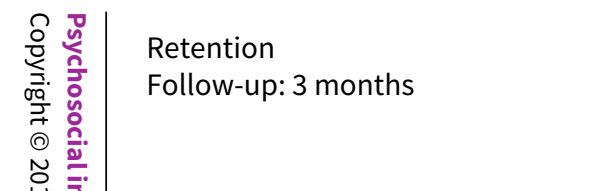 }} & \multicolumn{2}{|l|}{ Study population } & \multirow{2}{*}{$\begin{array}{l}\text { RR } 0.93 \\
\text { (0.60 to } 1.43 \text { ) }\end{array}$} & \multirow{2}{*}{$\begin{array}{l}160 \\
(2 \text { RCTs })\end{array}$} & \multirow{2}{*}{\multicolumn{2}{|c|}{$\begin{array}{l}\oplus \oplus \ominus \ominus \\
\text { LOW } 23\end{array}$}} \\
\hline & & 738 per 1,000 & $\begin{array}{l}671 \text { per } 1,000 \\
(553 \text { to } 811)\end{array}$ & & & & \\
\hline 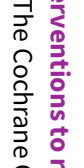 & \multicolumn{7}{|c|}{$\begin{array}{l}{ }^{*} \text { The risk in the intervention group (and its } 95 \% \text { confidence interval) is based on the assumed } \mathrm{r} \\
\text { its } 95 \% \mathrm{Cl} \text { ). } \\
\text { Cl: Confidence interval; RR: Risk ratio; MD: mean difference; PWID: people who use illicit drugs }\end{array}$} \\
\hline 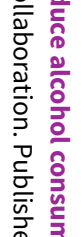 & \multicolumn{7}{|c|}{$\begin{array}{l}\text { GRADE Working Group grades of evidence } \\
\text { High quality: We are very confident that the true effect lies close to that of the estimate of the effect } \\
\text { Moderate quality: We are moderately confident in the effect estimate: The true effect is likely to be close to the estimate of the effect, but there is a possibility that it is sub- } \\
\text { stantially different } \\
\text { Low quality: Our confidence in the effect estimate is limited: The true effect may be substantially different from the estimate of the effect } \\
\text { Very low quality: We have very little confidence in the effect estimate: The true effect is likely to be substantially different from the estimate of effect }\end{array}$} \\
\hline 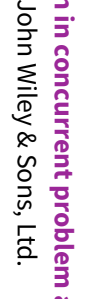 & \multicolumn{7}{|c|}{$\begin{array}{l}1 \text { Downgraded one level for imprecision: only two studies with relatively few participants included in comparison. } \\
2 \text { Downgraded one level for risk of bias: high risk of selection and detection bias (subjective outcomes). } \\
3 \text { Downgraded one level for imprecision: only one study with relatively few participants included in comparison. } \\
4 \text { The result corresponds to a small, statistically insignificant difference. }\end{array}$} \\
\hline $\overrightarrow{0}$ & \multicolumn{7}{|c|}{ Brief motivational interviewing (BMI) compared to assessment-only to reduce alcohol consumption in PWID } \\
\hline 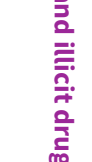 & \multicolumn{7}{|c|}{$\begin{array}{l}\text { Patient or population: concurrent problem alcohol and illicit drug users } \\
\text { Setting: addiction clinic } \\
\text { Intervention: brief motivational interviewing (BMI) } \\
\text { Comparison: assessment-only }\end{array}$} \\
\hline $\bar{n}$ & \multirow[t]{2}{*}{ Outcomes } & \multicolumn{2}{|c|}{ Anticipated absolute effects ${ }^{\star}(95 \% \mathrm{Cl})$} & \multirow{2}{*}{$\begin{array}{l}\text { Relative effect } \\
(95 \% \mathrm{CI})\end{array}$} & \multirow{2}{*}{$\begin{array}{l}\text { № of partici- } \\
\text { pants } \\
\text { (studies) }\end{array}$} & \multirow{2}{*}{$\begin{array}{l}\text { Quality of the } \\
\text { evidence } \\
\text { (GRADE) }\end{array}$} & \multirow[t]{2}{*}{ Comments } \\
\hline 迹. & & $\begin{array}{l}\text { Risk with assess- } \\
\text { ment-only }\end{array}$ & $\begin{array}{l}\text { Risk with Brief moti- } \\
\text { vational interviewing } \\
\text { (BMI) }\end{array}$ & & & & \\
\hline & $\begin{array}{l}\text { Number of days with alcohol use } \\
\text { Assessed with: timeline follow back } \\
\text { Scale from: } 0 \text { to } 31 \\
\text { Follow-up: } 6 \text { months }\end{array}$ & $\begin{array}{l}\text { The mean num- } \\
\text { ber of days with } \\
\text { alcohol use was } \\
9.1 \text { days }\end{array}$ & $\begin{array}{l}\text { MD } 1.5 \text { days lower } \\
\text { (4.56 lower to } 1.56 \\
\text { higher) }\end{array}$ & - & $\begin{array}{l}187 \\
(1 \mathrm{RCT})\end{array}$ & $\begin{array}{l}\oplus \oplus \oplus \ominus \\
\text { MODERATE } 1\end{array}$ & \\
\hline
\end{tabular}




\begin{tabular}{|c|c|c|c|c|c|c|}
\hline \multirow{2}{*}{\multicolumn{2}{|c|}{ 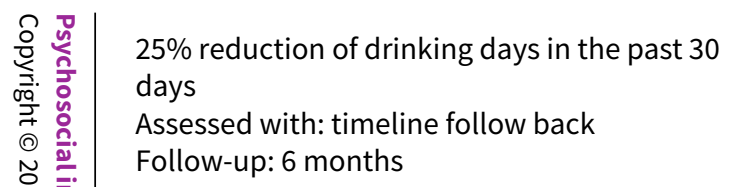 }} & \multicolumn{2}{|c|}{ Study population } & \multirow{2}{*}{$\begin{array}{l}\text { RR } 1.23 \\
(0.96 \text { to } 1.57)\end{array}$} & \multirow{2}{*}{$\begin{array}{l}187 \\
(1 \mathrm{RCT})\end{array}$} & \multirow{2}{*}{$\begin{array}{l}\oplus \oplus \oplus \ominus \\
\text { MODERATE } 1\end{array}$} \\
\hline & & 522 per 1,000 & $\begin{array}{l}642 \text { per } 1,000 \\
(501 \text { to } 819)\end{array}$ & & & \\
\hline 永 & $50 \%$ reduction of drinking days in the past 30 & \multicolumn{2}{|c|}{ Study population } & \multirow{2}{*}{$\begin{array}{l}\text { RR } 1.27 \\
\text { (0.96 to } 1.68 \text { ) }\end{array}$} & \multirow{2}{*}{$\begin{array}{l}187 \\
(1 \mathrm{RCT})\end{array}$} & \multirow{2}{*}{$\begin{array}{l}\oplus \oplus \oplus \ominus \\
\text { MODERATE } 1\end{array}$} \\
\hline 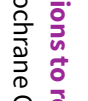 & $\begin{array}{l}\text { Assessed with: timeline follow back } \\
\text { Follow-up: } 6 \text { months }\end{array}$ & 457 per 1,000 & $\begin{array}{l}580 \text { per } 1,000 \\
\text { (438 to } 767 \text { ) }\end{array}$ & & & \\
\hline 言 & 7 or more drinking days' reduction in the past & \multicolumn{2}{|c|}{ Study population } & \multirow{2}{*}{$\begin{array}{l}\text { RR } 1.67 \\
\text { (1.08 to } 2.60)\end{array}$} & \multirow{2}{*}{$\begin{array}{l}187 \\
(1 \mathrm{RCT})\end{array}$} & \multirow{2}{*}{$\begin{array}{l}\oplus \oplus \oplus \ominus \\
\text { MODERATE } 1\end{array}$} \\
\hline 辛 & $\begin{array}{l}\text { Assessed with: timeline follow back } \\
\text { Follow-up: } 6 \text { months }\end{array}$ & 239 per 1,000 & $\begin{array}{l}399 \text { per } 1,000 \\
\text { (258 to } 622)\end{array}$ & & & \\
\hline $\begin{array}{l}\bar{y} \\
\frac{n}{0} \\
\frac{1}{2} \\
\frac{3}{0}\end{array}$ & Retention - end of treatment & \multicolumn{2}{|c|}{ Study population } & \multirow{2}{*}{$\begin{array}{l}\text { RR } 0.98 \\
\text { (0.94 to } 1.02 \text { ) }\end{array}$} & \multirow{2}{*}{$\begin{array}{l}190 \\
(1 \mathrm{RCT})\end{array}$} & \multirow{2}{*}{$\begin{array}{l}\oplus \oplus \oplus \ominus \\
\text { MODERATE } 1\end{array}$} \\
\hline 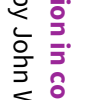 & pleted all treatment sessions & 968 per 1,000 & $\begin{array}{l}949 \text { per } 1,000 \\
\text { (910 to } 988)\end{array}$ & & & \\
\hline 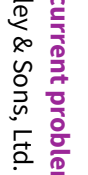 & \multicolumn{6}{|c|}{$\begin{array}{l}{ }^{\star} \text { The risk in the intervention group (and its } 95 \% \text { confidence interval) is based on the assumed } r \\
\text { its } 95 \% \mathrm{CI} \text { ). } \\
\text { Cl: Confidence interval; RR: Risk ratio; MD: mean difference; PWID: people who use illicit drugs }\end{array}$} \\
\hline 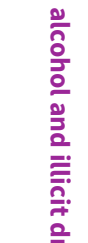 & \multicolumn{6}{|c|}{$\begin{array}{l}\text { GRADE Working Group grades of evidence } \\
\text { High quality: We are very confident that the true effect lies close to that of the estimate of the effect } \\
\text { Moderate quality: We are moderately confident in the effect estimate: The true effect is likely to be close to the estimate of the effect, but there is a po } \\
\text { stantially different } \\
\text { Low quality: Our confidence in the effect estimate is limited: The true effect may be substantially different from the estimate of the effect } \\
\text { Very low quality: We have very little confidence in the effect estimate: The true effect is likely to be substantially different from the estimate of effect }\end{array}$} \\
\hline 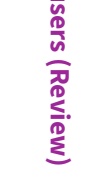 & $\begin{array}{l}1 \text { Downgraded one level for imprecision: only on } \\
\text { Summary of findings } 5 \text {. Motivational int }\end{array}$ & tudy with relativ & few participants i & comparison. & wing (MI & uce alcohol consumption in PWID \\
\hline & \multicolumn{6}{|c|}{ Motivational interviewing intensive (MII) compared to motivational interviewing (MI) to reduce alcohol consumption in PWID } \\
\hline & \multicolumn{6}{|c|}{$\begin{array}{l}\text { Patient or population: concurrent problem alcohol and illicit drug users } \\
\text { Setting: an outpatient substance use disorder treatment facility } \\
\text { Intervention: motivational interviewing intensive (MII) } \\
\text { Comparison: motivational interviewing (MI) }\end{array}$} \\
\hline
\end{tabular}




\begin{tabular}{|c|c|c|c|c|c|c|c|}
\hline \multirow{3}{*}{\multicolumn{2}{|c|}{ 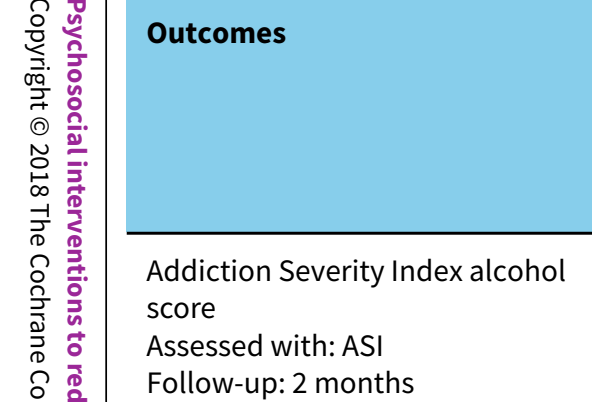 }} & \multicolumn{2}{|c|}{ Anticipated absolute effects ${ }^{\star}(95 \% \mathrm{Cl})$} & \multirow{2}{*}{$\begin{array}{l}\text { Relative effect } \\
(95 \% \mathrm{CI})\end{array}$} & \multirow{2}{*}{$\begin{array}{l}\text { № of partici- } \\
\text { pants } \\
\text { (studies) }\end{array}$} & \multirow{2}{*}{$\begin{array}{l}\text { Quality of the } \\
\text { evidence } \\
\text { (GRADE) }\end{array}$} & \multirow[t]{2}{*}{ Comments } \\
\hline & & $\begin{array}{l}\text { Risk with motivational } \\
\text { interviewing (MII) }\end{array}$ & $\begin{array}{l}\text { Risk with Motivational } \\
\text { interviewing intensive } \\
\text { (MI) }\end{array}$ & & & & \\
\hline & & $\begin{array}{l}\text { The mean addiction } \\
\text { Severity Index alcohol } \\
\text { score was } 0.11\end{array}$ & $\begin{array}{l}\text { MD } 0.03 \text { higher } \\
\text { (0.02 lower to } 0.08 \text { high- } \\
\text { er) }\end{array}$ & - & $\begin{array}{l}163 \\
(1 \mathrm{RCT})\end{array}$ & $\begin{array}{l}\oplus \oplus \Theta \ominus \\
\text { LOW } 12\end{array}$ & \\
\hline 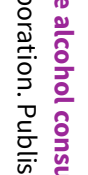 & $\begin{array}{l}\text { Addiction Severity Index alcohol } \\
\text { score } \\
\text { Assessed with: ASI } \\
\text { Follow-up: } 4 \text { months }\end{array}$ & $\begin{array}{l}\text { The mean addiction } \\
\text { Severity Index alcohol } \\
\text { score was } 0.16\end{array}$ & $\begin{array}{l}\text { MD } 0.01 \text { lower } \\
\text { (0.06 lower to } 0.04 \text { high- } \\
\text { er) }\end{array}$ & - & $\begin{array}{l}163 \\
(1 \mathrm{RCT})\end{array}$ & $\begin{array}{l}\oplus \oplus \odot \odot \\
\text { LOW } 12\end{array}$ & \\
\hline 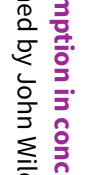 & $\begin{array}{l}\text { Addiction Severity Index alcohol } \\
\text { score } \\
\text { assessed with: ASI } \\
\text { Follow-up: } 6 \text { months }\end{array}$ & $\begin{array}{l}\text { The mean addiction } \\
\text { Severity Index alcohol } \\
\text { score was } 0.16\end{array}$ & $\begin{array}{l}\text { MD } 0.02 \text { lower } \\
\text { (0.07 lower to } 0.03 \text { high- } \\
\text { er) }\end{array}$ & - & $\begin{array}{l}163 \\
(1 \mathrm{RCT})\end{array}$ & $\begin{array}{l}\oplus \oplus \odot \odot \\
\text { LOW } 12\end{array}$ & \\
\hline 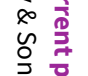 & \multirow{2}{*}{$\begin{array}{l}\text { Retention - end of treatment } \\
\text { Assessed with: number of people } \\
\text { who completed all treatment ses- } \\
\text { sions }\end{array}$} & Study population & & \multirow{2}{*}{$\begin{array}{l}\text { RR } 17.63 \\
\text { (1.03 to } 300.48)\end{array}$} & \multirow{2}{*}{$\begin{array}{l}163 \\
(1 \mathrm{RCT})\end{array}$} & \multirow{2}{*}{\multicolumn{2}{|c|}{$\begin{array}{l}\oplus \oplus \oplus \ominus \\
\text { LOW } 12\end{array}$}} \\
\hline$\frac{5}{\frac{2}{2}} \frac{\overline{0}}{\frac{0}{0}}$ & & 0 per 1,000 & $\begin{array}{l}0 \text { per } 1,000 \\
(0 \text { to } 0)\end{array}$ & & & & \\
\hline $\begin{array}{l}\frac{\bar{\sigma}}{\frac{0}{2}} \\
\frac{2}{2} \\
\overline{\bar{z}}\end{array}$ & \multicolumn{7}{|c|}{$\begin{array}{l}{ }^{\star} \text { The risk in the intervention group (and its } 95 \% \text { confidence interval) is based on the assumed risk in the comparison group and the relative effect of the intervention (and } \\
\text { its } 95 \% \mathrm{CI} \text { ). } \\
\text { CI: Confidence interval; RR: Risk ratio; OR: Odds ratio; PWID: people who use illicit drugs }\end{array}$} \\
\hline
\end{tabular}

\section{GRADE Working Group grades of evidence}

High quality: We are very confident that the true effect lies close to that of the estimate of the effect

Moderate quality: We are moderately confident in the effect estimate: The true effect is likely to be close to the estimate of the effect, but there is a possibility that it is substantially different

Low quality: Our confidence in the effect estimate is limited: The true effect may be substantially different from the estimate of the effect

Very low quality: We have very little confidence in the effect estimate: The true effect is likely to be substantially different from the estimate of effect

1 Downgrared one level for risk of bias: high risk of detection bias (subjective outcomes).

2 Downgraded one level for imprecision: only one study with relatively few participants included in comparison. 


\section{B A C K G R O U N D}

\section{Description of the condition}

Problem alcohol use is common among people who use illicit drugs (PWID) and is associated with adverse health outcomes, which have physical, psychological and social implications (Staiger 2013). Meta-analyses of US clinical trial data, performed by the National Institute on Drug Abuse (NIDA), found alcohol use disorders (AUDs) in $38 \%$ and $45 \%$ of opiate- and stimulant-using treatment seekers, respectively (Hartzler 2010; Hartzler 2011). The prevalence of 'heavy drinking' or diagnosis of alcohol use disorder among PWID enrolled in methadone maintenance treatment (MMT) ranges from 13\% to 28\% (Chen 2011; Klimas 2015a; Klimas 2017b). In comparison, cross-sectional studies have reported prevalence rates of 33\% to $50 \%$ in this setting (Islam 2013; Wurst 2011). Another study found that $28 \%$ of heroin users and methadone- or codeinemaintained patients consumed more than $40 \mathrm{~g}$ of alcohol daily (Backmund 2003).

Problem alcohol use is an expression that represents a spectrum of distinct drinking patterns (i.e. hazardous, harmful and dependent drinking). Hazardous drinking "is likely to result in harm should present habits persist" (Babor 2001), whereas harmful drinking, which is a diagnosis given in the International Classification of Diseases, Tenth Revision (ICD-10) (WHO 1993), "causes harm to the health (physical or mental) of the individual" without the presence of dependence (Babor 2001). Hazardous drinking that becomes severe is assigned the medical diagnosis of alcohol use disorder (AUD) under the Diagnostic and Statistical Manual of Mental Disorders, Fifth Edition (DSM-5), or ICD-10 criteria (WHO 1993). Eleven diagnostic criteria describe the DSM-5 AUD diagnosis, which is determined by the presence of any two of the 11 criteria during the last year. Based on the number of criteria fulfilled, an AUD can be mild ( 2 to 3 ), moderate (4 to 5 ) or severe (more than 6). According to the National Institute on Alcohol Abuse and Alcoholism, "binge drinking" refers to a pattern of drinking wherein blood alcohol level is regularly at or above $0.08 \%$ (NIAAA 2004). This corresponds to five or more standard drinks in males and four or more drinks in females within an approximate two-hour period.

In PWID, binge drinking is associated with increased all-cause mortality (Johnson 2015), while daily drinking is associated with increased incidence of HIV seroconversion (Young 2016). In addition, problematic alcohol use in PWID is associated with unsafe sex, incarceration, and the use of more than one drug (Maynié-François 2016). Alcohol use in PWID is also associated with increased risk of fatal overdose (Shah 2008); however, heavy drinking is not associated with all-cause or overdose mortality among people receiving opioid agonist treatment (OAT) (Klimas 2017a). PWID are at high risk of liver disease resulting from hepatitis $C$ virus infection because of its high prevalence in this population (Smyth 1998). Problem alcohol use is an important factor contributing to a poor prognosis among people with hepatitis $C$ virus as it impacts on progression to hepatic cirrhosis, increased hepatitis $C$ virus-RNA levels or fatal opiate overdose in opiate users (Du 2012; White 1999). However, alcohol may have little influence on response to hepatitis C treatment (Tsui 2017). Nevertheless, Teplin and colleagues noted that PWID have higher rates of mood, anxiety and personality disorders, all of which are exacerbated by alcohol use (Teplin 2007).
There exists some evidence that alcohol may have a negative impact on outcomes of substance-use disorder treatment (Byrne 2011; Gossop 2000). For example, a study of 114 participants enrolled in OAT found that drinking was associated with heroin and cocaine craving and actual use (Preston 2016). Sadly, in some countries substance-use disorder treatment programmes do not accept patients with AUDs who are receiving OAT, because this is viewed as a violation of their "drug free" policies (Harris 2010). However, these precautions diminish patients' access to treatment and are not justified, nor evidence-based, as shown in previous demonstration projects (Kipnis 2001). In PWID, initiation of OAT decreases initiation of heavy drinking (Klimas 2016). While shortterm OAT (four weeks' duration) decreases alcohol consumption (Caputo 2002), longer-term OAT (two years' duration) has been shown to increase alcohol consumption, potentially as a substitute substance (Dobler-Mikola 2005).

The emerging understanding of a high prevalence of problem alcohol use among current or former PWID, allied to the clear health implications of this problem for this population, necessitates a public health response to this issue.

\section{Description of the intervention}

Psychosocial interventions are best described as "psychologicallybased interventions aimed at reducing consumption behaviour or alcohol-related problems" (Anderson 2004; Kaner 2018), that exclude any pharmacological treatments. The term refers to a heterogeneous collection of interventions, which vary depending on:

- theoretical underpinnings (e.g. psychodynamic, behavioural, motivational);

- duration or intensity (e.g. brief, extended);

- setting (e.g. primary-care based, inpatient);

- mode of delivery (e.g. group, individual, web-based); or

- treatment goals (e.g. abstinence oriented, harm reduction).

To date, many psychosocial interventions specifically designed to address problem alcohol use have been described. The most frequently used interventions include: motivational interviewing (MI), cognitive-behavioural therapy (CBT), psychodynamic approaches, screening and brief interventions (SBIs), family therapy, drug counselling, 12-step programmes, therapeutic community (TC) and vocational rehabilitation (VR).

- MI is a client-centred approach, but in contrast to its nondirective Rogerian origins, it is a directive therapy system. A central role is played by the client's motivation and readiness to change. Change within this approach is facilitated over a series of stages (Prochaska 1992). Relapse is not viewed as a failure to maintain healthy behaviour, but rather as a part of the process of change (Miller 2004).

- CBT draws upon the principles of learning theory. Change in addictive behaviour is approached through altering irrational assumptions, coping skills training or other behavioural exercises. This therapy often deals with the identification and prevention of triggers contributing to drug use. Among the modern approaches utilising such behavioural techniques are Relapse Prevention (Marlatt 1996), Contingency Management (Budney 2001), and the Community Reinforcement Approach, 
which combines both contingency management and positive reinforcement for non-drinking behaviours (Hunt 1973).

- Psychodynamic approaches are based on the assumptions of psychoanalytic theory, which focuses on addressing inner conflict, childhood trauma or problematic relationship themes. Such approaches include a range of different methods designed to deal with the underlying conflict (e.g. interpersonal therapy, supportive-expressive techniques, etc.) (Crits-Christoph 1999).

- SBIs are time limited and therefore suitable for non-specialist facilities. Usually, the length and intensity of the intervention is determined by the levels of risky alcohol consumption (i.e. screening results), and can range from a couple of minutes to several sessions (three to six). Each session includes the provision of information and advice (Babor 2001). Increasingly, brief interventions (BIs) are based on the principles and techniques of MI, so that the distinction between these two modalities is blurred in this regard.

- Family therapy: the therapeutic change is achieved via intervening in the interaction between family members. Families are directly involved in a therapy session. The family therapist must be competent in eliciting the strengths and support of the wider family system. Frequently used family therapy models include multisystemic therapy and network therapy solution-focused brief therapy (CSAT 2004).

- Drug counselling: addiction is viewed as a chronic illness that has serious consequences to the individual's health and social functioning, in consonance with the 12-step model (see below). Recovery includes spiritual components and attendance at fellowship meetings. The primary focus of this approach is to help the individual attain abstinence by promoting behavioural changes, including trigger avoidance, sport and other constructive activities. Both individual and group forms of drug counselling have been used in the largest collaborative cocaine treatment study (Crits-Christoph 1999).

- The 12-step (facilitation) model emphasises the powerlessness of an individual over the addiction, which is seen as a disease, and the need for a spiritual recovery. The foundations of this approach lie in the 12 Steps and an accompanying document, 12 Traditions (Alcoholics Anonymous 1939). The largest of all 12-step programmes is that of Alcoholics Anonymous (AA), and all other programmes (e.g. those of Narcotics Anonymous, AlAnon etc.) have evolved from it. AA meetings, besides the 12 steps, utilise well-established therapeutic factors of group psychotherapy, such as group cohesiveness, interpersonal learning (i.e. sponsorship), peer pressure, etc.

- TC is a long-term (18- to 24-month), drug-free model of treatment, which usually runs in a residential form. This approach relies on the community itself, as the main therapeutic factor, and also on other factors, such as peer feedback, rolemodelling or recapitulation of the primary family experience. The community has a high degree of autonomy, is democratic and each member has a clearly defined role and responsibilities within the structure of TC. A structured regimen of daily activities in the TC often includes formal individual or group therapy sessions along with other educational and work activities (De Leon 2000; Staiger 2009).

- VR employment is seen as an important element of successful rehabilitation from drug addiction and is often considered as one of its key indicators (Platt 1995). VR aims to increase the employability of PWID by developing their job interview skills or obtaining further qualifications. A necessary part of increasing ex-users' access to the job market is linking with potential employers and addressing their concerns and prejudices related to PWID. An example of VR for unemployed individuals receiving methadone maintenance treatment is the customised employment supports model (Blankertz 2004).

\section{How the intervention might work}

Substantial evidence has described the value of psychosocial interventions in treating problem alcohol use.

A review by Raistrick and colleagues presented data on the effectiveness of many interventions, including screening, further assessment, Bls, more intensive treatments that can still be considered 'brief' and alcohol-focused specialist treatments (Raistrick 2006). They reported mixed evidence on the longer-term effects of BIs and whether extended Bls add anything to the effects of simple Bls.

The Mesa Grande project, which reviewed 361 controlled clinical trials (CCTs) (a three-year update), found Bls to be the most strongly supported psychosocial treatment effective in treating AUDs (Miller 2002). These findings are supported by an Australian systematic review that found BIs to be effective in reducing alcohol consumption in drinkers without dependence or those with a low level of dependence (Shand 2003). Another meta-analysis found the positive effect of BIs to be evident at the follow-up points of three, six and 12 months, and these results were more apparent when dependent drinkers were excluded (Moyer 2002). Indeed, dependent drinkers have been excluded from much of this research, indicating that they are possibly unsuitable for $\mathrm{BI}$ and should be routinely referred to specialist treatment (Raistrick 2006).

While BIs are generally delivered across a range of settings, primary care has an important role in the delivery of Bls for problem alcohol use among PWID. BIs are well suited to primary care owing to their feasibility and ease of delivery in general settings by nonspecialist staff in a short period of time, and to individuals not actively seeking treatment (Kaner 2018; Raistrick 2006; Williams 2011). While primary care physicians believe these interventions are feasible, many face challenges incorporating them into care and often underestimate problem alcohol use in this population (McCombe 2016). In particular, patients receiving methadone maintenance treatment in primary care settings are not routinely screened for alcohol (Klimas 2015b).

The efficacy of primary care-based interventions for people with problem alcohol use has been demonstrated in a Cochrane Review (Kaner 2018), although the authors judged the evidence as being of moderate quality and reported that longer counselling duration probably had little additional effect. Another systematic review of brief, multi-contact behavioural counselling among adults attending primary care reported an average reduction of $13 \%$ to $34 \%$ in drinks per week (Whitlock 2004). However, a recent meta-analysis of studies of adolescents and young adults showed that brief, alcohol-targeted interventions decreased alcohol consumption, but had no effect on illicit drug use. In comparison, the same intervention targeted at alcohol and drugs decreased both behaviours (Tanner-Smith 2015). Therefore, the evidence behind brief interventions for illicit drug use appears inconclusive (Saitz 2014). 
There have also been new pilot studies published of psychosocial interventions for hazardous alcohol use among persons receiving OAT. One study found $88 \%$ of participants attempted to reduce their alcohol intake after the sessions, while $57 \%$ significantly reduced their alcohol use (Varshney 2016). Another study, Rosa 2015 , also found a significant decrease in alcohol consumption after the intervention. Finally, an educational intervention to support primary care of problem alcohol use among PWID has been developed and process-evaluated (Klimas 2014).

Thus, brief psychosocial interventions are feasible and potentially highly efficacious components of an overall public health approach to reducing problem alcohol use, although there is considerable variation in trials of effectiveness, and PWID from primary care settings are under-represented in these trials (Kaner 2018; Whitlock 2004).

Because Bls have been developed and evaluated mainly in conventional general practice settings, it is not clear whether they can be effectively applied to excessive drinking among PWID, or whether new forms of intervention need to be developed and evaluated. Could the 'advice-giving' form of BI be effective in PWID or are motivational techniques, in which the impetus for change comes from the user, more likely to be effective in this population?

\section{Why it is important to do this review}

The high prevalence and serious consequences of problem alcohol use among PWID highlights an opportunity for a Cochrane systematic review in this population. The question being asked in this review is also of importance because there are no other systematic reviews published that could help answer it.

Several narrative literature reviews have dealt with this question to date. The oldest of these reviews discussed six reports of four studies among methadone patients and saw some promise for contingency management procedures (Bickel 1987). A more recent review described the implications of combining behavioural and pharmacological treatments, which are effective in treating either alcohol- or drug-use disorders alone, for the treatment of people who have both these disorders (Arias 2008). While pointing to the paucity of research specifically focused on the treatment of people with co-occurring alcohol and other substance use disorders, the review concluded that successful treatment must take into account both alcohol- and drug-use disorders. Similarly, a review on treatment of people seeking therapy primarily for alcohol problems, but who also used other drugs, concurred with this idea (Miller 1996). More recently, two narrative reviews examined the patterns of concurrent use among people in and out of the treatment for substance use disorders (Staiger 2013; Soyka 2015). Both reviews (Staiger 2013; Soyka 2015) concluded that while concurrent alcohol use is often "overlooked and underestimated" in drug treatment, no clear patterns have emerged and the literature remains inconclusive. Another narrative review calls for creation of a set of guidelines for screening and treatment of alcohol use in OAT participants, based on the high prevalence of problem alcohol use and limited alcohol treatment access in this patient population (Nolan 2016). It also concluded that there is no clinical evidence to justify denial of treatment for alcohol use disorders, or reduction of opioid agonist dose, in OAT participants.

Cochrane Reviews have so far examined the effectiveness of psychosocial interventions for stimulant, opiate and alcohol use disorders (Amato 2011a; Minozzi 2016; Lui 2008). Although other reviews and review protocols have targeted poly-drug use, they concentrated either on specific populations, for example women and adolescents, or particular interventions, such as case management and MI, but not on 'alcohol-specific' interventions (Dalsbø 2010; Hesse 2007; Smedslund 2011; Smith 2006; Terplan 2015; Thomas 2011). None of the published reviews on psychosocial interventions examined the effectiveness of alcohol-specific interventions in PWID. The main problem driving the lack of quality studies in this area seems to flow from the administrative separation of drug problems from alcohol problems. This separation has led researchers to focus on one or the other but not on both. In the USA, the National Institutes of Health had planned to correct this separation by forming a new institute that covers both drugs and alcohol - the proposed National Institute of Substance Use and Addiction Disorders (NIH 2012) - although this plan was quickly abandoned.

The lack of systematic evaluation, together with the anticipated differences in the responsiveness of PWID to psychosocial interventions, provides additional reasons for conducting this review. In other words, the results of reviews on the effectiveness of psychosocial interventions among the general population might not be applicable to specific groups, such as PWID, because they may have a different responsiveness to psychosocial interventions (Nilsen 2010; Klimas 2012b). Several factors could possibly influence the responsiveness of PWID to treatment interventions (for example, stability of drug use, engagement with the service, concurrent personality disorders, etc). Evidence suggests that PWID with antisocial personality disorders are more likely to respond to rewarding than to punitive approaches (Messina 2003), and the use of more intensive psychosocial interventions is recommended in those who have achieved a sufficient degree of stability and compliance with a service regimen (Pilling 2010; Saitz 2015).

Moreover, it has been suggested that evidence on the effectiveness of many psychosocial interventions has been overestimated, that limitations of this evidence have been overlooked, and that results are difficult to generalise (McCambridge 2017). These criticisms further highlight the necessity of a comprehensive systematic review evaluating and consolidating the body of literature on various psychosocial interventions in PWID.

\section{O B J E C T IVES}

To assess the effectiveness of psychosocial interventions to reduce alcohol consumption in people who use illicit drugs (PWID) (users of opioids and stimulants).

\section{METHODS}

\section{Criteria for considering studies for this review \\ Types of studies}

We included randomised controlled trials (RCTs) and controlled clinical trials (CCTs).

\section{Types of participants}

We included people who use illicit drugs (PWID), aged 18 years or more, attending a range of services (i.e. community, inpatient or residential, including receiving opioid agonist treatment). Problem drug use was defined according to the definition of the European 
Monitoring Centre for Drugs and Drug Addiction, as "injecting drug use or long-duration/regular use of opioids, cocaine and/ or amphetamines" (EMCDDA 2008, page 10). This definition also encompasses other similar terms, for example substance use, misuse, abuse, dependence, addiction or people who use illicit drugs.

Only studies that defined participants as problem drug and alcohol users at randomisation were included. Studies including PWID without concurrent problem alcohol use were excluded. We excluded participants whose primary drug of use was alcohol.

\section{Types of interventions}

Experimental interventions: any psychosocial intervention that was described by the study's author(s) as such.

Control interventions: other psychosocial interventions that allowed for comparisons between different types of interventions (e.g. CBT, contingency management, family therapy, etc.), standard care, no intervention, waiting list, or any other non-pharmacological therapy, including moderate drinking, assessment-only.

We intended to exclude studies comparing psychosocial with pharmacological treatments. However, trials with two psychosocial arms in addition to pharmacological arms were exempted from this rule.

\section{Types of outcome measures}

\section{Primary outcomes}

1. Alcohol use (reduction or stabilisation), as measured by either biological markers or self-report tests

2. Retention in treatment (measured as number of people completing all treatment sessions, or retained at three months - for studies of brief interventions)

\section{Secondary outcomes}

1. Illicit drug use (changes in illicit drug use), as measured by either biological markers or self-report tests

2. Alcohol-related problems or harms, as represented by physical or mental health outcomes associated with problem alcohol use.

\section{Search methods for identification of studies}

\section{Electronic searches}

For this second update of a previously published review update, we searched the following databases up to 3 August 2017.

- Cochrane Drugs and Alcohol Review Group (CDAG) Specialised Register* (June 2014 to August 2017; 20 hits)

- Cochrane Central Register of Controlled Trials (CENTRAL, July 2017, Issue 7) in the Cochrane Library

- MEDLINE (PubMed) (June 2014 to August 2017)

- Embase (Elsevier) (June 2014 to August 2017)

- CINAHL EBSCO (June 2014 to August 2017)

- PsycINFO (ProQuest) (June 2014 to August 2017)

* All trials from the CDAG Specialised Register can be found in the Cochrane Library by searching on SR-ADDICTN.
Details of the previous search strategies are available in the previously published updates (Klimas 2012a; Klimas 2014b).

We searched the databases using a strategy developed incorporating the filter for the identification of RCTs (Higgins 2011), combined with selected medical subject heading (MeSH) terms and free-text terms relating to alcohol use. The CDAG Information Specialist conducted the electronic searches of all the databases listed above except PsycINFO, which the first author of the review conducted. We adapted the MEDLINE search strategy for use with the other databases using the appropriate controlled vocabulary, as applicable. Since the initial search yielded several RCTs, we continued to use the RCT filter for subsequent database searches. We collated the results of the two sets of electronic searches into a single EndNote database.

The search strategies for all databases are shown in Appendix 1, Appendix 2, Appendix 3, Appendix 4 and Appendix 5.

For the 2017 update, we searched for ongoing clinical trials and unpublished studies via searches on the following websites:

1. www.controlled-trials.com (search date: 17 May 2017);

2. www.clinicaltrials.gov (search date: 17 May 2017);

3. www.centrewatch.com (search date: 17 May 2017);

4. World Health Organization International Clinical Trials Registry Platform, www.who.int/ictrp/en/ (search date: 17 May 2017).

\section{Searching other resources}

We also searched:

1. reference lists of articles considered eligible based on full report screening and other relevant papers;

2. conference proceedings (online archives only) of the Society for the Study of Addiction, International Harm Reduction Association, International Conference on Alcohol Harm Reduction and American Association for the Treatment of Opioid Dependence.

In addition, we contacted investigators and relevant trial authors seeking information about unpublished or incomplete trials.

All searches included non-English language literature and we assessed any with English abstracts for inclusion. When we considered the studies likely to meet inclusion criteria, we obtained translations of any abstracts.

\section{Data collection and analysis}

\section{Selection of studies}

Two review authors (JK, ChF) independently screened titles and abstracts and selected studies potentially relevant. We resolved any differences between selection lists by discussion with a third and fourth review author with respective thematic and methodological expertise (WC, CSMOG). We obtained full-text copies of each potentially relevant paper, as well as full reports of references with inadequate information in order to definitively determine relevance. Two review authors (JK, ChF) independently re-evaluated whether studies were eligible for the update or not, according to the inclusion criteria. A second opinion was not needed. We screened abstracts, full texts and extracted data using the Eppi Reviewer 4 software (Eppi 2017). 


\section{Data extraction and management}

Two review authors (JK, ChF) independently extracted data from the full-text reports using an electronic version of an amended data extraction form of the Cochrane Drug and Alcohol Review Group. We resolved disagreements by mutual discussion. We sought information on study participants, characteristics of experimental and control intervention, primary and secondary outcomes, funding and conflict of interest from reports of included studies.

\section{Assessment of risk of bias in included studies}

We performed 'Risk of bias' assessments for RCTs and CCTs using the criteria recommended in the Cochrane Handbook for Systematic Reviews of Interventions (Higgins 2011). The recommended approach for assessing risk of bias in studies included in a Cochrane Review is a two-part tool addressing six specific domains (namely sequence generation, allocation concealment, blinding of participants and personnel, blinding of outcome assessor, incomplete outcome data and selective outcome reporting). The first part of the tool involves describing what was reported to have happened in the study. The second part of the tool involves assigning a judgement relating to the risk of bias for that entry in terms of high, low or unclear risk. To make these judgements we used the criteria indicated in the Cochrane Handbook for Systematic Reviews of Interventions adapted to the addiction field. See the table in Appendix 6 for details.

We addressed the domains of sequence generation and allocation concealment (avoidance of selection bias) using a single entry for each study.

Blinding of participants and providers was not possible for this kind of intervention. Moreover, knowledge of participation in a psychosocial intervention is part of the therapeutic effect; therefore, we think that lack of blinding of participants and personnel does not introduce bias in trials of psychosocial interventions. "In psychotherapy, it is impossible for the principle participants to be blind to the treatment used."(Beutler 2016, p.102) For this reason, we did not assess the risk of performance bias. We considered the blinding of outcome assessors (avoidance of detection bias) separately for objective outcomes (e.g. dropouts from therapy, substance use measured by urinalysis, participants relapsed at the end of follow-up, participants engaged in further treatments), and subjective outcomes (e.g. duration and severity of signs and symptoms of withdrawal, individual self-reported use of substance, side effects, social functioning as integration at school or at work, family relationship, etc.).

We considered incomplete outcome data (avoidance of attrition bias) for all outcomes with the exception of dropouts from therapy, which is usually the primary outcome measure in trials on addiction. We assessed this separately for results at the end of the study period, and for results at follow up.

\section{Measures of treatment effect}

For continuous data, we calculated mean differences (MDs), and standardised MDs (where appropriate) between the intervention and comparator groups, with 95\% confidence intervals (Cls). We present dichotomous outcomes as risk ratios (RRs), with 95\% Cls.

\section{Unit of analysis issues}

We included only one multiarm trial, Nyamathi 2010, in the review and it was not included more than once in any of the comparisons. This study had three arms; of those, two were experimental (group and single format). We collapsed them into a single experimental group which we entered into a single comparison so they were not counted twice.

In accordance with the Cochrane Handbook (Higgins 2011), the actual sample sizes of included cluster-randomised trials have been reduced by a design effect coefficient to their effective sample size.

\section{Dealing with missing data}

We contacted the authors of the seven original studies by email for missing data (April 2012; July 2016) and sent reminders after two weeks. To date, five study authors have responded and provided additional information.

\section{Assessment of heterogeneity}

We analysed heterogeneity by using the $\mathrm{I}^{2}$ statistic and the $\mathrm{Chi}^{2}$ test. Cut-off points included an $\mathrm{I}^{2}$ value greater than $50 \%$ and a $\mathrm{P}$ value for the $\mathrm{Chi}^{2}$ test less than 0.1 .

\section{Assessment of reporting biases}

We planned to further explore the potential for reporting bias using funnel plots if more than 10 RCTs were included (plotting the effect from each trial against the sample size or effect's standard error); however, this was not possible because only seven RCTs were identified.

\section{Data synthesis}

For comparisons of sufficiently similar studies, we used the random-effects model. For the comparisons where we considered that no two studies were sufficiently similar to allow pooling of data, we reported the results of included studies individually for each trial. We used a fixed-effect model if there was only one trial for each comparison.

\section{Subgroup analysis and investigation of heterogeneity}

If sufficient information had been available, we had planned to conduct the following subgroup analyses:

1. types of psychosocial intervention (e.g. motivational versus behavioural or brief interventions);

2. length of the intervention (short, medium, extended).

We had also intended to conduct the following subgroup analyses, but did not due to there being insufficient data:

1. sustained benefit at six and 12 months after intervention;

2. gender differences;

3. single-drug (alcohol) versus poly-drug-focused interventions;

4. single-drug (alcohol) versus poly-drug-focused interventions that also address other health-related behaviours.

\section{Sensitivity analysis}

If sufficient information had been available, we intended to conduct the following sensitivity analyses according to the following criteria: 
- excluding studies with a high risk of bias from the analysis: this decision was to be based on a predefined cut-off score (i.e. studies judged to be at high risk of bias for three or more domains, including selection bias, were to be excluded);

- excluding CCTs.

However, we did not perform sensitivity analyses because of insufficient information.

\section{'Summary of findings' tables}

We assessed the overall quality of the evidence for the primary outcomes using the GRADE system for grading the quality of evidence (Schunemann 2013), which takes into account issues not only related to internal validity but also to external validity, such as directness, consistency, imprecision of results and publication bias. The 'Summary of findings' tables present the main findings of a review in a transparent and simple tabular format. In particular, they provide key information concerning the quality of evidence, the magnitude of effect of the interventions examined and the sum of available data on the main outcomes.

The GRADE system uses the following criteria for assigning grades of evidence.

- High quality: we are very confident that the true effect lies close to that of the estimate of the effect.

- Moderate quality: we are moderately confident in the effect estimate. The true effect is likely to be close to the estimate of the effect, but there is a possibility that it is substantially different.

- Low quality: our confidence in the effect estimate is limited. The true effect may be substantially different from the estimate of the effect

- Very low quality: we have very little confidence in the effect estimate. The true effect is likely to be substantially different from the estimate of effect.

Grading of the quality of evidence is decreased for the following reasons.

- Serious (-1) or very serious (-2) study limitations due to risk of bias.

- Serious $(-1)$ or very serious $(-2)$ inconsistency between study results.

- Some (-1) or major (-2) uncertainty about directness (the correspondence between the population, the intervention, or the outcomes measured in the studies actually found and those under consideration in our systematic review).

- Serious $(-1)$ or very serious $(-2)$ imprecision of the pooled estimate.
- Publication bias strongly suspected (-1).

\section{Consumer participation}

We sought consumer participation in the preparation of the protocol and the original review: a) the first review author (JK) is a member of the Cochrane Consumers Network, b) the Cochrane Consumers Network was approached to assist with the plain language summary of the review, and c) one of the co-authors of this review (EK) contributed to consumer consultation during the protocol and review development, as he was a practicing clinician in a healthcare facility with a high prevalence of this problem.

\section{RES U L T S}

\section{Description of studies}

See Characteristics of included studies, Characteristics of excluded studies and Characteristics of studies awaiting classification.

\section{Results of the search}

This is an update of a Cochrane Review first published in 2012 (Klimas 2012a), and updated in 2014 (Klimas 2014b). In the first version of our review, we retrieved a total of 7207 records from the initial search of the Cochrane Drugs and Alcohol Review Group (CDAG) Register, the Cochrane Central Register of Controlled Trials (CENTRAL), PubMed, Embase, CINAHL and PsycINFO. Removing duplicates left 5548 records. After screening titles and abstracts, we identified 25 potentially eligible studies; we excluded 18 fulltext reports and included seven reports which described four randomised controlled trials (RCTs). We found no additional studies through reference checking.

For the 2014 update, we retrieved a total of 1836 records from a more up-to-date search of the CDAG Register, CENTRAL, PubMed, Embase, CINAHL and PsycINFO. Removing duplicates left 960 records. After screening titles and abstracts we identified 16 potentially eligible records and included one record (Feldman 2013). This record was a 2013 correction of Feldman 2013, a paper we included in the first version of this review (Klimas 2012a).

For this 2017 update, we retrieved a total of 3503 records from a more up-to-date search of the CDAG Register, CENTRAL, PubMed, Embase, CINAHL and PsycINFO. We identified one additional study through other sources. Removing duplicates left 921 records. After screening titles and abstracts we identified 17 potentially eligible studies; we excluded 14 full-text reports and included three new RCTs (Darker 2016; Feldman 2013; Henihan 2016). Four studies are awaiting classification (Aharonovich 2017; Poblete 2017; Staiger 2009; Thapaliya 2017). A PRISMA (Moher 2009) flowchart of study selection for this review update is shown in Figure 1. 
Figure 1. Study flow diagram for the 2017 review update: previous studies incorporated into results of new literature search

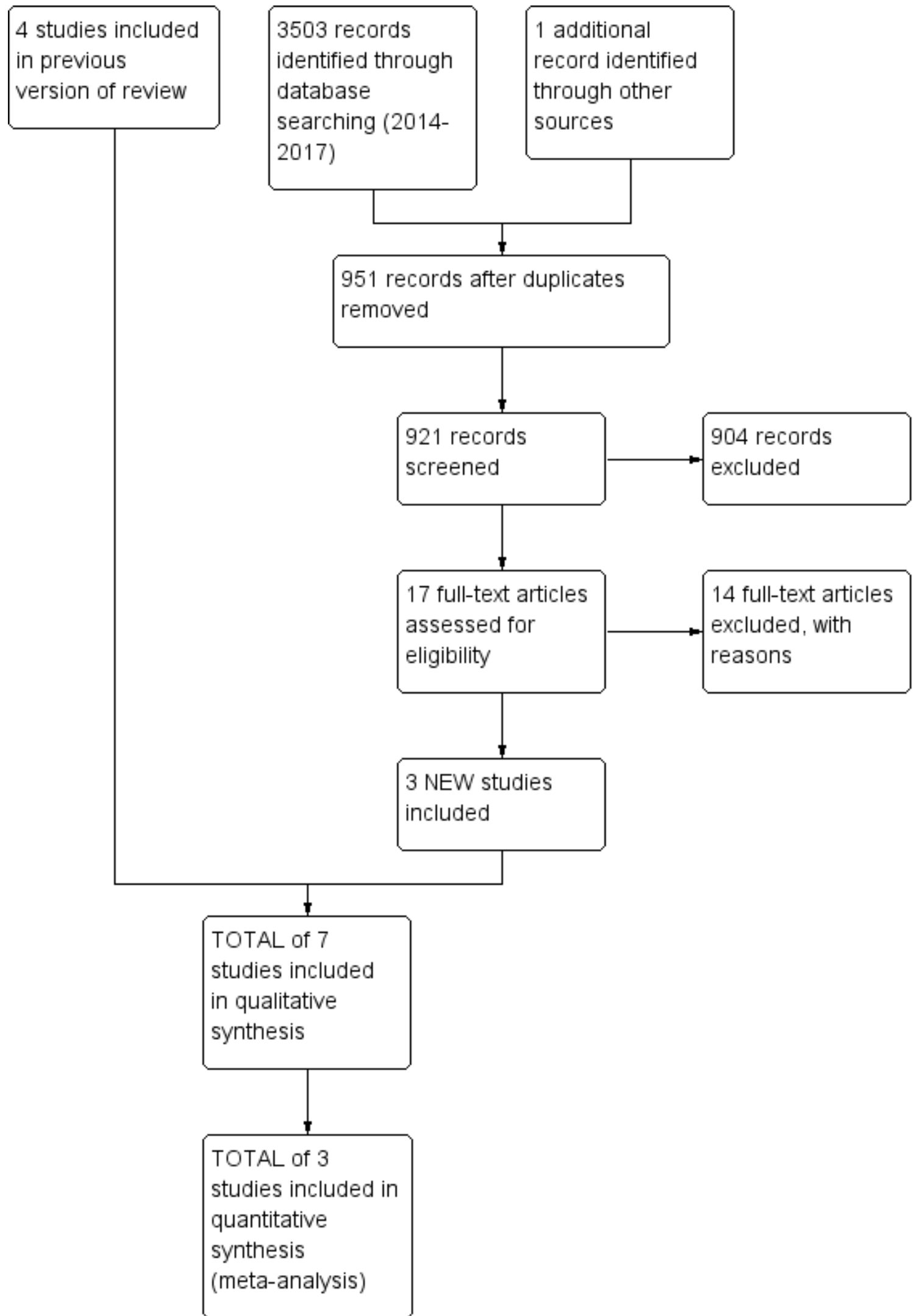




\section{Included studies}

We included seven studies (825 participants) in this review.

\section{Study designs}

Five studies were parallel RCTs and two were cluster-RCTs (Darker 2016; Henihan 2016)

\section{Participants}

Participants included 825 people who use illicit drugs (PWID). One multiarm trial included 122 participants (Carroll 1998), however, from this study only 41 participants from two psychosocial therapy arms were considered for this review. The mean age of participants was 38.6 years, and $28 \%$ were female.

\section{Intervention}

The studies assessed the effectiveness of eight psychosocial interventions: cognitive-behavioural coping skills training (CBCST), twelve-step facilitation (TSF) programme, brief intervention (BI), motivational interviewing (MI) (group based), MI (individual), educational hepatitis health promotion (HHP), brief motivational interviewing (BMI), and $\mathrm{MI}$ (intensive, group based). CBCST and TSF involved 16 individual sessions, twice weekly, over 12 weeks. $\mathrm{BI}$ involved one session that lasted approximately 15 minutes. MI (group and single) and HHP were delivered over three 60-minute sessions, spaced two weeks apart. BMI included two therapist sessions, one month apart; the first session was 60 minutes long and the second session was 30 to 45 minutes long. MI (intensive, group based) involved a total of nine 50-minute sessions, with three sessions being delivered each week (versus one 90-minute session of standard MI and eight 60-minute nutrition sessions).

\section{Types of comparisons and setting}

- CBCST versus TSF in an outpatient clinic (Carroll 1998)

- BI versus treatment as usual in an opioid agonist clinic (Darker 2016)

- Bl versus treatment as usual in an outpatient clinic with/without opioid agonist treatment (Feldman 2013)

- BI versus treatment as usual in a primary care setting (Henihan 2016)

- MI versus HHP in an opioid agonist clinic (Nyamathi 2010)
- BMI versus assessment-only in a needle exchange programme (Stein 2002)

- MI intensive (group) versus MI (group) in an outpatient substance use treatment facility (Korcha 2014)

\section{Country}

Four studies were conducted in the USA, two in Ireland, and one in Switzerland.

\section{Duration of the trials}

Duration of the trials ranged from one to 12 weeks (mean 3.9 weeks), plus various follow-ups. Between one and 16 sessions were offered to participants (mean 4.7, providing from three minutes to 16 hours of treatment time).

\section{Funding}

Six of the studies were funded by the National Institutes for Health or by the Health Research Board; one study did not report its funding source. Four studies reported no competing interests (Darker 2016; Feldman 2013; Henihan 2016; Nyamathi 2010), while three studies did not provide information about conflicts of interests (Carroll 1998; Korcha 2014; Stein 2002).

See the Characteristics of included studies table for more details.

\section{Excluded studies}

We excluded 46 studies (17 in 2012, 15 in 2014, and 14 in 2017) that did not meet the criteria for inclusion in this review; for more information see the Characteristics of excluded studies table.

We considered grounds for exclusion as follows: type of intervention not in the inclusion criteria (no studies); type of participants not in the inclusion criteria (37 studies); types of outcomes not in the inclusion criteria (six studies); study design not in the inclusion criteria (three studies).

\section{Risk of bias in included studies}

All the studies were RCTs. For a summary of the our judgements regarding risk of bias for each domain in each included study and across studies, see Figure 2 and Figure 3. See the Characteristics of included studies table for more detailed information. 
Figure 2. Risk of bias graph: review authors' judgements about each risk of bias item presented as percentages across all included studies.

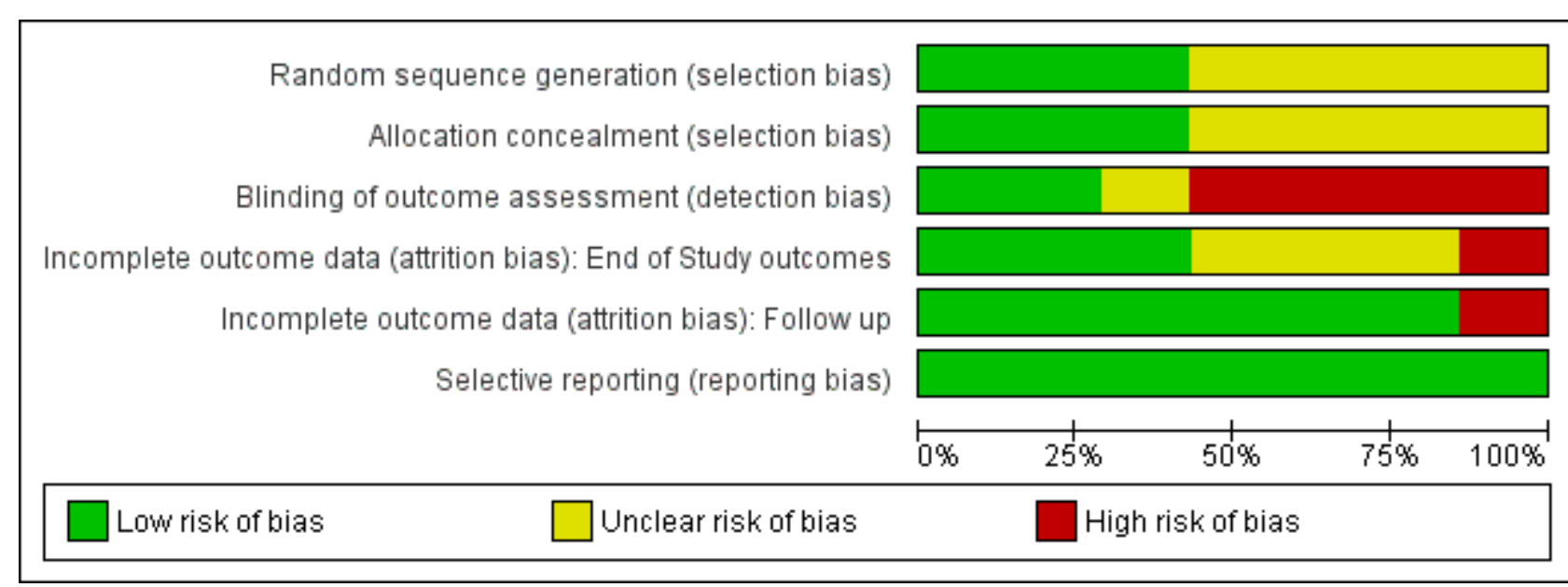


Figure 3. Risk of bias summary: review authors' judgements about each risk of bias item for each included study.

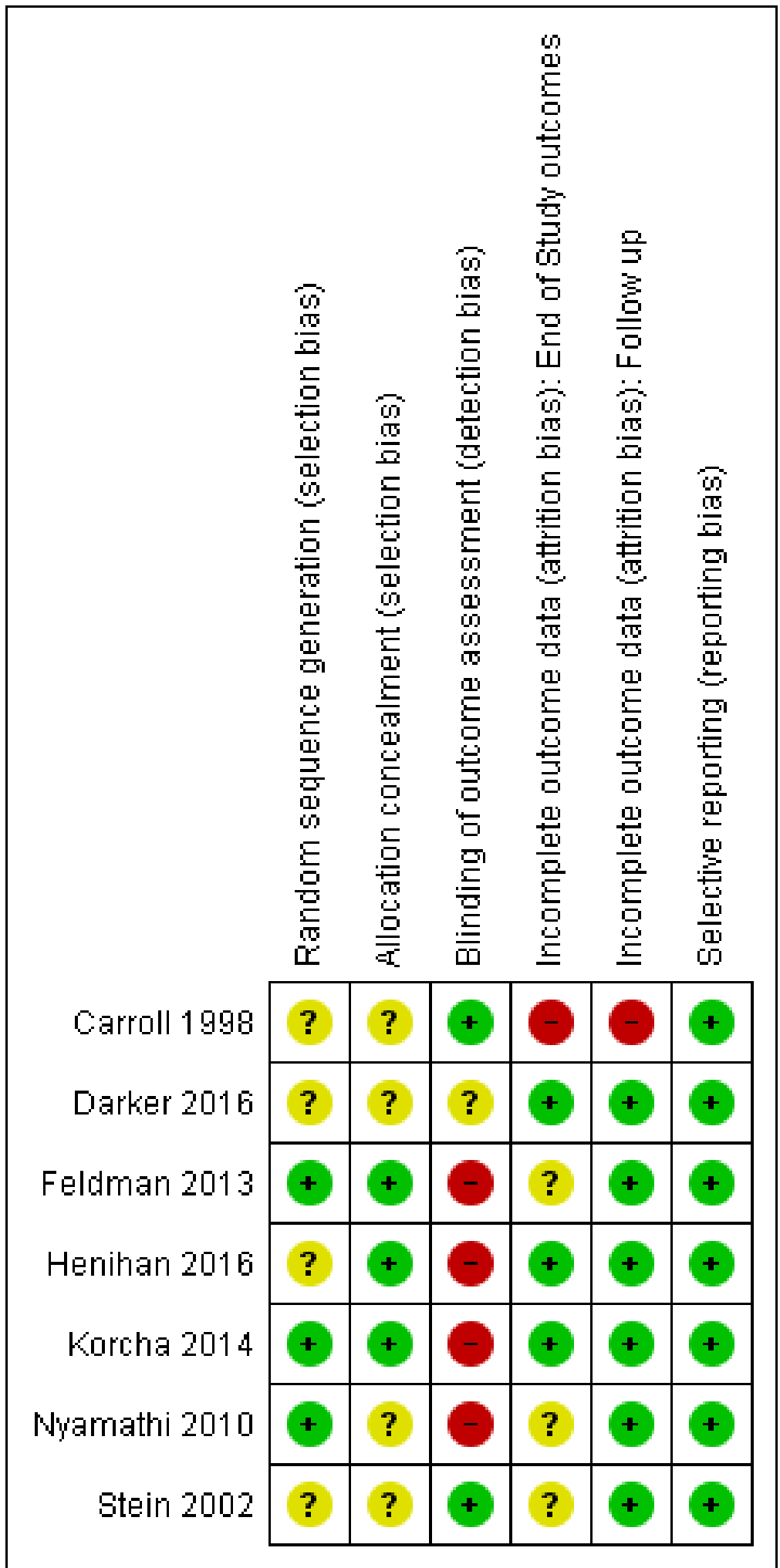

\section{Allocation}

Random sequence generation

We judged random sequence generation to be adequate in three studies (for two studies, this was based on unpublished information obtained via email communication with the study authors), and unclear in the remaining trials.

Psychosocial interventions to reduce alcohol consumption in concurrent problem alcohol and illicit drug users (Review) 20 Copyright $\odot 2018$ The Cochrane Collaboration. Published by John Wiley \& Sons, Ltd. 


\section{Allocation concealment}

We judged three studies as being at low risk of bias, and the remaining trials as having unclear risk of bias.

\section{Blinding}

\section{Detection bias}

\section{Objective outcomes}

None of the included studies reported objective outcomes, so we did not assess risk of detection bias for these outcomes.

\section{Subjective outcomes}

We assessed the following outcome for this 'Risk of bias' domain: abstinence or use of a substance, as measured by self-reported or interviewer-administered questionnaires. Two studies (27\%) specified that outcome assessors were blinded and we judged these studies to be at low risk of bias. Four studies reported that the outcome assessor was not blinded and we judged these to be at high risk of bias; for two of them, this was unpublished information obtained via email communication with the study authors. We judged one study to have an unclear risk of bias because it did not specify the blindness of outcome assessor.

\section{Incomplete outcome data}

\section{End-of-study outcomes}

With the exception of retention in treatment, four studies measured end-of-study outcomes. We judged three to be at low risk of bias because of low or balanced dropout rates across all groups. We judged one study to be at high risk of bias because the dropout rates were not balanced across all groups: "the psychotherapy groups had significantly lower retention rates than the medication [disulfiram] groups" (Carroll 1998), although the difference between the two psychotherapy arms included in the present review was not significant ( $70 \%$ versus $78 \%$ ), see Analysis 1.4 .

\section{Follow-up outcomes}

With the exception of retention in treatment, we judged six studies to be at low risk of attrition bias because few participants (less than $10 \%$ ) withdrew from the studies, or because there was a high rate of drop-out but percentages were balanced across intervention groups, and reasons for withdrawal were provided or authors performed an intention-to-treat (ITT) analysis. We judged one study to be at high risk of bias because of a high dropout rate that was unbalanced across groups.

\section{Selective reporting}

All studies reported on the primary outcomes pre-specified in the methods sections of the full reports. See Figure 2 and Figure 3.

\section{Effects of interventions}

See: Summary of findings for the main comparison Cognitivebehavioural coping skills training (CBCST) compared to twelvestep facilitation (TSF) programme to reduce alcohol consumption in people who use illicit drugs (PWID); Summary of findings 2 Brief intervention (BI) compared to treatment as usual (TAU) to reduce alcohol consumption in PWID; Summary of findings 3 Motivational interviewing (MI) compared to treatment as usual (TAU) or educational intervention only to reduce alcohol consumption in
PWID; Summary of findings 4 Brief motivational interviewing (BMI) compared to assessment-only to reduce alcohol consumption in PWID; Summary of findings $\mathbf{5}$ Motivational interviewing intensive (MII) compared to motivational interviewing (MI) to reduce alcohol consumption in PWID

We were unable to pool data for any of the comparisons, except that of "brief intervention versus treatment as usual" and "motivational interviewing versus treatment as usual". We therefore summarise the results according to the type of psychosocial intervention, with comparisons of quantitative data where possible. The included studies used different questionnaires to measure their outcomes and, for many, the authors did not report post-treatment/followup scores, or they did not state what was considered to represent mild, moderate and severe categories. This prevented comparison of results across the studies. See the Characteristics of included studies table for more detailed information.

We present the effects of the interventions by the comparisons examined in the primary studies. The primary outcomes of this review were alcohol use (or abstinence) and retention in treatment. The main secondary outcome was illicit drug use (or abstinence). We were unable to report alcohol-related problems or harms because they were not measured in the included trials.

\section{Cognitive-behavioural coping skills training (CBCST) versus twelve-step facilitation (TSF)}

See: Summary of findings for the main comparison for this comparison.

\section{Primary outcomes}

1.1 Alcohol abstinence as number achieving three or more weeks of consecutive alcohol abstinence during treatment

There was no significant difference between CBCST and TSF for this outcome (risk ratio (RR) 1.96, 95\% confidence interval (CI) 0.43 to 8.94; one study, 41 participants (Carroll 1998); very low-quality evidence), see Analysis 1.1.

\subsection{Alcohol abstinence as maximum number of weeks of consecutive alcohol abstinence during treatment}

There was no significant difference between CBCST and TSF for this outcome (mean difference (MD) $0.40,95 \% \mathrm{Cl}-1.14$ to 1.94 ; one study, 41 participants (Carroll 1998); very low-quality evidence), see Analysis 1.2.

\subsection{Alcohol abstinence during follow-up year}

There was no significant difference between CBCST and TSF for this outcome (RR $2.38,95 \% \mathrm{Cl} 0.10$ to 55.06; one study, 41 participants (Carroll 1998); very low-quality evidence), see Analysis 1.3.

\subsection{Retention as number of people who completed all treatment sessions (unpublished)}

There was no significant difference between CBCST and TSF for this outcome (RR $0.89,95 \% \mathrm{Cl} 0.62$ to 1.29 ; one study, 41 participants (Carroll 1998); very low-quality evidence), see Analysis 1.4. 


\section{Secondary outcomes}

1.5 Illicit drug abstinence as maximum number of weeks of consecutive abstinence from cocaine during treatment

There was no significant difference between CBCST and TSF for this outcome (MD 0.80, $95 \% \mathrm{Cl}-0.70$ to 2.30 ; one study, 41 participants (Carroll 1998); very low-quality evidence), see Analysis 1.5.

1.6 Illicit drug abstinence as number achieving three or more weeks of consecutive abstinence from cocaine during treatment

There was no significant difference between CBCST and TSF for this outcome (RR 1.10, $95 \% \mathrm{Cl} 0.42$ to 2.88 ; one study, 41 participants (Carroll 1998); very low-quality evidence), see Analysis 1.6.

1.7 Illicit drug abstinence as abstinence from cocaine during follow-up year

There was no significant difference between CBCST and TSF for this outcome (RR $0.39,95 \% \mathrm{Cl} 0.04$ to 3.98 ; one study, 41 participants (Carroll 1998); very low-quality evidence), see Analysis 1.7.

\subsection{Alcohol-related harms or problems}

There were no data for this outcome.

\section{Brief intervention (BI) versus treatment as usual (TAU)}

See Summary of findings 2 for this comparison.

\section{Primary outcomes}

2.1 Alcohol use as scores on the Alcohol Use Disorders Identification Test (AUDIT) or Alcohol, Smoking and Substance Involvement Screening Test (ASSIST) at three months

There was no significant difference between $\mathrm{BI}$ and TAU for this outcome (standardised mean difference (SMD) 0.07, 95\% -0.24 to 0.37; three studies, 170 participants (Darker 2016; Feldman 2013; Henihan 2016); low-quality evidence), see Analysis 2.1.

\subsection{Alcohol use as AUDIT scores at nine months}

There was no significant difference between $\mathrm{BI}$ and TAU for this outcome (MD 2.30, 95\% Cl -0.58 to 5.18; one study, 110 participants (Feldman 2013); low-quality evidence), see Analysis 2.2.

\subsection{Alcohol use as decreased alcohol use at three months}

There was no significant difference between $\mathrm{BI}$ and TAU for this outcome (RR $1.13,95 \% \mathrm{Cl} 0.67$ to 1.93 ; one study, 110 participants (Feldman 2013); low-quality evidence), see Analysis 2.3.

\subsection{Alcohol use as number of drinks per week at three months}

There was no significant difference between $\mathrm{BI}$ and TAU for this outcome (MD $0.70,95 \% \mathrm{Cl}-3.85$ to 5.25 ; one study, 110 participants (Feldman 2013); low-quality evidence), see Analysis 2.4.

\subsection{Alcohol use as number of drinks per week at nine months}

There was no significant difference between $\mathrm{BI}$ and TAU for this outcome (MD $-0.30,95 \% \mathrm{Cl}-4.79$ to 4.19 ; one study, 110 participants (Feldman 2013); low-quality evidence), see Analysis 2.5.

\subsection{Alcohol use as decreased alcohol use at nine months}

There was no significant difference between $\mathrm{BI}$ and TAU for this outcome (RR 1.09, 95\% Cl 0.62 to 1.92; one study, 110 participants (Feldman 2013); low-quality evidence), see Analysis 2.6.

\subsection{Retention at three months (unpublished and published data)}

There was no significant difference between $\mathrm{BI}$ and TAU for this outcome (RR $0.94,95 \% \mathrm{Cl} 0.78$ to 1.13 ; three studies, 170 participants (Darker 2016; Feldman 2013; Henihan 2016); lowquality evidence), see Analysis 2.7.

\section{Secondary outcomes}

\subsection{Illicit drug use}

There were no data for this outcome.

\subsection{Alcohol-related harms or problems}

There were no data for this outcome.

3. Motivational interviewing (MI) versus treatment as usual or educational intervention only

See: Summary of findings 3 for this comparison.

\section{Primary outcomes}

\subsection{Alcohol use as AUDIT or ASSIST scores at three months}

There was no significant difference between $\mathrm{BI}$ and TAU/education for this outcome (SMD 0.04, 95\% Cl -0.29 to 0.37; two studies, 141 participants (Darker 2016; Feldman 2013); low-quality evidence), see Analysis 3.1.

\subsection{Alcohol use as AUDIT scores at nine months}

There was no significant difference between $\mathrm{BI}$ and TAU for this outcome (MD 2.30, 95\% Cl -0.58 to 5.18; one study, 110 participants (Feldman 2013); low-quality evidence), see Analysis 3.2.

3.3 Alcohol use (unpublished) as number of standard drinks consumed per day over the last 30 days

There was no significant difference between $\mathrm{MI}$ and educational intervention for this outcome (MD $-0.20,95 \% \mathrm{Cl}-1.76$ to 1.36 ; one study, 225 participants (Nyamathi 2010); low-quality evidence), see Analysis 3.3.

\subsection{Alcohol use as number of drinks consumed per week at three months}

There was no significant difference between $\mathrm{BI}$ and TAU for this outcome (MD $0.70,95 \% \mathrm{Cl}-3.85$ to 5.25 ; one study, 110 participants (Feldman 2013); low-quality evidence), see Analysis 3.4.

3.5 Alcohol use as number of drinks consumed per week at nine months

There was no significant difference between $\mathrm{BI}$ and TAU for this outcome (MD $-0.30,95 \% \mathrm{Cl}-4.79$ to 4.19 ; one study, 110 participants (Feldman 2013); low-quality evidence), see Analysis 3.5.

3.6 Alcohol use as greater than $\mathbf{5 0 \%}$ reduction in number of standard drinks consumed per day over the last 30 days

There was no significant difference between $\mathrm{MI}$ and Educational intervention for this outcome (RR $1.01,95 \% \mathrm{Cl} 0.77$ to 1.31 ; One study, 256 participants (Nyamathi 2010); low-quality evidence), see Analysis 3.6.

3.7 Alcohol abstinence as abstinence from alcohol over the last $\mathbf{3 0}$ days

There was no significant difference between $\mathrm{MI}$ and Educational intervention for this outcome ( $\mathrm{RR} 0.93,95 \% \mathrm{Cl} 0.57$ to 1.50 ; one 
study, 256 participants (Nyamathi 2010); low-quality evidence), see Analysis 3.7.

\subsection{Alcohol use as decreased alcohol use at three months}

There was no significant difference between $\mathrm{BI}$ and TAU for this outcome (RR 1.13, 95\% Cl 0.67 to 1.93; one study, 110 participants (Feldman 2013); low-quality evidence), see Analysis 3.8.

\subsection{Alcohol use as decreased alcohol use at nine months}

There was no significant difference between $\mathrm{BI}$ and TAU for this outcome (RR 1.09, 95\% Cl 0.62 to 1.92; one study, 110 participants (Feldman 2013); low-quality evidence), see Analysis 3.9.

\subsection{Retention at end of treatment}

There was no significant difference between $\mathrm{MI}$ and educational intervention for this outcome (RR $0.96,95 \% \mathrm{Cl} 0.87$ to 1.06 ; one study, 256 participants (Nyamathi 2010); low-quality evidence), see Analysis 3.10.

\subsection{Retention at three months (unpublished and published data)}

There was no significant difference between $\mathrm{BI}$ and TAU for this outcome (RR $0.93,95 \% \mathrm{Cl} 0.60$ to 1.43; two studies, 160 participants (Darker 2016; Feldman 2013); low-quality evidence), see Analysis 3.11 .

\section{Secondary outcomes}

3.12 Illicit drug use (unpublished) as frequency of drug use, as measured by Addiction Severity Index (ASI drug)

There was no significant difference between $\mathrm{MI}$ and educational intervention for this outcome (MD $0.00,95 \% \mathrm{Cl}-0.03$ to 0.03 ; one study, 225 participants (Nyamathi 2010); low-quality evidence), see Analysis 3.12 .

\subsection{Illicit drug use (unpublished) as a composite drug score (frequency* severity for all drugs taken)}

There was no significant difference between $\mathrm{MI}$ and educational intervention for this outcome (MD $-0.00,95 \% \mathrm{Cl}-0.34$ to 0.34 ; one study, 229 participants (Nyamathi 2010); low-quality evidence), see Analysis 3.13.*

${ }^{\star}$ Nyamathi 2010 reported an additional outcome as a change score for: daily drug use since baseline (past 30 days and six-month recall). We do not report this calculated variable here because the authors provided us with unpublished results of two original variables that fed into this composite score.

\subsection{Alcohol-related harms or problems}

There were no data for this outcome.

\section{Brief motivational interviewing (BMI) versus assessment- only control}

See Summary of findings 4 for this comparison.

\section{Primary outcomes}

4.1 Alcohol use as number of days in the past 30 days with alcohol use at one month

There was no significant difference between BMI and assessmentonly for this outcome (MD $-0.30,95 \% \mathrm{Cl}-3.38$ to 2.78 ; one study, 187 participants (Stein 2002); moderate-quality evidence), see Analysis 4.1.

4.2 Alcohol use as number of days in the past 30 days with alcohol use at six months

There was no significant difference between BMI and assessmentonly for this outcome (MD $-1.50,95 \% \mathrm{Cl}-4.56$ to 1.56; one study, 187 participants (Stein 2002); moderate-quality evidence), see Analysis 4.2.

\subsection{Alcohol use as $25 \%$ reduction of drinking days in the past 30 days}

There was no significant difference between BMI and assessmentonly for this outcome (RR $1.23,95 \% \mathrm{Cl} 0.96$ to 1.57 ; one study, 187 participants (Stein 2002); moderate-quality evidence), see Analysis 4.3.

\subsection{Alcohol use as $\mathbf{5 0} \%$ reduction of drinking days in the past $\mathbf{3 0}$ days}

There was no significant difference between $\mathrm{BMI}$ and assessmentonly for this outcome (RR $1.27,95 \% \mathrm{Cl} 0.96$ to 1.68 ; one study, 187 participants (Stein 2002); moderate-quality evidence), see Analysis 4.4.

\subsection{Alcohol use as $75 \%$ reduction of drinking days in the past 30 days}

There was no significant difference between BMI and assessmentonly for this outcome (RR $1.21,95 \% \mathrm{Cl} 0.84$ to 1.75 ; one study, 187 participants (Stein 2002); moderate-quality evidence), see Analysis 4.5.

\subsection{Alcohol use as one or more drinking days' reduction in the past 30 days}

There was no significant difference between BMI and assessmentonly for this outcome (RR 1.12, 95\% Cl 0.91 to 1.38; one study, 187 participants (Stein 2002); moderate-quality evidence), see Analysis 4.6.

\subsection{Alcohol use as seven or more drinking days' reduction in the past 30 days}

There was a significant difference between BMI and assessmentonly for this outcome (RR $1.67,95 \% \mathrm{Cl} 1.08$ to 2.60 ; $\mathrm{P}=0.02$; one study, 187 participants (Stein 2002); moderate-quality evidence), see Analysis 4.7.

\subsection{Retention as number of people who completed all treatment sessions}

There was no significant difference between BMI and assessmentonly for this outcome (RR $0.98,95 \% \mathrm{Cl} 0.94$ to 1.02 ; one study, 187 participants (Stein 2002); moderate-quality evidence), see Analysis 4.8 .

\section{Secondary outcomes}

\subsection{Illicit drug use}

There were no data for this outcome.

\subsection{Alcohol-related harms or problems}

There were no data for this outcome.

\section{Intensive motivational interviewing (MII) versus motivational interviewing (MI)}

See Summary of findings 5 for this comparison. 


\section{Primary outcomes}

5.1 Alcohol addiction severity as Addiction Severity Index alcohol score at two months

There was no significant difference between MII and MI for this outcome (MD 0.03, $95 \% \mathrm{Cl}-0.02$ to 0.08 ; one study, 163 participants (Korcha 2014); low-quality evidence), see Analysis 5.1.

\subsection{Alcohol addiction severity as Addiction Severity Index alcohol score at four months}

There was no significant difference between MII and MI for this outcome (MD -0.01, 95\% Cl -0.06 to 0.04; one study, 163 participants (Korcha 2014); low-quality evidence), see Analysis 5.2.

\subsection{Alcohol addiction severity as Addiction Severity Index alcohol score at six months}

There was no significant difference between $\mathrm{MII}$ and $\mathrm{MI}$ for this outcome (MD -0.02, 95\% Cl -0.07 to 0.03 ); one study, 163 participants (Korcha 2014); low-quality evidence), see Analysis 5.3.

\subsection{Retention as number of people who completed all treatment} sessions (published and unpublished information)

There was no significant difference between $\mathrm{MII}$ and $\mathrm{MI}$ for this outcome (RR 17.63, 95\% Cl 1.03 to 300.48; one study, 163 participants (Korcha 2014); low-quality evidence), see Analysis 5.4.

\section{Secondary outcomes}

5.5 Illicit drug abstinence as percentage of days methamphetamine abstinent in the past six months (as determined by timeline followback)

There was no significant difference between $\mathrm{MII}$ and $\mathrm{MI}$ for this outcome (MD 3.91, 95\% Cl -5.28 to 13.10; One study, 163 participants (Korcha 2014); low-quality evidence), see Analysis 5.5.

\subsection{Alcohol-related harms or problems}

There were no data for this outcome.

\section{DISCUSSION}

\section{Summary of main results}

We included seven studies involving 825 participants in this review. The studies assessed the effectiveness of eight psychosocial interventions: cognitive-behavioural cognitive skills training (CBCST), twelve-step facilitation (TSF) programme, brief intervention (BI), motivational interviewing (MI) (group based), MI (individual), educational hepatitis health promotion (HHP), brief motivational interviewing (BMI), and intensive motivational interviewing (MII). Comparing different psychosocial interventions, we found three studies investigating $\mathrm{BI}$ versus treatment as usual (TAU), and three studies investigating MI versus TAU (or educational intervention only). We found only one study investigating each of the remaining interventions. None of the comparisons showed significant differences between the treatments in terms of alcohol use, with the exception that participants receiving BMI were significantly more likely to reduce their alcohol use by seven or more days in the past 30 days at six months' follow up compared with participants receiving assessment-only.

\section{Overall completeness and applicability of evidence}

The studies identified are insufficient to address all the objectives of this review. All included studies were conducted either in the USA, Ireland or Switzerland, which limits their applicability to other contexts. A substantial proportion of participants in the included studies had significant problems with alcohol (e.g. a diagnosis of abuse or dependence), which may have impacted on the effectiveness of the short-term therapies and brief interventions offered to them. These people may require more intensive interventions, as Bls have been shown to be effective among people with less severe alcohol problems (Raistrick 2006). Only two studies examined a longer type of intervention (i.e. nine or 16 sessions); however, they reported their outcomes in a way that precluded comparison with other studies (Carroll 1998; Korcha 2014).

This review selected a very narrow clinical question that was limited to a very specific population. Although the size of this population is not negligible, it is highly unlikely that all of the individuals in a treatment service in a real-life setting will have both of the conditions selected as the eligibility criteria for this review. These stringent eligibility criteria strengthened the internal validity of the review; however, with an inevitable detriment to its external validity. A typical clinician in an actual treatment clinic would normally deal with a mixture of people who use illicit drugs (PWID), who may or may not have other concurrent conditions or comorbidities. To manage this demanding workload, they may want to consider other studies, which did not meet the eligibility criteria of our review.

\section{Quality of the evidence}

\section{Key methodological limitations}

Overall, we found mostly low-quality evidence for the comparisons and outcomes reported in this review. The methodological quality of studies included in the review was variable. Most of the studies did not describe the randomisation procedure and the method to conceal allocation. All studies used only subjective outcomes and $57 \%$ (four out of seven) were open-label. Risk of attrition bias at the end of treatment was unclear or high in the $57 \%$ of the studies (four out of seven) and low at follow-up (86\%).

\section{Indirectness of evidence}

We did not include studies providing indirect evidence about our research question in this review, for example trials that included illicit drug users with and without concurrent problem alcohol use. We did not identify other sources of indirectness, for example interventions, outcomes or comparators.

\section{Inconsistency of results}

We identified only low levels of unexplained heterogeneity or inconsistency in the results. Most studies did not find significant, or found only small, differences in effectiveness between the compared interventions on their primary outcomes.

\section{Potential biases in the review process}

There is a small chance that we missed some trials during the identification of relevant studies. We did not limit our searches to studies published in English; however, studies in non-English languages may have been missed because they are commonly less indexed in the selected databases. We may also have 
missed unpublished studies. Unpublished studies are likely to have negative results, which can be a reason why they are not published. Owing to the small number of included studies, we did not construct a funnel plot to assess publication bias. The major limitation of the review process was that most trials did not provide enough published data, or did not provide data in a form that could be extracted for meta-analysis. Although we emailed authors from all responded and provided further data. Furthermore, we could not include a number of potentially relevant studies, because they involved PWID without problem alcohol use in their samples.

\section{Agreements and disagreements with other studies or reviews}

Substantial evidence has described the value of psychosocial interventions in treating problem alcohol use; however, it has related mostly to the general population, as noted above (EMCDDA 2015). Furthermore, comparing the findings of our review with those of other reviews is complicated by the fact that other studies did not perform meta-analysis and we have minimal aggregated results that would allow comparisons. As described in the background section, other narrative literature reviews have dealt with our research population (Arias 2008; Bickel 1987). Similarly to our work, these reviews were unable to identify evidence to answer our question or to conduct a meta-analysis. Subsequently, they based their conclusions on evidence from a mixed type of studies (e.g. case studies, randomised controlled trials), or from studies that included PWID without concurrent problem alcohol use. We excluded these type of studies from our review. Nevertheless, the review by Arias and colleagues discussed 14 reports/studies about the treatment of co-occurring alcohol and cocaine/opioid dependence, two of which were included in our review (Arias 2008). Two recent reviews examined alcohol consumption among people pre- and post-treatment for other substance use disorders (Staiger 2013; Soyka 2015). They concluded that while concurrent alcohol is often highly prevalent in drug treatment, no clear patterns have emerged and the literature remains inconclusive with respect to toxicity for liver and effective interventions. Another recent review questioned the evidence behind denial of treatment for alcohol use disorders and behind reduction of opioid agonist dose in patients receiving opioid agonist treatment who test positive on alcohol breathalysers (Nolan 2016). Online technologies show promise in real-time assessment (handheld electronic diaries) and treatment (smartphone apps and videos) of problem alcohol use among concurrent PWID (Aharonovich 2017; Preston 2016).

This review is unintentionally entering the sensitive subject regarding the requirement of providing ancillary counselling services to individuals in opioid agonist treatments. The questions are whether counselling services provided to individuals receiving methadone maintenance treatment improve their outcomes, and whether adding any psychosocial support to standard maintenance treatments yields additional benefits. There are a number of ways to answer these questions. While previous studies attempted to answer these questions by providing evidence of the effectiveness of psychosocial interventions (Amato 2011a; Gossop 2006; McLellan 1993; Schwartz 2012), they have done so for general/mixed conditions/outcomes, in studies in mixed populations with or without concurrent alcohol problems, or involving mixed types of interventions (i.e. pharmacological plus psychosocial). Moreover, it remains controversial to make these treatments mandatory as the evidence for the effectiveness of compulsory treatment is lacking (Werb 2016). In this review, however, we focused on a single type of intervention and a 'pure' population in which all participants had both alcohol and drug problems. This may be one of the reasons why our review found such a small number of studies. A recent trial, which did not pose such restrictions, found that if counselling was optional, and if counsellor was being responsible for enforcing clinic rules, there was no difference from treatment as usual with methadone (Schwartz 2017). Nevertheless, our findings support the notion that the current evidence base is too weak to answer this important question, as reported in a previous Cochrane Review (Amato 2011a).

Another important question is what constitutes standard maintenance/outpatient treatment. It appears that all standard treatments contain some type of psychosocial support, which varies considerably, and this makes it difficult to evaluate the added value of additional services. This was apparent in studies included in our review.

\section{AUTHORS' CONCLUSIONS}

\section{Implications for practice}

Based on the evidence we identified, which was mainly of low quality, no reliable conclusions can be drawn regarding the effectiveness of different types of psychosocial interventions to reduce alcohol consumption in concurrent problem alcohol and illicit drug users. Given the high rates of co-occurrence of problem alcohol use and other drug problems, the integration of alcohol- and drug-orientated interventions appears a logical action; however, the findings of this review are inconclusive.

\section{Implications for research}

This review emphasises the need for randomised controlled trials (RCTs) to test the effectiveness of psychosocial interventions in reducing problem alcohol use in people who use illicit drugs (PWID). We recommend trials use robust methodology and are well reported to allow for critical appraisal. For researchers planning an RCT in this area, we recommend that they design their study considering the following (according to the EPICOT format for research recommendations on the effects of treatments; Brown 2006).

- Evidence (what is the current state of the evidence?): the current evidence is limited to seven RCTs conducted in an outpatient/ community setting, three of them with an accompanying opioid agonist treatment. More RCTs are needed.

- Population (what is the population of interest?): adults, including younger adults, who are identified as PWID with concurrent and confirmed problem alcohol use; people in or out of formal addiction treatment.

- Intervention (what are the interventions of interest?): psychosocial interventions (e.g. motivational interviewing (MI), cognitive-behavioural therapy (CBT), contingency management, family therapy, brief intervention (BI), etc.).

- Comparison (what are the comparisons of interest?): treatment as usual, no intervention, waiting list, other psychosocial interventions; pharmacological treatments (alone, or in combination with psychosocial treatments); interventions of different type, length and intensity. 
- Outcome (what are the outcomes of interest?): reduction in/ abstinence from alcohol or drug use, or from both. In order to be able to combine the outcomes of future trials with our current data, outcome measures of future trials should include formal validated instruments, for example the AUDIT questionnaire or other core set of outcomes that researchers agree on and apply (see COMET initiative). Objective measures of these outcomes should be used in conjunction with self-reports wherever possible (for example, breathalysers, urinalysis).

- Time stamp (date of literature search): for this review, searches were conducted on 22 November 2011, then updated in June 2014 and August 2017.

\section{ACKN OWLEDGEMENTS}

Health Research Board Ireland funded the original review. For the first version of our review, Jennifer Collery and Kathryn Smyth from UCD Health sciences library provided extensive support with the search strategy, in conjunction with the support from Cochrane Drugs and Alcohol (CDAG), especially Suzanna Mitrova (records screening) and Silvia Minozzi (quality advice). For the 2017 update, Lauren Adye-White and Lauren Gorfinkel assisted with updating the text of the review, risk-of-bias assessments and summary of findings tables. We thank the following individuals for retrieving full-text papers: Cendrine Robinson (Uniformed Services University of the Health Sciences, USA); Constance M Pollack (The College of Problems on Drug Dependence, USA); Jan R Böhnke (University of Trier, Germany); Maria Jakubekova (helped with German translations); Amy Drahota and Marialena Trivela (UK Cochrane Centre) for excellent training in systematic reviews and answering follow-up questions; and Adeline Nyamathi, Nelson Feldman, Catherine Darker, Lucy Whinston, Geoff McCombe and Anne Marie Henihan for providing additional information/data regarding their trials included in our review. 


\section{RE F E R E N C E S}

\section{References to studies included in this review}

Carroll 1998 \{published data only (unpublished sought but not used)\}

Carroll KM, Nich C, Ball SA, McCance E, Frankforter TL, Rounsaville BJ. One-year follow-up of disulfiram and psychotherapy for cocaine-alcohol users: sustained effects of treatment. Addiction 2000;95(9):1335-49.

* Carroll KM, Nich C, Ball SA, McCance E, Rounsavile BJ. Treatment of cocaine and alcohol dependence with psychotherapy and disulfiram. Addiction 1998;93(5):713-27.

Darker 2016 \{published and unpublished data\}

Darker CD, Sweeney B, Keenan E, Whiston L, Anderson R, Barry J. Screening and brief interventions for illicit drug use and alcohol use in methadone maintained opiate-dependent patients: results of a pilot cluster randomized controlled trial feasibility study. Substance Use \& Misuse 2016;51(9):1104-15.

Darker CD, Sweeney B, Keenan E, Whiston L, Anderson R, Barry J. Tailoring a brief intervention for illicit drug use and alcohol use in Irish methadone maintained opiate dependent patients: a qualitative process. BMC Psychiatry 2017;16(1):373.

\section{Feldman 2013 \{published and unpublished data\}}

* Feldman N, Chatton A, Khan R, Khazaal Y, Zullino D. Alcoholrelated brief intervention in patients treated for opiate or cocaine dependence: a randomized controlled study. Substance Abuse Treatment, Prevention, and Policy 2011;6(22):1-8.

Feldman N, Chatton A, Khan R, Khazaal Y, Zullino D. Correction: Alcohol-related brief intervention in patients treated for opiate or cocaine dependence: a randomized controlled study. Substance Abuse Treatment, Prevention, and Policy 2013;8(1):28.

Henihan 2016 \{published and unpublished data\}

Henihan AM, McCombe G, Klimas J, Swan D, Leahy D, Anderson R, et al. Feasibility of alcohol screening among patients receiving opioid treatment in primary care. BMC Family Practice 2016;17(1):153.

\section{Korcha 2014 \{published and unpublished data\}}

Korcha RA, Polcin DL, Evans K, Bond JC, Galloway GP. Intensive motivational interviewing for women with concurrent alcohol problems and methamphetamine dependence. Journal of Substance Abuse Treatment 2014;46(2):113-9.

\section{Nyamathi 2010 \{published and unpublished data\}}

Nyamathi A M, Nandy K, Greengold B, Marfisee M, Khalilifard F, Cohen $A$, et al. Effectiveness of intervention on improvement of drug use among methadone maintained adults. Journal of Addictive Disorders 2011;30(1):6-16.

* Nyamathi A, Shoptaw S, Cohen A, Greengold B, Nyamathi K, Marfisee $\mathrm{M}$, et al. Effect of motivational interviewing on reduction of alcohol use. Drug Alcohol Dependence 2010;107(1):23-30. [1879-0046: (Electronic)]
Stein 2002 \{published data only (unpublished sought but not used)\}

Stein MD, Anderson B, Charuvastra A, Maksad J, Friedmann PD. $A$ brief intervention for hazardous drinkers in a needle exchange program. Journal of Substance Abuse Treatment 2002;22(1):23-31.

Stein MD, Charuvastra A, Anderson BJ. Social support and zero sharing risk among hazardously drinking injection drug users. Journal of Substance Abuse Treatment 2002;23(3):225-30.

* Stein MD, Charuvastra A, Makstad J, Anderson BJ. A randomized trial of a brief alcohol intervention for needle exchanges (BRAINE). Addiction 2002;97(6):691. [09652140]

\section{References to studies excluded from this review}

\section{Aldridge 2017 \{published data only\}}

Aldridge A, Dowd W, Bray J. The relative impact of brief treatment versus brief intervention in primary health-care screening programs for substance use disorders. Addiction 2017;112 Suppl 2:54-64.

\section{Aldridge 2017b \{published data only\}}

Aldridge A, Linford R, Bray J. Substance use outcomes of patients served by a large US implementation of Screening, Brief Intervention and Referral to Treatment (SBIRT). Addiction 2017;112 Suppl 2:43-53.

\section{Bennett 2002 \{published data only\}}

Bennett GA, Edwards S, Bailey J. Helping methadone patients who drink excessively to drink less: short-term outcomes of a pilot motivational intervention. Journal of Substance Use 2002; Vol. 7, issue 4:191-7. [1465-9891]

\section{Bernstein 2005 \{published data only\}}

Bernstein J, Bernstein E, Tassiopoulos K, Heeren T, Levenson S, Hingson R. Brief motivational intervention at a clinic visit reduces cocaine and heroin use. Drug Alcohol Dependence 2005;77(1):49-59.

\section{Bowen 2006 \{published data only\}}

Bowen S, Witkiewitz K, Dillworth TM, Chawla N, Simpson TL, Ostafin BD, et al. Mindfulness meditation and substance use in an incarcerated population. Psychology of Addictive Behaviors 2006;20:343-7.

\section{Chambers 2016 \{published data only\}}

Chambers J E, Brooks A C, Medvin R, Metzger D S, Lauby J, Carpenedo $C M$, et al. Examining multi-session brief intervention for substance use in primary care: research methods of a randomized controlled trial. Addiction Science and Clinical Practice 2016;11(1):8.

\section{Cohen 1982 \{published data only\}}

Cohen M, Korts D, Hanbury R, Sturiano V, Jackson G, Stimmel B. The effect of alcoholism in methadone-maintained persons on productive activity: a randomized control trial. Alcoholism, Clinical and Experimental Research 1982;6:358-61. 
Stimmel B, Cohen M, Sturiano V, Hanbury R, Korts D, Jackson $\mathrm{G}$. Is treatment for alcoholism effective in persons on methadone maintenance?. American Journal of Psychiatry 1983;140(7):862-6.

\section{Darker 2016a \{published data only\}}

Darker C, Sweeney B, Keenan E, Whiston L, Anderson R, Barry J. Tailoring a brief intervention for illicit drug use and alcohol use in Irish methadone maintained opiate dependent patients: a qualitative process. BMC Psychiatry 2016;16(1):373.

\section{Drumright 2011 \{published data only\}}

Drumright LN, Hagan H, Thomas DL, Latka MH, Golub ET, Garfein RS, et al. Predictors and effects of alcohol use on liver function among young HCV-infected injection drug users in a behavioral intervention. Journal of Hepatology 2011;55(1):45-52.

\section{Karno 2017 \{published data only\}}

Karno MP. Screening and brief intervention for alcohol and drug use among latinos and non-latinos in mental health treatment settings. Alcoholism, Clinical and Experimental Research 2017;41(S1):315A.

\section{Kennedy 2016 \{published data only\}}

Kennedy DP, Hunter S B, Chan Osilla K, Maksabedian E, Golinelli D, Tucker JS. A computer-assisted motivational social network intervention to reduce alcohol, drug and HIV risk behaviors among Housing First residents. Addiction Science and Clinical Practice 2016;11(1):4

\section{Moyers 2016 \{published data only\}}

Moyers TB, Houck J, Rice SL, Longabaugh R, Miller WR. Therapist empathy, combined behavioral intervention, and alcohol outcomes in the COMBINE research project. Journal of Consulting and Clinical Psychology 2016;84(3):221-9.

\section{O'Farrell 2008 \{published data only\}}

O'Farrell TJ, Murphy M, Alter J, Fals-Stewart W. Brief family treatment intervention to promote continuing care among alcohol-dependent patients in inpatient detoxification: a randomized pilot study. Journal of Substance Abuse Treatment 2008;34(3):363-9. [PUBMED: 17614242]

\section{Worden 2010 \{published data only\}}

Worden BL. Effectiveness of a feedback-based brief intervention for alcohol use disorders in community care [thesis]. Newark, NJ: Graduate School-New Brunswick Rutgers, The State University of New Jersey, 2010.

\section{References to studies awaiting assessment}

\section{Aharonovich 2017 \{published data only\}}

Aharonovich E, Stohl M, Cannizzaro D, Hasin D. Mobile technology targeting concurrent alcohol and drug use in HIV+ adults: A pilot study. Proceedings of the 40th Annual RSA Scientific Meeting June 24-28, 2017, Denver, Colorado, published in the Alcoholism Clinical \& Experimental Research. 2017; Vol. 41 (Supplement S1):256A. [DOI: 10.1111/acer.13392]
Poblete 2017 \{published and unpublished data\}

Poblete F, Barticevic NA, Zuzulich MS, Portilla R, CastilloCarniglia A, Sapag JC, et al. A randomized controlled trial of a brief intervention for alcohol and drugs linked to the Alcohol, Smoking and Substance Involvement Screening Test (ASSIST) in primary health care in Chile. Addiction 2017;112(8):1462-9. [DOI: 10.1111/add.13808]

\section{Staiger 2011 \{unpublished data only\}}

Staiger PK, Gruenert S, Manning M, Lake A, Long C. Preventing Relapse: A responsible drinking program for recovering drug users. Final Report. Burwood, Australia: Deakin University, 2011.

\section{Thapaliya 2017 \{published and unpublished data\}}

Thapaliya S, Jain R, Ambekar A, Kumar Mishra A, Yadav D. Effectiveness of brief intervention for moderate/high risk alcohol use among patients on buprenorphine maintenance: A clinical and alcohol-biomarker study. Second European Conference on addictive behaviours and dependencies, Lisbon, October 24th. 2017.

\section{Additional references}

\section{Alcoholics Anonymous 1939}

Alcoholics Anonymous. The story of how more than one hundred men have recovered from alcoholism. New York: Alcoholics Anonymous World Services, Inc., 1939.

\section{Amato 2011a}

Amato L, Minozzi S, Davoli M, Vecchi S, Ferri M, Mayet S. Psychosocial combined with agonist maintenance treatments versus agonist maintenance treatments alone for treatment of opioid dependence. Cochrane Database of Systematic Reviews 2011, Issue 10. [DOI: 10.1002/14651858.CD004147.pub4]

\section{Anderson 2004}

Anderson P, Laurant M, Kaner E, Wensing M, Grol R. Engaging general practitioners in the management of hazardous and harmful alcohol consumption: results of a meta-analysis. Journal of Studies on Alcohol 2004;65(2):191-9.

\section{Arias 2008}

Arias AJ, Kranzler HR. Treatment of co-occurring alcohol and other drug use disorders. Alcohol Research and Health 2008;31(2):155-67.

\section{Babor 2001}

Babor T, Higgins-Biddle J. Brief intervention for hazardous and harmful drinking. A manual for use in primary care. Geneva: WHO, 2001.

\section{Backmund 2003}

Backmund M, Schütz CG, Meyer K, Eichenlaub D, Soyka M. Alcohol consumption in heroin users, methadone-substituted and codeine-substituted patients-frequency and correlates of use. European Addiction Research 2003;9(1):45-50.

\section{Beutler 2016}

Beutler LE, Someah K, Kimpara S, Miller K. Selecting the most appropriate treatment for each patient. International Journal of 
Clinical and Health Psychology 2016;16(1):99-108. [DOI: 10.1016/ j.ijchp.2015.08.001]

\section{Bickel 1987}

Bickel WK, Marion I, Lowinson JH. The treatment of alcoholic methadone patients: a review. Journal of Substance Abuse Treatment 1987;4(1):15-9.

\section{Blankertz 2004}

Blankertz L, Magura S, Staines GL, Madison EM, Spinelli M, Horowitz E, et al. A new work placement model for unemployed methadone maintenance patients. Substance Use and Misuse 2004;39(13-14):2239-60.

\section{Brown 2006}

Brown P, Brunnhuber K, Chalkidou K, Chalmers I, Clarke M, Fenton $\mathrm{M}$, et al. How to formulate research recommendations. BMJ 2006;33(7572):804-6. [DOI: 10.1136/bmj.38987.492014.94]

\section{Budney 2001}

Budney AJ, Sigmon SC, Higgins ST. Contingency management: using science to motivate change. In: Coombs RH editor(s). Addiction Recovery Tools: A Practical Handbook. London: Sage, 2001:147-72.

\section{Byrne 2011}

Byrne SA, Petry NM. Concurrent alcohol dependence among methadone-maintained cocaine abusers is associated with greater abstinence. Experimetal and Clinical Psychopharmacology 2011;19(2):116-22.

\section{Caputo 2002}

Caputo F, Addolorato G, Domenicali M, Mosti A, Viaggi M, Trevisani F, et. al. Short-term methadone administration reduces alcohol consumption in non-alcoholic heroin addicts. Alcohol and Alcoholism 2002;37(2):164-8.

\section{Chen 2011}

Chen IC, Chie WC, Hwu HG, Chou SY, Yeh YC, Yu CY, et al. Alcohol use problem among patients in methadone maintenance treatment in Taiwan. Journal of Substance Abuse Treatment 2011;40(2):142-9.

\section{Crits-Christoph 1999}

Crits-Christoph P, Siqueland L, Blaine J, Frank A, Luborsky L, Onken LS, et al. Psychosocial treatments for cocaine dependence: National Institute on Drug Abuse Collaborative Cocaine Treatment Study. Archives of General Psychiatry 1999;56(6):493-502.

\section{CSAT 2004}

Center for Substance Abuse Treatment. Substance Abuse Treatment and Family Therapy. Treatment Improvement Protocol (TIP) Series, No. 39. DHHS Publication No. (SMA) 04-3957. Rockville, MD: Substance Abuse and Mental Health Services Administration, 2004.

\section{Dalsbø 2010}

Dalsbø TK, Hammerstrøm KT, Vist Gunn E, Gjermo H, Smedslund G, Steiro A, et al. Psychosocial interventions for retention in drug abuse treatment. Cochrane
Database of Systematic Reviews 2010, Issue 1. [DOI: 10.1002/14651858.CD008220]

\section{De Leon 2000}

De Leon G. The Therapeutic Community: Theory, Model, and Method. New York: Springer Publishing Company, 2000.

\section{Dobler-Mikola 2005}

Dobler-Mikola A, Hättenschwiler J, Meili D, Beck T, Böni E, Modestin J. Patterns of heroin, cocaine, and alcohol abuse during long-term methadone maintenance treatment. Journal of Substance Abuse Treatment 2005;29(4):259-265.

\section{DSM-5}

American Psychiatric Publishing. Diagnostic and Statistical Manual of Mental Disorders DSM-5 Fifth Edition. American Psychiatric Publishing, Inc., 2013. [0890425558]

\section{Du 2012}

Du J, Wang Z, Xie B, Zhao M. Hepatitis C knowledge and alcohol consumption among patients receiving methadone maintenance treatment in Shanghai, China. The American Journal of Drug and Alcohol Abuse 2012;38(3):228-32.

\section{EMCDDA 2008}

Scalia Tomba GP, Rossi C, Taylor C, Klempova D, Wiessing L. Guidelines for Estimating the Incidence of Problem Drug Use. EMCDDA, Lisbon 2008.

\section{EMCDDA 2015}

EMCDDA. The role of psychosocial interventions in drug treatment [Perspectives on Drugs]. EMCDDA, Lisbon 2015.

\section{Eppi 2017 [Computer program]}

Evidence for Policy and Practice Information (EPPI) centre. EPPI-Reviewer. Version 4. London: Institute of Education, University of London (eppi.ioe.ac.uk), 2017.

\section{Galloway 2000}

Galloway G P, Marinelli-Casey P, Stalcup J, Lord R, Christian D, Cohen J, et al. Treatment-as-usual in the methamphetamine treatment project. Journal of Psychoactive Drugs 2000;32(2):165-75.

\section{Galloway 2007}

Galloway G P, Polcin D, Kielstein A, Brown M, Mendelson J. A nine session manual of motivational enhancement therapy for methamphetamine dependence: adherence and efficacy. Journal of Psychoactive Drugs 2007;Suppl 4:393-400.

\section{Gossop 2000}

Gossop M, Marsden J, Stewart D, Rolfe A. Patterns of drinking and drinking outcomes among drug misusers: 1-year follow-up results. Journal of Substance Abuse Treatment 2000;19(1):45-50.

\section{Gossop 2006}

Gossop M, Stewart D, Marsden J. Effectiveness of drug and alcohol counselling during methadone treatment: content, frequency, and duration of counselling and association with substance use outcomes. Addiction 2006;101(3):404-12. 


\section{Harris 2010}

Harris GH, Strauss SM, Katigbak C, Brar BS, Brown Jr LS, Kipnis SS, et al. Variation among state-level approaches to addressing alcohol abuse in opioid treatment programs. Journal of Substance Abuse Treatment 2010;39(1):58-64.

\section{Hartzler 2010}

Hartzler B, Donovan DM, Huang Z. Comparison of opiateprimary treatment seekers with and without alcohol use disorder. Journal of Substance Abuse Treatment 2010;39(2):114-23.

\section{Hartzler 2011}

Hartzler B, Donovan DM, Huang Z. Rates and influences of alcohol use disorder comorbidity among primary stimulant misusing treatment-seekers: meta-analytic findings across eight NIDA CTN trials. The American Journal of Drug and Alcohol Abuse 2011;37(5):460-71.

\section{Hesse 2007}

Hesse M, Vanderplasschen W, Rapp R, Broekaert E, Fridell M. Case management for persons with substance use disorders. Cochrane Database of Systematic Reviews 2007, Issue 4. [DOI: 10.1002/14651858.CD006265]

\section{Higgins 2011}

Higgins JPT, Green S (editors). Cochrane Handbook for Systematic Reviews of Interventions Version 5.1.0. [updated March 2011]. The Cochrane Collaboration, 2011. Available from www.cochrane-handbook.org. Wiley.

\section{Hunt 1973}

Hunt GM, Azrin NH. A community-reinforcement approach to alcoholism. Behavioural Research and Therapy 1973;11(1):91-104.

\section{Islam 2013}

Islam MM, Day CA, Conigrave KM, Topp L. Self-perceived problem with alcohol use among opioid substitution treatment clients. Addictive Behaviors 2013;38(4):2018-21.

\section{Johnson 2015}

Johnson C, Dong H, Ahamad K, Hayashi K, Milloy MJ, Kerr T, et al. Impact of binge alcohol on mortality among people who inject drugs. Addictive Behaviors Reports 2015;2(Dec):28-32.

\section{Kaner 2018}

Kaner EF, Beyer FR, Muirhead C, Campbell F, Pienaar ED, Bertholet N, Daeppen JB, Saunders JB, Burnand B. Effectiveness of brief alcohol interventions in primary care populations. Cochrane Database of Systematic Reviews 2018, Issue 2. [DOI: 10.1002/14651858.CD004148.pub4]

\section{Kipnis 2001}

Kipnis S S, Herron A, Perez J, Joseph H. Integrating the methadone patient in the traditional addiction inpatient rehabilitation program--problems and solutions. Mt Sinai Journal of Medicine 2001;68(1):28-32.

\section{Klimas 2012b}

Klimas J, Field CA, Barry J, Bury G, Keenan E, Lyons S, et al. Commentary on 'The research translation problem: alcohol screening and brief intervention in primary care - real world evidence supports theory'. Drugs Education Prevention Policy 2012;19(1):88-90. [DOI: 10.3109/09687637.2011.577462]

\section{Klimas 2014}

Klimas J, Lally K, Murphy L, Crowley L, Anderson R, Meagher D, et al. Development and process evaluation of an educational intervention to support primary care of problem alcohol among drug users. Drugs and Alcohol Today 2014;14(2):76-86.

\section{Klimas 2015a}

Klimas J, Muench J, Wiest K, Croff R, Rieckman T, McCarty D. Alcohol screening among opioid agonist patients in a primary care clinic and an opioid treatment program. Journal of Psychoactive Drugs 2015;47(1):65-70.

\section{Klimas 2015b}

Klimas J, Henihan A, McCombe G, Swan D, Anderson R, Bury G. Psychosocial interventions for problem alcohol use in primary care settings (PINTA): baseline feasibility data. Journal of Dual Diagnosis 2015;11(2):97-106.

\section{Klimas 2016}

Klimas J, Wood E, Nguyen P, Dong H, Milloy MJ, Kerr T, Hayashi K. The impact of enrolment in methadone maintenance therapy on initiation of heavy drinking among people who use heroin. European Addiction Research 2016;22(4):210-4.

\section{Klimas 2017a}

Klimas J, Dong H, Dobrer S, Milloy MJ, Kerr T, Wood E, Hayashi K. Alcohol use among persons on methadone treatment. Addictive Disorders \& Their Treatment 2017;16(1):36-7.

\section{Klimas 2017b}

Klimas J, Wood E, Nosova E, Milloy MJ, Kerr T, Hayashi K. Prevalence of heavy alcohol use among people receiving methadone following change to methadose. Substance Use and Misuse 2017; In press(2):270-5.

\section{Lui 2008}

Lui S, Terplan M, Smith EJ. Psychosocial interventions for women enrolled in alcohol treatment during pregnancy. Cochrane Database of Systematic Reviews 2008, Issue 3. [DOI: 10.1002/14651858.CD006753]

\section{Marlatt 1996}

Marlatt GA. Taxonomy of high-risk situations for alcohol relapse: evolution and development of a cognitive-behavioral model. Addiction 1996;91(Suppl):S37-49.

\section{Maynié-François 2016}

Maynié-François C, Cheng DM, Samet JH, Lloyd-Travaglini C, Palfai T, Bernstein J, Saitz R. Unhealthy alcohol use in primary care patients who screen positive for drug use. Substance Abuse 2016;Aug 2(Epub ahead of print):1-6. 


\section{McCambridge 2017}

McCambridge J, Saitz R. Rethinking brief interventions for alcohol in general practice. The BMJ 2017;356:j116. [PUBMED: 28108452]

\section{McCombe 2016}

McCombe G, Henihan AM, Klimas J, Swan D. Leahy D, Anderson R, et al. Enhancing alcohol screening and brief intervention among people receiving opioid agonist treatment: qualitative study in primary care. Drugs and Alcohol Today 2016;16(4):247-8.

\section{McLellan 1993}

McLellan AT, Arndt IO, Metzger DS, Woody GE, O'Brien CP. The effects of psychosocial services in substance abuse treatment. JAMA 1993;269(15):1953-9.

\section{Meader 2010}

Meader N, Li R, Des Jarlais DC, Pilling S. Psychosocial interventions for reducing injection and sexual risk behaviour for preventing HIV in drug users. Cochrane Database of Systematic Reviews 2010, Issue 1. [DOI: 10.1002/14651858.CD007192.pub2]

\section{Messina 2003}

Messina N, Farabee D, Rawson R. Treatment responsivity of cocaine-dependent patients with antisocial personality disorder to cognitive-behavioral and contingency management interventions. Journal of Consulting and Clinical Psychology 2003;71(2):320-9.

\section{Miller 1996}

Miller WR, Bennett ME. Treating alcohol problems in the context of other drug abuse. Alcohol Health and Research World 1996;20(2):118-23.

\section{Miller 2002}

Miller WR, Wilbourne PL. Mesa Grande: a methodological analysis of clinical trials of treatments for alcohol use disorders. Addiction 2002; Vol. 97, issue 3:265-77. [0965-2140: (Print)]

\section{Miller 2004}

Miller WR, Rollnick S. Talking oneself into change: motivational interviewing, stages of change, and therapeutic process. Journal of Cognitive Psychotherapy 2004;18:299-308.

\section{Minozzi 2016}

Minozzi S, Saulle R, De Crescenzo F, Amato L. Psychosocial interventions for psychostimulant misuse. Cochrane Database of Systematic Reviews 2016, Issue 9. [DOI: 10.1002/14651858.CD011866.pub2]

\section{Moher 2009}

Moher D, Liberati A, Tetzlaff J, Altman DG, The Prisma Group. Preferred reporting items for systematic reviews and meta-analyses: the PRISMA statement. PLoS Medicine 2009;6(7):e1000097. [DOI: 10.1371/journal.pmed.1000097]

\section{Moyer 2002}

Moyer A, Finney JW, Swearingen CE, Vergun P. Brief interventions for alcohol problems: a meta-analytic review of controlled investigations in treatment-seeking and nontreatment-seeking populations. Addiction 2002; Vol. 97:279-92.

\section{NIAAA 2004}

National Institute of Alcohol Abuse and Alcoholism. NIAAA council approves definition of binge drinking. NIAAA Newsletter 2004;3(3):3

\section{NIH 2012}

National Institutes of Health. Request for Information (RFI): input into the scientific strategic plan for the proposed National Institute of Substance Use and Addiction Disorders. grants.nih.gov/grants/guide/notice-files/NOT-OD-12-045.html 8 February 2012 (accessed 5 November 2014).

\section{Nilsen 2010}

Nilsen P. Brief alcohol intervention - where to from here? Challenges remain for research and practice. Addiction 2010; Vol. 105, issue 6:954-9. [1360-0443]

\section{Nolan 2016}

Nolan S, Klimas J, Wood E. Alcohol use in opioid agonist treatment. Addiction Science \& Clinical Practice 2016;11(1):17.

\section{Pilling 2010}

Pilling S, Hesketh K, Mitcheson L. Routes to recovery: psychosocial interventions for drug misuse. A framework and toolkit for implementing NICE-recommended treatment interventions. London: NTA, 2010.

\section{Platt 1995}

Platt JJ. Vocational rehabilitation of drug abusers. Psychological Bulletin 1995;117(3):416-33.

\section{Preston 2016}

Preston KL, Jobes ML, Phillips KA, Epstein DH. Real-time assessment of alcohol drinking and drug use in opioiddependent polydrug users. Behavioral Pharmacology 2016;27(7):579-84. [DOI: 10.1097/FBP.0000000000000250]

\section{Prochaska 1992}

Prochaska JO, DiClemente CC, Norcross JC. In search of how people change: applications to addictive behaviors. American Psychologist 1992;47(9):1102-14.

\section{Raistrick 2006}

Raistrick D, Heather N, Godfrey C. Review of the Effectiveness of Treatment for Alcohol Problems. London: National Treatment Agency for Substance Misuse, 2006.

\section{Rosa 2015}

Rosa NRP, Abreu AMM. de Andrade TMMD. Effect of brief interventions in reducing hazardous alcohol consumption in users receiving methadone treatment [Efeito das intervenções breves na redução do consumo de risco nos utentes em tratamento com metadona/Efecto de las intervenciones breves para reducir el consumo de riesgo de los usuarios en tratamiento con metadona]. Revista de Enfermagem Referência 2015;4(6):27-34. 


\section{Saitz 2014}

Saitz, R. Screening and brief intervention for unhealthy drug use: little or no efficacy. Frontiers in Psychiatry 2014;2(5):121.

\section{Saitz 2015}

Saitz R. 'SBIRT' is the answer? Probably not. Addiction 2015;110(9):1416-7.

\section{Schunemann 2013}

Schunemann H, Brozek J, Guyatt G, Oxman A, editors. GRADE handbook for grading quality of evidence and strength of recommendations. The GRADE Working Group. http:// gdt.guidelinedevelopment.org/app/handbook/handbook.html, 2013.

\section{Schwartz 2012}

Schwartz RP, Kelly SM, O'Grady KE, Gandhi D, Jaffe JH. Randomized trial of standard methadone treatment compared to initiating methadone without counseling: 12-month findings. Addiction 2012;107(5):943-52. [DOI: 10.1111/ j.1360-0443.2011.03700.x]

\section{Schwartz 2017}

Schwartz RP, Kelly SM, Mitchell SG, Gryczynski Jan, O'Grady KE, Gandhi Devang, et al. Patient-centered methadone treatment: a randomized clinical trial. Addiction 2017;112(3):454-64.

\section{Shah 2008}

Shah NG, Lathrop SL, Reichard RR, Landen MG. Unintentional drug overdose death trends in New Mexico, USA, 1990-2005: combinations of heroin, cocaine, prescription opioids and alcohol. Addiction 2008;103(1):126-36.

\section{Shand 2003}

Shand F, Gates J, Fawcett J, Mattick R. The treatment of alcohol problems: a review of the evidence, 2003. www.alcohol.gov.au/internet/alcohol/publishing.nsf/ Content/1980DFD151B3287FCA257261000E0955/\$File/ alcproblems.pdf. (accessed 27 September 2012).

\section{Smedslund 2011}

Smedslund G, Berg RC, Hammerstrøm KT, Steiro A, Leiknes KA, Helene DM, et al. Motivational interviewing for substance abuse. Cochrane Database of Systematic Reviews 2011, Issue 5. [DOI: 10.1002/14651858.CD008063]

\section{Smith 2006}

Smith LA, Gates S, Foxcroft D. Therapeutic communities for substance related disorder. Cochrane Database of Systematic Reviews 2006, Issue 1. [DOI: 10.1002/14651858.CD005338]

\section{Smyth 1998}

Smyth BP, Keenan E, O'Connor JJ. Bloodborne viral infection in Irish injecting drug users. Addiction 1998; Vol. 93, issue 11:1649-56. [0965-2140: (Print)]

\section{Soyka 2015}

Soyka M. Alcohol use disorders in opioid maintenance therapy: prevalence, clinical correlates and treatment. European Addiction Research 2015;21(2):18-87.

\section{Staiger 2009}

Staiger PK, Gruenert S, Manning M, Lake A, Long C. A brief alcohol intervention program for adults in residential treatment: Resutls from a randomised controlled trial. Drug and Alcohol Review. Sydney, Australia: Proceedings of the Australasian Professional Society on Alcohol and other Drugs, 2017:A60

\section{Staiger 2013}

Staiger PK, Richardson B, Long CM, Carr V, Marlatt GA. Overlooked and underestimated? Problematic alcohol use in clients recovering from drug dependence. Addiction 2013;108(7):1188-93.

\section{Stalcup 2006}

Stalcup S A, Christian D, Stalcup J, Brown M, Galloway G P. A treatment model for craving identification and management. Journal of Psychoactive Drugs 2006;38(2):189-202.

\section{Tanner-Smith 2015}

Tanner-Smith EE, Steinka-Fry KT, Hennessy EA, Lipsey MW, Winters KC. Can brief alcohol interventions for youth also address concurrent illicit drug use? Results from a metaanalysis. Journal of Youth and Adolescence 2015;44(5):1011-23.

\section{Teplin 2007}

Teplin D, Raz B, Daiter J, Varenbut M, Plater-Zyberk C. Screening for alcohol use patterns among methadone maintenance patients. American Journal of Drug and Alcohol Abuse 2007; Vol. 33 , issue 1:179-83.

\section{Terplan 2015}

Terplan M, Ramanadhan S, Locke A, Longinaker N, Lui S. Psychosocial interventions for pregnant women in outpatient illicit drug treatment programs compared to other interventions. Cochrane Database of Systematic Reviews 2015, Issue 4. [DOI: 10.1002/14651858.CD006037.pub3]

\section{Thomas 2011}

Thomas RE, Lorenzetti D, Spragins W. Mentoring adolescents to prevent drug and alcohol use. Cochrane Database of Systematic Reviews 2011, Issue 11. [DOI: 10.1002/14651858.CD007381]

\section{Tsui 2017}

Tsui JI, Williams EC, Green PK, Berry K, Su F, Ioannou GN. Alcohol use and hepatitis $C$ virus treatment outcomes among patients receiving direct antiviral agents. Drug and Alcohol Dependence 2017; Vol. 169, issue Dec:101-9.

\section{Varshney 2016}

Varshney M, Ambekar A, Lal R, Yadav D, Rao R, Mishra A. Brief interventions for harmful alcohol use in opioid-dependent patients on maintenance treatment with buprenorphine: a prospective study from India. Addictive Disorders \& Their Treatment 2016;15(3):129-35.

\section{Werb 2016}

Werb D, Kamarulzaman A, Meacham MC, Rafful C, Fischer B, Strathdee SA, et al. The effectiveness of compulsory drug treatment: A systematic review. International Journal of Drug Policy 2016;28:1-9. 


\section{White 1999}

White JM, Irvine RJ. Mechanisms of fatal opioid overdose. Addiction 1999; Vol. 94, issue 7:961-72.

\section{Whitlock 2004}

Whitlock EP, Polen MR, Green CA, Orleans T, Klein J. Behavioral counseling interventions in primary care to reduce risky/ harmful alcohol use by adults: a summary of the evidence for the U.S. Preventive Services Task Force. Annals of Internal Medicine 2004; Vol. 140, issue 7:557-68.

\section{WHO 1993}

World Health Organization. The ICD-10 Classification of Mental and Behavioural Disorders: Diagnostic Criteria for Research, 1993. www.who.int/classifications/icd/en/GRNBOOK.pdf. (accessed 27 September 2012).

\section{Williams 2011}

Williams EC, Johnson ML, Lapham GT, Caldeiro RM, Chew L, Fletcher GS, et al. Strategies to implement alcohol screening and brief intervention in primary care settings: $a$ structured literature review. Psychology of Addictive Behaviors 2011;25(2):206-14.

\section{Wurst 2011}

Wurst FM, Thon N, Yegles M, Halter C, Weinmann W, Laskowska B, et al. Optimizing heroin-assisted treatment (HAT): assessment of the contribution of direct ethanol metabolites in identifying hazardous and harmful alcohol use. Drug and Alcohol Dependence 2011;115(1-2):57-61.

\section{CHARACTERISTICS OFSTUDIES}

Characteristics of included studies [ordered by study ID]

\section{Young 2016}

Young SV, Wood E, Dong H, Kerr T, Hayashi K. Daily alcohol use as an independent risk factor for HIV seroconversion among people who inject drugs. Addiction 2016;111(8):1360-1365.

\section{References to other published versions of this review \\ Klimas 2012a}

Klimas J, Field CA, Cullen W, O'Gorman CS, Glynn LG, Keenan E, et al. Psychosocial interventions to reduce alcohol consumption in concurrent problem alcohol and illicit drug users. Cochrane Database of Systematic Reviews 2012, Issue 11. [DOI: 10.1002/14651858.CD009269.pub2]

\section{Klimas 2013}

PMC3564788Klimas J, Field CA, Cullen W, O'Gorman CS, Glynn LG, Keenan E, et al. Psychosocial interventions to reduce alcohol consumption in concurrent problem alcohol and illicit drug users: Cochrane Review. Systematic Reviews 2013;2(1):3. [PUBMED: PMC3564788]

\section{Klimas 2014b}

Klimas J, Tobin H, Field CA, Cullen W, O'Gorman CS, Glynn LG, Keenan $\mathrm{E}$, et al. Psychosocial interventions to reduce alcohol consumption in concurrent problem alcohol and illicit drug users. Cochrane Database of Systematic Reviews 2014, Issue 12. [DOI: 10.1002/14651858.CD009269.pub3]

* Indicates the major publication for the study

Carroll 1998

Methods Study design: RCT, single blind.

Recruitment modality of participants: individuals seeking treatment at the outpatient treatment unit of the APT Foundation, or respondents to newspaper advertisements or public service announcements.

Gender: $27 \%$ female.

Mean age: 30.8 years (SD 5.5 years).

Condition: "All subjects met current DSM-III-R criteria for cocaine dependence, and for concurrent alcohol dependence $(85 \%)$ or alcohol abuse $(15 \%) "$.

\section{Other relevant information:}

(1) TSF arm - baseline substance use:

- mean weekly cocaine use $5.4 \pm 8.6$;

- days cocaine use/past 30 days $12.7 \pm 8.0$;

- cocaine use g/week/past 30 days $4.6 \pm 6.6$;

- mean drinks per drinking day/past 30 days $10.2 \pm 5.7$;

- days of alcohol use/past 30 days $12.3 \pm 8.0$; 
- years of cocaine use - lifetime $7.5 \pm 3.9$;

- years of alcohol misuse - lifetime $7.1 \pm 6.3$;

- lifetime psychiatric disorders: any affective disorder $24 \%$, any anxiety disorder $24 \%$, ASP $42 \%$, any non-ASP 35\%;

- ASI composite scores: medical $0.15 \pm 0.26$, employment $0.71 \pm 0.28$, legal $0.09 \pm 0.18$, family/social 0.21 \pm 0.15 , psychological $0.26 \pm 0.17$, alcohol $0.30 \pm 0.19$, cocaine $0.58 \pm 0.24$, other drugs $0.06 \pm 0.06$;

- race: white $40 \%$, African-American $56 \%$, Hispanic $0 \%$, other $4 \%$;

- married/cohabiting $42 \%$;

- unemployed $76 \%$;

- education: less than high school $40 \%$;

- primary route of administration: nasal $20 \%$, smoking $72 \%$, intravenous $8 \%$;

- previous treatment: alcohol $36 \%$, drugs $72 \%$.

(2) CBCST arm - baseline substance use:

- mean weekly cocaine use (mean \pm SD) $5.6 \pm 6.2$;

- days cocaine use/past 30 days; $15.6 \pm 6.5$;

- cocaine use $\mathrm{g} /$ week/past 30 days $5.0 \pm 5.1$;

- mean drinks per drinking day/past 30 days $10.6 \pm 8.0$;

- days of alcohol use/past 30 days $18.5 \pm 7.6$;

- years of cocaine use - lifetime $5.8 \pm 3.1$;

- years of alcohol misuse - lifetime $7.3 \pm 6.4$;

- lifetime psychiatric disorders: any affective disorder 33\%, any anxiety disorder 6\%, ASP 46\%, any nonASP 50\%;

- ASI composite scores: medical $0.19 \pm 0.29$, employment $0.67 \pm 0.32$, legal $0.09 \pm 0.17$, family/social 0.12 \pm 0.15 , psychological $0.16 \pm 0.19$, alcohol $0.40 \pm 0.20$, cocaine $0.58 \pm 0.18$, other drugs $0.07 \pm 0.05$;

- race: white $32 \%$, African-American $63 \%$, Hispanic $1 \%$, other $0 \%$;

- married/cohabiting 32\%;

- unemployed 53\%;

- education: less than high school 32\%;

- primary route of administration: nasal $11 \%$, smoking $84 \%$, intravenous $5 \%$;

- previous treatment: alcohol $32 \%$, drugs $58 \%$.

Interventions The trial included 5 treatment arms: CBCST plus disulphiram; TSF plus disulphiram; CM plus disulphiram; CBCST plus no medication; TSF plus no medication.

We considered the 2 non-medication psychotherapy arms only:

(1) CBCST was based on Marlatt 1996's relapse prevention model;

(2) TSF was adapted from that used in Project MATCH and was grounded in the concept of substance use disorder as a spiritual and medical disease.

Route of delivery: treatments were manual-guided; 4 doctoral-level psychologists conducted CBCST; 2 masters-level clinicians conducted TSF.

Number of participants allocated to each group: 25 in CBCST plus no medication; 19 in TSF plus no medication (data provided for 24 and 18 participants, respectively).

Duration of the intervention: 16 individual sessions, twice weekly over 12 weeks.

Duration of follow-up: 12 weekly assessments within-treatment, and at 1, 3, 6, 12 months.

Country of origin, setting: a non-profit substance use treatment centre - APT foundation (https://aptfoundation.org/) - affiliated with Yale University in New Haven, Connecticut, USA.

- Alcohol abstinence as maximum number of weeks of consecutive alcohol abstinence during treatment 
- Illicit drug abstinence as maximum number of weeks of consecutive abstinence from cocaine during treatment

- Alcohol abstinence as number achieving 3 or more weeks of consecutive alcohol abstinence during treatment

- Illicit drug abstinence as number achieving 3 or more weeks of consecutive abstinence from cocaine during treatment

- Alcohol abstinence during follow-up year

- Illicit drug abstinence as abstinence from cocaine during follow-up year

- Retention - end of treatment (unpublished)

Notes

All sessions were recorded and checked and rated for accuracy and fidelity of the intervention.

"Subjects also met weekly with an independent clinical evaluator who collected urine specimens, assessed cocaine and alcohol use and monitored other clinical symptoms."

"Patients were paid $\$ 25$ for each follow-up interview, with a $\$ 10$ increase for each consecutive interview they attended, to encourage more complete data collection. In addition, patients were paid a $\$ 5$ bonus for attending an interview within 28 days of the target interview date."

- Only 39 participants completed the full 12-week treatment (compliant treatment completers).

- Participants in the pharmacological arms stayed longer in treatment (participants were not blind to their intervention), although the difference between the two psychotherapy arms included in the present review was not significant (70\% versus $78 \%$ ), see Analysis 1.4 .

- The specific type of self-report questionnaires was not reported in the primary paper (1998), only in the follow-up paper.

- Results are reported as number of weeks of continuous abstinence.

- The follow-up report (2000) does not provide any endpoint scores (only results of the random-effects regression model).

- Use of cocaine and alcohol was strongly associated with each other during treatment, particularly for the subjects assigned to disulphiram.

- The study was funded by National Institutes of Health; information on conflicts of interest was not provided.

\section{Risk of bias}

\begin{tabular}{lll}
\hline Bias & Authors' judgement & Support for judgement \\
\hline $\begin{array}{l}\text { Random sequence genera- } \\
\text { tion (selection bias) }\end{array}$ & Unclear risk & $\begin{array}{l}\text { Not enough information provided; e.g. "Of the 122 randomised subjects, } 117 \\
\text { initiated the treatment". }\end{array}$ \\
\hline
\end{tabular}

\begin{tabular}{lll}
\hline $\begin{array}{l}\text { Allocation concealment } \\
\text { (selection bias) }\end{array}$ & Unclear risk & Not stated. \\
\hline $\begin{array}{l}\text { Blinding of outcome as- } \\
\text { sessment (detection bias) } \\
\text { Subjective outcomes }\end{array}$ & Low risk & $\begin{array}{l}\text { Within-study assessments: } \\
\text { "independent clinical evaluator who collected urine specimens, assessed co- } \\
\text { caine and alcohol use; the evaluator saw patients in an office physically sepa- } \\
\text { rated from the therapy offices and instructed patients not to disclose detail of } \\
\text { their therapist or treatment". } \\
\text { Follow-up assessments (2000 paper): } \\
\text { "Patients were assessed at face-to-face follow-up interviews conducted } 1,3,6 \\
\text { and } 12 \text { months after the } 12 \text {-week termination point by an independent clinical } \\
\text { evaluator who was blind to both psychotherapy and pharmacotherapy condi- } \\
\text { tion". }\end{array}$ \\
\hline
\end{tabular}

$\begin{array}{ll}\begin{array}{l}\text { Incomplete outcome data } \\ \text { (attrition bias) }\end{array} & \text { High risk } \\ \begin{array}{ll}\text { End of Study outcomes } & \text { Within-treatment assessments (1998): } \\ & \text { "Assignment to disulphiram was associated with significantly better retention } \\ & \text { in treatment". }\end{array}\end{array}$


Carroll 1998 (Continued)

Incomplete outcome data High risk (attrition bias)

Follow up
The psychotherapy groups had significantly lower retention rates than the medication groups:

"subjects assigned to disulphiram treatment were retained significantly longer than those assigned to no medication (8.4 versus 5.8 weeks. $F=8.7, p<$ 0.05)".

Retention rates:

- CBT/disulphiram group (mean 8.8 weeks);

- CM/disulphiram (8.4 weeks);

- TSF/disulphiram (8.0);

- $\mathrm{CBT} /$ no medication (6.3);

- TSF/no medication (5.3).

"However, such analyses, ..., are confounded by differences among the treatments in retention".

Only 30\% completed treatment, however:

"Subjects who remained in treatment the full 12 weeks/16 sessions $(n=39)$ did not differ from those who did not start treatment or dropped out $(n=83)$ in terms of gender, race, employment status, route of administration, presence of lifetime affective, anxiety or antisocial personality disorder, but those who met criteria for a nonASP Axis II disorder, were significantly more likely to complete treatment than these who did not (48.1\% versus $23.1 \%) "$.

Comments:

1) baseline characteristics provided for the ITT sample $(n=122)$; but

2) rates of consecutive abstinence provided for the exposed sample $(n=117)$;

3) it is not known whether missing outcome data were balanced in numbers across intervention groups, because group breakdowns for drop-outs are not provided;

4) psychotherapy groups (CBT, TSF) differed significantly at baseline: for frequency of alcohol use; and medication groups had lower baseline cocaine use.

All groups had a comparable number of follow-up data points. However, number of drop-outs was not reported for each group separately.

"It is possible that poorer-functioning subjects who dropped out of treatment early were under-represented in the follow-up data, inflating outcomes in all groups".

"Participants who completed more sessions had better outcomes during follow-up".

- Subjects with higher age of onset of drug use had more follow-up data

- Subjects with non-ASP Axis II disorders had more follow-up data

- No significant differences between those followed up and those not followed up

Percentage of treatment days abstinent from cocaine, percentage of treatment days abstinent from alcohol, percentage of cocaine-negative urine screens, medication compliance during treatment.

Number of dropouts and reasons:

Number randomised: 122 (25 TSF, 19 CBT)

Number initiated: 117 (23 TSF, 18 CBT) - no other reason provided

Number removed from the trial: 8 ( 1 did not comply with medication, 1 medication side effects. 4 clinical deterioration, 2 administrative discharge) 
Carroll 1998 (Continued)

Number drop-outs: 70 (no group breakdowns - no other reasons)

Number completed treatment: 39

Number followed up at least once: 96 , i.e.:

- 1 month: 68;

- 3 months: 67 ;

- 6 months: 63 ;

- 12 months: 72 .

Selective reporting (re- Low risk

porting bias)

Darker 2016

Methods Study design: cluster-RCT ("Pilot cluster randomized controlled trial feasibility study")

Recruitment modality of participants: four addiction clinics in Dublin, Ireland

Participants

Number of participants: 465

- Of the total 465 trial participants, we included a subgroup of 50 participants for whom alcohol was the target substance (i.e. those who received a BI for alcohol in the intervention group), or who were eligible to receive an intervention for alcohol based on their ASSIST score in the control group (but received TAU).

- After accounting for the cluster-RCT design effect, the effective size of the included sample was $n=31$.

Gender: $64.5 \%$ male (300/465)

Mean age: 37 years

Condition: participants with opioid use disorder receiving methadone who also had concurrent problem alcohol use, as determined by positive ASSIST-alcohol score.

Other relevant information: no significant differences between intervention and control group for: gender, age, age leaving school, age at first drug use, length of current treatment, global risk score at baseline.

Interventions

(1) Brief Intervention (BI) $n=13$

(2) Treatment as usual (TAU) $n=18$

Clinical staff were trained in the use of the Alcohol, Smoking and Substance Involvement Screening Test (ASSIST) questionnaire.

Clinical staff in the intervention sites were also trained in the delivery of brief interventions (BIs) using the modified BI manual.

All patients received an ASSIST screening, and patients in the intervention clinics who were identified as moderate or high risk for a particular substance received a BI by staff immediately after screening.

High-risk patients were also referred for further follow-up and counselling with the in-house counselling team $(n=196)$.

Patients in the control clinics received treatment as usual (TAU) $(n=269)$.

Outcomes

- The primary outcome measure was the change in ASSIST score from baseline to 3-month follow-up.

- Substance use global risk score (except smoking)

- Retention - at three months 
Darker 2016 (Continued)

- The secondary outcome was feasibility of administering a BI within daily practice, as assessed by intervention fidelity checks, patient satisfaction questionnaires and process evaluation clinician focus groups.

- For the purposes of this review, the study authors provided unpublished data for ASSIST-alcohol at baseline and 3 months.

- The data used in this review include only those participants for whom alcohol was the target substance, i.e. those who received an intervention for alcohol in the intervention group, or whom were eligible to receive an intervention for alcohol based on their ASSIST score in the control group (but received treatment as usual).

\section{Notes}

- Patients with high-risk ASSIST scores also received a referral to further follow-up and counselling with the in-house counselling team.

- Further clinician training in administering the ASSIST questionnaire and BI was delivered "where necessary" with top-up sessions, but it is not clear which treatment group was affected. Furthermore, ongoing fidelity of BI treatment was assessed over the course of the study, and feedback was provided to the clinicians.

- Unpublished quote: "In our study we screened participants for a range of substances (e.g. alcohol, cannabis, cocaine, opioids) and only intervened on the substance that received the highest score based on the ASSIST. We screened for tobacco use but due to the population it was decided not to intervene for tobacco. If tobacco was the target substance clinicians were instructed in administer the intervention for the second highest scoring substance."

- Unpublished quote: "Our study was not powered to detect changes in individual substances. Our reported results are based on participants global risk scores. However, we can see from the means depicted in the table above that there appears to be a trend for a greater reduction in alcohol ASSIST scores in the intervention groups as opposed to the control group. There is a reduction in the control group that was determined to be as a result of the Hawthorn effect."

- Selection of clinics is not explicitly described but is assumed to be based on convenience.

- The study was funded by Health Research Board Ireland; no conflicts of interest were reported.

\section{Risk of bias}

\begin{tabular}{|c|c|c|}
\hline Bias & Authors' judgement & Support for judgement \\
\hline $\begin{array}{l}\text { Random sequence genera- } \\
\text { tion (selection bias) }\end{array}$ & Unclear risk & $\begin{array}{l}\text { Personal communication: "randomization was conducted by a third party bio- } \\
\text { statistician." }\end{array}$ \\
\hline $\begin{array}{l}\text { Allocation concealment } \\
\text { (selection bias) }\end{array}$ & Unclear risk & Not reported. \\
\hline $\begin{array}{l}\text { Blinding of outcome as- } \\
\text { sessment (detection bias) } \\
\text { Subjective outcomes }\end{array}$ & Unclear risk & $\begin{array}{l}\text { Blindness of participants and personnel not possible for the kind of interven- } \\
\text { tion. Blindness of outcome assessor not specified. }\end{array}$ \\
\hline $\begin{array}{l}\text { Incomplete outcome data } \\
\text { (attrition bias) } \\
\text { End of Study outcomes }\end{array}$ & Low risk & $\begin{array}{l}\text { Information on dropout from the study provided; missing outcome data were } \\
\text { balanced in numbers across intervention groups, with similar reasons for miss- } \\
\text { ing data across groups. }\end{array}$ \\
\hline $\begin{array}{l}\text { Incomplete outcome data } \\
\text { (attrition bias) } \\
\text { Follow up }\end{array}$ & Low risk & $\begin{array}{l}\text { Missing data have been imputed using appropriate methods. } \\
\text { Comment: although the primary outcome measure was a change in ASSIST } \\
\text { score, the paper doesn't present this in any graph, but instead mentions the } \\
\text { difference in ASSIST scores at } 3 \mathrm{~m} \text { in a single paragraph (p.1109 - did the in- } \\
\text { tervention work?). It's not clear whether this is the total score or the change } \\
\text { in score. Also, the published graphs focus on key predictors of higher ASSIST } \\
\text { scores, which was not part of the projected outcome measure. } \\
\text { - At } 3 \text { months, in the ASSIST-alcohol positive subgroup, } 13 \text { participants (100\%) } \\
\text { were retained in the intervention arm, and } 18 \text { participants (100\%) in the con- } \\
\text { trol arm (unpublished data); }\end{array}$ \\
\hline
\end{tabular}



control (published data)

Selective reporting (re- Low risk
porting bias)

porting bias)

Feldman 2013

Methods Study design: RCT.

Recruitment modality of participants: for 1 year, participation in the study was proposed systematically to each adult outpatient who was treated for opioid or cocaine use disorder.

\begin{abstract}
Participants
Number of participants: 110

Gender: $72.3 \%$ male

Mean age (mean $\pm S D): 35 \pm 7.8$ years

Condition: problem alcohol use based on questions from the AUDIT questionnaire, i.e. excessive drinking ( $7 \leq$ AUDIT score $<13$ for men and $6 \leq$ AUDIT score $<13$ for women); and alcohol use disorder (score $>13)$.

43.8\% were classified as having excessive drinking and $56.2 \%$ as having alcohol use disorder.

\section{Other relevant information}

Opioid use disorder treatment with methadone (56.2\%) or diacetyl morphine (12\%);

No opioid agonist and treatment for opioid or cocaine use disorder (31.7\%).

Most participants with opioid or cocaine use disorder also had tobacco or cannabis use disorder.

Most participants had 1 or more concomitant psychiatric disorders (mood disorder, 35.6\%; personality disorder, 34\%; anxiety disorders, $14.7 \%$; psychotic disorders, $9.4 \%$ ).

"Diagnoses were established according to the criteria of the ICD-10 by a resident and a senior psychiatrist".
\end{abstract}

Interventions

(1) $\mathrm{BI}(\mathrm{n}=60)$

BI was delivered in 1 session, based on WHO guidelines, delivered by trained staff ( 4 hours' training). The intervention group received the same TAU as controls. The outpatient staff consisted of a psychiatrist, general practitioner, psychologist, nurse, and social worker.

(2) TAU $(n=52)$

"The control group received TAU in addition to AUDIT and score feedback. TAU refers to outpatient pharmacological and psychosocial treatment. Maintenance treatment with methadone or heroin included medical and psychiatric follow-up, primary health care, psychosocial interventions, and administration of opiate treatments in a clinical setting. Psychosocial treatment included medical and psychiatric follow-up, primary health care, psychosocial interventions, and, if necessary, administration of pharmacotherapy in a clinical setting."

Duration of the intervention: (mean $\pm S D$ ): $16 \pm 4.7$ minutes

Duration of follow-up: 3 and 9 months

Country of origin, setting: specialised outpatient clinic in the Division of Substance Abuse of the University Hospitals of Geneva, Switzerland. 
- Alcohol use as AUDIT scores at 9 months

- Alcohol use as number of drinks per week at 3 months (number of glasses of alcohol per week, 1 glass: $10 \mathrm{~g}$ of alcohol; wine $=100 \mathrm{~mL}$; beer $=250 \mathrm{~mL}$; spirits $=25 \mathrm{~mL}$ )

- Alcohol use as number of drinks per week at 9 months

- Alcohol use as decreased alcohol use at 3 months

- Alcohol use as decreased alcohol use at 9 months

- Increased or unchanged alcohol use at 3 and 9 months (i.e. reverse of the above)

- Retention - at 3 months

Notes

The participants in both groups were already in treatment for opioid or cocaine dependence before study inclusion. Participants allocated to BI received this intervention 2 or 3 weeks after AUDIT screening.

The WHO Manual recommends the referral of individuals with alcohol dependence to specialist treatment without providing $\mathrm{BI}$.

All screened participants received feedback that explained the meaning of their AUDIT score.

The study funding source was not reported; no conflicts of interest were reported.

\section{Risk of bias}

\begin{tabular}{lll}
\hline Bias & Authors' judgement & Support for judgement \\
\hline $\begin{array}{l}\text { Random sequence genera- } \\
\text { tion (selection bias) }\end{array}$ & Low risk & $\begin{array}{l}\text { Quote: "The randomisation scheme was drawn by a statistician, who used the } \\
\text { Web site [http://www.randomizer.org/]. A random permuted block method } \\
\text { was used, with blocks of 4 patients". }\end{array}$ \\
\hline $\begin{array}{l}\text { Allocation concealment } \\
\text { (selection bias) }\end{array}$ & Low risk & $\begin{array}{l}\text { Quote: "The sequence was concealed from all investigators with numbered } \\
\text { opaque sealed envelopes prepared by the statistician and handed over to the } \\
\text { physician in charge of the study". }\end{array}$ \\
\hline
\end{tabular}

\begin{tabular}{lll}
\hline Blinding of outcome as- & High risk & Not stated. \\
$\begin{array}{l}\text { sessment (detection bias) } \\
\text { Subjective outcomes }\end{array}$ & Unpublished information: "There is no blinding assessment".
\end{tabular}

Incomplete outcome data Unclear risk Not available. The study did not assess outcomes at the time of the study end.
(attrition bias)
End of Study outcomes

\section{Incomplete outcome data Low risk} (attrition bias)

Follow up

\author{
Modified ITT analysis (multiple imputation, random assumption). \\ At T0 - 1 person not included in analysis because of data-entry errors, both in \\ both control and intervention group.
}

Number of dropouts and reasons:

"Of the BI group, 59.3\% completed the last observation and of the control group, $58.8 \%$ completed it"

- Intervention $(\mathrm{T0}=51, \mathrm{~T} 3=29, \mathrm{~T} 9=30)$

- Control $(\mathrm{TO}=59, \mathrm{~T} 3=30, \mathrm{~T} 9=35)$

No reasons provided for dropouts, but regression showed no differences: "logistic regressions showed that the - Type of drinker - and - Treatment group did not explain the missingness of data".

"Hence, these variables displayed no particular pattern, meaning that the data for excessive drinkers and for alcohol-dependent patients, as well as for the control group and the intervention group, were equally likely to be missing". 
Comment: dichotomous outcomes: $40 \%$ of participants dropped out, but the proportion of missing outcomes compared with the observed event risk (for all outcomes except retention in treatment or drop out), which was 10\%-20\% (control), and 60\%-80\% (intervention), was not enough to have a clinically relevant impact on the intervention effect estimate.

Selective reporting (re- Low risk porting bias)

Henihan 2016

Methods Study design: cluster-RCT.

Recruitment modality of participants: 16 general practitioners selected by random stratified sampling (by location and level of methadone provision training), each recruited 10 consecutive patients receiving addiction care, including methadone.

Participants

Number of participants: 81 participants were included in the trial (34 in the intervention group, 47 in the control group). Only participants with positive AUDIT at baseline $(n=30)$ were included in this systematic review.

Gender: $61.7 \%$ male

Mean age (mean $\pm S D): 42 \pm 8.5$ years

Condition: participants were $>18$ years old, receiving primary care addiction treatment including methadone (80/81 patients). For the purpose of this review, only patients who were AUDIT-positive at baseline were included. The threshold for positive scores was 8 or more points.

\section{Other relevant information}

Participants were excluded if they were age $<18$ years, acutely intoxicated, cognitively impaired including severe mental illness, or had language difficulties.

Interventions $\quad(1) \mathrm{BI}(\mathrm{n}=13)$ :

Physicians randomised to the intervention group screened participants using the AUDIT-C and provided a brief intervention to patients who were positive for 'hazardous' or 'harmful' alcohol use.

Delivery of the intervention was confirmed by interviews with physicians, patients, and chart reviews.

Cointeventions: GPs received a complex intervention to promote screening and brief intervention which included practice visits, best practice guidelines and education, multimedia educational tools, MI-related training presentations, and demonstration of interventions.

(2) TAU $(n=17)$ :

Physicians randomised to the control group were given training at the end of the trial ( 3 months).

Duration of follow-up: 3 months

Country of origin, setting: 16 general practices in Ireland (Health Service Executive Mid-West and Dublin Mid-Leinster regions)

Outcomes

- Alcohol use as AUDIT scores at 3 months

- Retention at 3 months

- Feasibility of the study was assessed by physician and patient retention.

- Acceptability of the intervention was assessed by a physician Short Alcohol and Alcohol Problems Perception Questionnaire, as well as by qualitative interviews of both physicians and patients. 
Henihan 2016 (Continued)

- Efficacy among patients was assessed by an AUDIT-C and AUDIT assessment at baseline and 3 months, as well as rates of patients self-reporting screening, brief interventions and referral to treatment at 3 months after intervention.

Notes

The BI was part of a complex implementation strategy to increase the uptake of BIs by general practitioners. Actual delivery of the intervention by GPs and fidelity of the intervention were not tested.

The study was funded by Health Research Board Ireland; no conflicts of interest were reported.

The trial analysis calculated an intra cluster correlation coefficient (ICC) for care process and outcome measures. The ICC for the proportion of patients with positive AUDIT-C (follow up) results was 0.11

(standard error $[\mathrm{SE}]=0.013$ ). The ICCS for screening, $\mathrm{BI}$ and referral to treatment were $0.016(\mathrm{SE} 0.014)$, -0.06 (SE 0.017), and 0.22 (SE 0.026), respectively.

\section{Risk of bias}

\begin{tabular}{|c|c|c|}
\hline Bias & Authors' judgement & Support for judgement \\
\hline $\begin{array}{l}\text { Random sequence genera- } \\
\text { tion (selection bias) }\end{array}$ & Unclear risk & Personal communication: "external statistician”. \\
\hline $\begin{array}{l}\text { Allocation concealment } \\
\text { (selection bias) }\end{array}$ & Low risk & $\begin{array}{l}\text { "External statistician emailed anonymous sequence of numbers to researcher } \\
\text { who matched them with the unique study identifiers of participants." }\end{array}$ \\
\hline $\begin{array}{l}\text { Blinding of outcome as- } \\
\text { sessment (detection bias) } \\
\text { Subjective outcomes }\end{array}$ & High risk & $\begin{array}{l}\text { Blinding of participants and personnel not possible for the kind of interven- } \\
\text { tion. } \\
\text { "Outcome assessors not blinded." }\end{array}$ \\
\hline $\begin{array}{l}\text { Incomplete outcome data } \\
\text { (attrition bias) } \\
\text { End of Study outcomes }\end{array}$ & Low risk & $\begin{array}{l}\text { "Baseline: } 1 \text { GP dropped out." } \\
\text { Random allocation: "dropouts: two intervention GP practices and } 11 \text { patients } \\
\text { from these practices." }\end{array}$ \\
\hline $\begin{array}{l}\text { Incomplete outcome data } \\
\text { (attrition bias) } \\
\text { Follow up }\end{array}$ & Low risk & $\begin{array}{l}\text { Follow up: "14 patient dropouts (intervention }(n=7) \text { and Control }(n=7) \text { )" } \\
\text { information on drop out from the study provided; Missing outcome data bal- } \\
\text { anced in numbers across intervention groups, with no reasons for missing da- } \\
\text { ta provided; }\end{array}$ \\
\hline
\end{tabular}

Selective reporting (re- Low risk porting bias)

\section{Korcha 2014}

Methods Study design: RCT - open label

Recruitment modality of participants: an outpatient substance use treatment facility in Northern California and by local advertisements.

\section{Participants}

Number of participants: 163 participants with methamphetamine (MA) use disorder were randomly assigned to Intensive MI or a Standard MI intervention with an attention control activity to achieve time equivalence for the Intensive $\mathrm{MI}$ intervention.

Gender: 53.3\% female

Mean age: 37.8 years 
Condition: diagnosis of both methamphetamine use disorder and 1+ criterion of alcohol abuse/dependence (DSM-IV criteria) within previous 12 months.

\section{Other relevant information}

- Among this sample of participants with MA use disorder, a majority $(75 \%)$ also reported some level of problems with alcohol.

- The included paper examined outcomes for alcohol problem severity among men and women in both study conditions.

- Caucassian: $68.5 \%$ (experimental), $66.3 \%$ (control).

\begin{tabular}{|c|c|}
\hline Interventions & $\begin{array}{l}\text { (1) Intensive motivational interviewing }(\mathrm{n}=80) \text { : } \\
\text { - an intensive 9-session version of motivational interviewing (MII) was compared to a standard, single } \\
\text { MI session. } \\
\text { - } 9 \times 50 \text { mins, group } 3 \times \text { week } \\
\text { - } 3 / 9 \text { of presentation slides taken from NIDA CTN manuals; } \\
\text { (2) Standard motivational interviewing + nutrition education }(n=83) \text { : } \\
\text { - attention control active } \\
\text { - } 1 \times 90 \text { min of standard MI }+8 \text { nutrition classes } \times 60 \text { mins each. }\end{array}$ \\
\hline
\end{tabular}

Outcomes

- Alcohol use at 2-, 4- and 6-month follow-up as measured by Addiction Severity Index- Lite (ASI).

- Methamphetamine use (PDA \% days abstinent, TLFB).

- The number of days of non-use between study entry and the 6-month follow-up interview were summed and divided by the total number of days to obtain a percentage of days of abstinent (PDA).

- Therapeutic alliance as measured by Helping alliance questionnaire.

- Retention - end of treatment (unpublished)

Notes

Both groups received outpatient CBT on craving 3x/week for up to 12 weeks (Galloway 2000; Stalcup 2006; Galloway 2007).

Participants also received weekly research interviews, Helping Alliance Questionnaires (HAQ) and Timeline Follow-Back (TLFB) assessments of CM use - all assessment/interventions that could potentially influence outcomes.

We are unsure whether alcohol was covered in the nutrition class (control intervention).

Retention in control arm (comprised of a single MI session + 8 nutrition classes):

- none (zero) completed all 9 control arm sessions;

- 8 controls completed 8 control arm sessions.

While participants with "serious" psychiatric diagnoses were excluded from the study, those with "psychiatric conditions that could be managed on an outpatient basis" were referred to mental health services while they were in the study.

Nine (5.5\%) participants were legally mandated to treatment.

The study was funded by National Institutes of Health; information on conflicts of interest was not provided.

\section{Risk of bias}

\begin{tabular}{lll}
\hline Bias & Authors' judgement & Support for judgement \\
\hline $\begin{array}{l}\text { Random sequence genera- } \\
\text { tion (selection bias) }\end{array}$ & Low risk & $\begin{array}{l}\text { Quote: "Participants were assigned to a condition using stratified permuted } \\
\text { blocks to ensure that gender and MA severity were balanced in both condi- } \\
\text { tions." }\end{array}$
\end{tabular}


Korcha 2014 (Continued)

Personal communication: participants were assigned to a study condition based on stratified randomisation procedures that ensured gender and MA severity were approximately equal in both conditions (four strata). MA severity was determined by past 30 day use at the baseline interview, per timeline follow-back, operationalised as 10 or more days of use of methamphetamine vs. less than 10 days of use.

\begin{tabular}{|c|c|c|}
\hline $\begin{array}{l}\text { Allocation concealment } \\
\text { (selection bias) }\end{array}$ & Low risk & $\begin{array}{l}\text { Personal communication: opaque randomisation envelopes were prepared } \\
\text { in advance and not opened until immediately prior to the initial individual MI } \\
\text { therapy session. }\end{array}$ \\
\hline
\end{tabular}

Blinding of outcome as- High risk Personal communication: no blinding.

sessment (detection bias)

Subjective outcomes

\begin{tabular}{lll}
\hline $\begin{array}{l}\text { Incomplete outcome data } \\
\text { (attrition bias) } \\
\text { End of Study outcomes }\end{array}$ & Low risk & $\begin{array}{l}\text { Quote: "Follow-up rates were excellent, with over 90\% completing interviews } \\
\text { at each follow-up time point." }\end{array}$ \\
\hline $\begin{array}{l}\text { Incomplete outcome data } \\
\text { (attrition bias) }\end{array}$ & Low risk & $\begin{array}{l}\text { Personal communication: "longitudinal analysis using maximum likelihood } \\
\text { methods allowed for inclusion of all study participants, regardless of whether } \\
\text { they were interviewed at each time point or not. Additionally, over } 90 \% \text { com- } \\
\text { pleted 2- and 6-month interviews with over } 87 \% \text { completing all interviews." }\end{array}$ \\
\hline
\end{tabular}

Selective reporting (re- Low risk
porting bias)

Nyamathi 2010

Methods Study design: RCT open label, 3 arms.

Recruitment modality of participants: flyers displayed in 5 methadone treatment sites.

\section{Participants}

\section{Number of participants: 256}

Gender: $59.2 \%$ male

Mean age $($ mean $\pm S D): 51.2 \pm 8.4$ years

Condition: reported moderate-to-heavy alcohol use based on questions from the ASI. Methadone maintenance treatment was an inclusion criterion (minimum 3 months).

\section{Other relevant information:}

- Fair/poor health: $60.4 \%$

- Depressive symptoms: $80.8 \%$

- Poor emotional well-being: $67.5 \%$

- Ethnicity: African-American: 45.1\%; white: 18.8, Latino: 26.7, Other: 9.4. Education: high school graduate $58 \%$

- Partnered: $54.3 \%$

- Employed: $17.3 \%$

- Recent alcohol use at baseline (mean number standard drinks last 30 days): 0-40: 25.1; 41-89: 24.7; 90-180: $26.7 ; 180+: 23.5$

- Marijuana use in past 30 days: $16 \%$

- IDU in past 30 days: $40 \%$

- Smoke > 1 pack/day: $56.1 \%$

- Self-help programme in past 30 days: $21.2 \%$ 
Nyamathi 2010 (Continued)

- Social support: a) primarily from drug users $12.6 \%$; b) primarily non-drug users $48.6 \%$, c) both: $34.9 \%$

Interventions

(1) HHP: didactic style, also interactive as the group raised questions. Delivered by a nurse and hepatitis-trained research assistant. Sessions based on "The comprehensive health seeking and coping paradigm (CHSCP; Nyamathi 1989), originally adapted from Lazarus and Folkman's (1984) stress and coping paradigm and Schlotfeldt's (1981) health seeking paradigm." Staff trained on the integration of the CHSCP into their education delivery.

Focus: progression of HCV infection and the culturally sensitive strategies that infected individuals can adopt to prevent or reduce accumulated damage to liver functioning. Strategies included: discussing the dangers of alcohol use on hepatitis (cognitive factors), discussing ways to avoid alcohol and other drugs, eating a balanced diet, dangers of reinfection of HCV by IDU, receiving unsafe tattoos and piercing, having unprotected sexual behaviour, and being consistent in engaging in other health-related behaviours. Additional health promoting activities: enhancing coping, such as seeking positive social support, getting support from religion and building self-esteem in individuals with a history of drug and alcohol addiction. The HHP was directed by a detailed protocol $(n=87)$.

(2) MI-group: focus: alcohol, risky behaviours, MI spirit; by trained MI specialists, i.e. a PhD-prepared psychologist conducted primarily the Ml-group sessions. Content of the individual and group sessions was identical, guided by a detailed protocol and biweekly meetings with the investigator and therapists. The average number of participants was 6 (range 5 to 7$)(n=79)$.

(3) MI-single: focus: alcohol, risky behaviours, MI spirit; a MSW-prepared researcher conducted primarily the individual MI sessions $(\mathrm{n}=90)$.

Duration of the interventions: $3 \times 60$-minute sessions, spaced 2 weeks apart.

Duration of follow-up: 6 months.

Country of origin, setting: 5 methadone treatment sites in Los Angeles and Santa Monica, USA.

$\begin{array}{ll}\text { Outcomes } & \text { Alcohol use (unpublished) as number of standard drinks consumed per day over the last } 30 \text { days } \\ \text { - Illicit drug use (unpublished) as frequency of drug use (as measured by ASI drug) } \\ \text { - Illicit drug use (unpublished) as a composite drug score (frequency }{ }^{\star} \text { severity for all drugs taken) } \\ \text { - Alcohol use as }>50 \% \text { reduction in number of standard drinks consumed per day over the last } 30 \text { days } \\ \text { - Alcohol abstinence as abstinence from alcohol over the last } 30 \text { days } \\ \text { - Retention - end of treatment }\end{array}$

Notes 6 participants reported no alcohol use at baseline.

A total of $86.7 \%$ of participants completed all 3 sessions and $91.3 \%$ completed the 6 -month follow up.

The sessions were open; i.e. participants who had not completed their 3 sessions with their original cohort could complete with a later cohort.

The original protocol describes HHP as a control intervention (UCG).

Means (SD) of outcomes measures (ASI, TLFB) are not provided for any of the outcomes; baseline scores are also not provided.

The study was funded by National Institutes of Health; no conflicts of interest were reported.

\section{Risk of bias}

\begin{tabular}{lll}
\hline Bias & Authors' judgement & Support for judgement \\
\hline $\begin{array}{l}\text { Random sequence genera- } \\
\text { tion (selection bias) }\end{array}$ & Low risk & $\begin{array}{l}\text { Quote: "This study was a randomised controlled trial" } \\
\text { Unpublished information: "As participants were enrolled, they were systemat- } \\
\text { ically assigned to each of the three arms. In terms of randomisation, we used } \\
\text { random assignment using a random number table". }\end{array}$ \\
\hline
\end{tabular}


Nyamathi 2010 (Continued)

Allocation concealment Unclear risk Information not reported.
(selection bias)

$\begin{array}{lll}\text { Blinding of outcome as- } & \text { High risk } & \text { Masking: open label. } \\ \text { sessment (detection bias) } & & \text { Source of information: published protocol of the trial. }\end{array}$

Subjective outcomes

Incomplete outcome data Unclear risk Not available. The study did not assess outcomes at the time of the study end.
(attrition bias)
End of Study outcomes

\begin{tabular}{|c|c|c|}
\hline $\begin{array}{l}\text { Incomplete outcome data } \\
\text { (attrition bias) } \\
\text { Follow up }\end{array}$ & Low risk & $\begin{array}{l}\text { Comment: } \\
\text { All analyses were ITT; however, it is not stated which method of data imputa- } \\
\text { tion was used for ITT analysis. } \\
\text { Missing data balanced across groups. } \\
\text { Comparability of all } 3 \text { arms assessed at baseline. }\end{array}$ \\
\hline
\end{tabular}

Number of dropouts and reasons:

- MI-S (90), 86\% completed all sessions, $9 \%$ lost to follow up;

- MI-G (79), $85 \%$ completed all sessions, $10 \%$ lost to follow up;

- HHP (87), 89\% completed all sessions, $7 \%$ lost to follow up.

Unpublished information: "The 6 reported abstainers were distributed as follows: 2 in MI-Single, 3 in MI-Group and 1 in HHP.

No one was excluded from the final regression model based on ethnicity. The statement was erroneously carried over from preliminary modelling. However, since ethnicity was not important in that modelling, it was not included in the final model and there was no need to exclude anyone based on ethnicity. The 6 abstainers were excluded from the logistic regression analysis. "A missing value for drug-using partners caused an additional case to be omitted (actually there were 248 cases in the regression model rather than 249 . Two subjects had missing values for drug-using partners)".

Selective reporting (re- Low risk
porting bias)

porting bias)

Stein 2002

Methods Study design: RCT.

Recruitment modality of participants: study was advertised at 3 NEP sites using posters. NEP volunteers offered all clients referral cards. NEP clients called a study telephone to be screened by a research assistant at a separate research site in hospital. During the initial study visit, all NEP clients presented their study cards (received at NEP). Conducted between February 1998 - October 1999.

Participants Number of participants: 187

Gender: 119 male (63.6\%)

Mean age: 36.2 years

Condition: problem alcohol use, i.e. AUDIT-positive (> 8) active IDUs. "Current alcohol abuse or dependence diagnosis was ascertained using the SCID interview. 159 (85.0\%) met DSM-IV criteria for current alcohol abuse $(80 \%)$ or dependence (70\%)". Participants were eligible if they were not receiving formal drug or alcohol treatment, with the exception of self-help groups.

\section{Other relevant information}

Psychosocial interventions to reduce alcohol consumption in concurrent problem alcohol and illicit drug users (Review) 
Stein 2002 (Continued)

Baseline sample characteristics:

- mean number of years of education: 11.5 years;

- ethnicity: 162 (86.6\%) Caucasian;

- most frequently injected drug: heroin for 141 (75.4\%) participants, cocaine for 15 (8.0\%), heroin and cocaine for $31(16.6 \%)$;

- 120 (64.1\%) participants visited the NEP at least once a month;

- mean AUDIT score at screening was 22.2;

- 159 (85.0\%) met DSM-IV criteria for current alcohol abuse or dependence (80\% for abuse, $70 \%$ for dependence);

- mean \pm SD number of drinking days in the past 30 days prior to baseline assessment: $12.0 \pm 10.3$;

- $71.4 \%$ of quantities on all drinking days exceeded conventional criteria defining heavy alcohol consumption (5+ drinks for men and $3+$ drinks for women);

- mean \pm SD drinks per drinking days $7.3 \pm 5.8$.

Interventions

(1) MI group: focus on alcohol use and HIV risk-taking $(\mathrm{n}=95)$

Goals: to assess the degree to which the participant engages in hazardous drinking; to identify relationships between alcohol consumption and alcohol-related negative consequences including HIV risk behaviour; to identify goals for behaviour change and any barriers to change.

- Included a written change plan, designed to reduce the link between alcohol consumption and hazardous behaviours that may lead to negative consequences of drinking, including HIV risk behaviour

- Interventionist trained by studying the manual and watching MI tapes from Project MATCH

- Standard delivery of the MI protocol

- Adherence monitoring by: an MI checklist completed by the therapist after each session and audiotapes of sessions were randomly reviewed by a supervisor trained in MI

(2) Control group: assessment-only, approximately 3 hours $(n=92)$

Duration of the intervention: 2 therapist sessions, 1 month apart; 1st session: 60 minutes, 2 nd session: 30 to 45 minutes.

Duration of follow-up: 1 and 6 months

Country of origin, setting: NEP clients, study site: Rhode Island Hospital in Providence, USA.

Outcomes

- Alcohol use as number of days in the past 30 days with alcohol use at 1 month

- Alcohol use as number of days in the past 30 days with alcohol use at 6 months

- Alcohol use as $25 \%$ reduction of drinking days in the past 30 days

- Alcohol use as $50 \%$ reduction of drinking days in the past 30 days

- Alcohol use as $75 \%$ reduction of drinking days in the past 30 days

- Alcohol use as 1 or more drinking days' reduction in the past 30 days

- Alcohol use as 7 or more drinking days' reduction in the past 30 days

- Number of days in the past 30 days with IRRB - defined as answer to a question: "Have you used needles etc. after someone else?" (reported only for a subset of 109 participants in the Stein 2002b paper).

- Retention - end of treatment

Notes

Control and MI subjects received identical research assessments at baseline, 1 and 6 months:

- at baseline and 1 month later, both MI and control group received a list of referrals for substance abuse and medical treatment;

- participants in the control group spent approximately 3 total hours (assessment time) with research staff, "the assessment included sections on demographics, drug and alcohol use, drug and alcohol treatment, health-related quality of life, attitudes and experiences with alcohol and HIV risk behavior";

- the assessment control group also experienced meaningful reduction in alcohol use;

- 6-month follow up: 11 subjects were interviewed in prison and 6 were interviewed by telephone; 
Stein 2002 (Continued)

- total reimbursement: $\$ 90$ with $\$ 20$ given at baseline, $\$ 30$ at the 1 -month interview and $\$ 40$ at the final interview;

- $65(34.8 \%)$ participants reported 4 or fewer drinking days at baseline: their maximum possible decrease in drinking days at follow-up is 4 or less (i.e. floor and ceiling effects);

- change in heroin use was not associated with change in alcohol use;

- the association between change in IRRB days and change in alcohol use days was not statistically significant.

- The paper reporting IRRB outcomes (Stein 2002b) was included in another Cochrane Review (Meader 2010); therefore, it was not considered for this review.

- The study was funded by National Institutes of Health; information on conflicts of interest was not provided.

\section{Risk of bias}

\begin{tabular}{lll}
\hline Bias & Authors' judgement & Support for judgement \\
\hline $\begin{array}{l}\text { Random sequence genera- } \\
\text { tion (selection bias) }\end{array}$ & Unclear risk & $\begin{array}{l}\text { Not enough information provided: "Following the baseline interview subjects } \\
\text { were assigned to treatment conditions using a randomisation schedule creat- } \\
\text { ed with permuted blocks of eight assignments." "After randomisation, the re- } \\
\text { search interventionist saw participants assigned to MI...". }\end{array}$
\end{tabular}

Allocation concealment Unclear risk

(selection bias)

Not stated how the randomisation schedule was prepared: "This method ensured that the treatment groups were balanced in number to within four patients throughout the trial. The data manager prepared the randomisation schedule before the first patient enrolled".

\begin{tabular}{|c|c|c|}
\hline $\begin{array}{l}\text { Blinding of outcome as- } \\
\text { sessment (detection bias) } \\
\text { Subjective outcomes }\end{array}$ & Low risk & $\begin{array}{l}\text { "At each follow-up assessment, research assistants were blinded to the treat- } \\
\text { ment condition of the subject; the interventionist did not perform research as- } \\
\text { sessments". }\end{array}$ \\
\hline
\end{tabular}

Incomplete outcome data Unclear risk

(attrition bias)

Not available. The study did not assess outcomes at the time of the study end.

End of Study outcomes

Incomplete outcome data Low risk

(attrition bias)

Follow up

\begin{abstract}
"We conducted an intent-to-treat analysis using a conservative 'worst case scenario' strategy in which observations with missing follow-up data were assigned the maximum value of 30 drinking days, a data imputation approach which tends to minimize observed reductions in mean drinking days across time.

To ensure that our substantive results were not sensitive to missing observations (there were no condition differences in missing data) we replicated our analyses using observations with complete data $(n=181)$, and using other imputation strategies (e.g. mean substitution, regression estimation and 'best case scenario'). All imputation strategies resulted in substantively consistent findings.

To evaluate the adequacy of random assignment, we used t- and $\times 2$-tests to compare treatment groups with respect to background characteristics and baseline measures of drinking behaviours and alcohol problems".

Number of dropouts and reasons:

There were no study withdrawals: 93 of 95 in the MI group received both MI sessions: 2 people missed their second session. 6-month follow-up data were available for $96.8 \%(n=181)$ of the 187 randomly assigned subjects. 3 subjects in each treatment arm were lost to follow-up at 6 months.
\end{abstract}

Selective reporting (reporting bias)
Low risk

Psychosocial interventions to reduce alcohol consumption in concurrent problem alcohol and illicit drug users (Review) Copyright $\odot 2018$ The Cochrane Collaboration. Published by John Wiley \& Sons, Ltd. 
ASI: Addiction Severity Index; ASSIST: Alcohol, Smoking and Substance Involvement Screening Test; ASP: antisocial personality disorder; BAL: blood alcohol level; BI: brief intervention; CBCST: cognitive-behavioural coping skills training; CBT: cognitive behavioural therapy; CM: clinical management; DSM-III-R: Diagnostic and Statistical Manual of Mental Disorders, Third Edition - Revised; DSM-IV: Diagnostic and Statistical Manual of Mental Disorders, Fourth Edition; HCV: hepatitis C virus; HIV: human immunodeficiency virus; HHP: hepatitis health promotion; ICD-10: International Classification of Diseases - Tenth Revision; IDU: injection drug use; ITT: intention to treat; IRRB: injectionrelated HIV risk behaviour; MI: motivational intervention; MSW: master in social work; NEP: needle exchange programme; PhD: doctor of philosophy; PWID: people who use illicit drugs; RCT: randomised controlled trial; SD: standard deviation; TAU: treatment as usual; TLFB: timeline follow-back; TSF: twelve-step facilitation programme; UCG: usual care group; WHO: World Health Organization.

\section{Characteristics of excluded studies [ordered by study ID]}

\begin{tabular}{ll}
\hline Study & Reason for exclusion \\
\hline Aldridge 2017 & $\begin{array}{l}\text { Participants did not meet our inclusion criteria: concurrent problem alcohol use was not an inclu- } \\
\text { sion criterion. Excluded in } 2017 .\end{array}$
\end{tabular}

Aldridge 2017b

Participants did not meet our inclusion criteria: concurrent problem alcohol use was not an inclusion criterion. Excluded in 2017.

\begin{tabular}{ll}
\hline Bennett 2002 & Study design did not meet our inclusion criteria: not an RCT. \\
\hline Bernstein 2005 & $\begin{array}{l}\text { Outcome did not meet our inclusion criteria: alcohol use was not measured, because the interven- } \\
\text { tion focused on drug use and the participants were not reported to have problem alcohol use at } \\
\text { randomisation. }\end{array}$ \\
\hline
\end{tabular}

Bowen 2006 Study design did not meet our inclusion criteria: not an RCT. sion criterion. Excluded in 2017.

Cohen 1982

Participants did not meet our inclusion criteria: concurrent problem alcohol use not an inclusion criterion for all subjects randomised into trial. Quote: "Approximately one-third of all the active alcoholics [ $n=105$ ] were assigned to each of the three study groups (1983, p864; 1982, p360)." Comment: it is highly probable that non-alcoholics were randomised into trial. Operative alcoholics $(\mathrm{N}=$ $105)$ versus all subjects randomised into trial $(\mathrm{N}=127)$.

\section{Darker 2016a}

Drumright 2011

Karno 2017

Kennedy 2016

Moyers 2016

O'Farrell 2008
Study design did not meet our inclusion criteria: concurrent problem alcohol use was not an inclusion criterion. Excluded in 2017.

Study design did not meet our inclusion criteria: not an RCT. A secondary analysis of 2 RCTs that did not have concurrent problem alcohol use not an inclusion criterion

Participants did not meet our inclusion criteria: concurrent problem alcohol use was not an inclusion criterion. Excluded in 2017.

Participants did not meet our inclusion criteria: concurrent problem alcohol use was not an inclusion criterion. Excluded in 2017.

Participants did not meet our inclusion criteria: concurrent problem alcohol use was not an inclusion criterion. Excluded in 2017.

Participants did not meet our inclusion criteria: participants were eligible if they had alcohol dependence diagnosis with or without comorbid drug diagnosis.

Worden 2010
Participants did not meet our inclusion criteria: concurrent problem alcohol use was not an inclusion criterion. Additionally, $46.6 \%$ reported alcohol as their primary drug (review exclusion criterion). 
$\mathrm{RCT}$ : randomised controlled trial.

Characteristics of studies awaiting assessment [ordered by study ID]

Aharonovich 2017

Methods Participants were HIV+ binge drinking, non-injection drug users recruited in New York City via newspaper ads $(\mathrm{N}=47)$.

They were randomised to brief MI-only $(n=21)$ or BMI + HealthCall $(n=21)$.

Participants Mean age was $50.8(\mathrm{SD}=7.13), 71 \%$ were male, $76 \%$ African-American, $7 \%$ employed, primary drug crack (92.8\%).

At baseline, mean days of drug use in past 30 days was $14.05(S D=6.1)$, mean drinking days 13.95 $(\mathrm{SD}=6.7)$.

Interventions

(1) Authors adapted their technology-based intervention, called "HealthCall", to enhance and extend brief motivational interviewing (BMI) to target concurrent drug and alcohol use in HIV+ individuals.

(2) HealthCall involves 60 days of daily self-monitoring of alcohol and drug use and related behaviours via smartphone app with video, positive reinforcements and personalized feedback.

Outcomes Of the 42 individuals who initiated treatment, all (100\%) completed the study.

The majority of participants were highly engaged in HealthCall; those randomised to it used it a mean of $89.6 \%$ of all possible days.

At end of treatment (60 days), participants assigned toMI + HealthCall had fewer days of primary drug use than the BMI-only group $(4.95[S D=4.7]$ days vs. $8.3[S D=6.1])$ days, respectively $(P=$ 0.06).

Those in BMI + HealthCall also had fewer drinking days (mean 7.04 days; $\mathrm{SD}=7.6$ ) vs. the BMI-only group (8.14 days; SD 5.7) $(P=0.09)$.

"A larger randomized trial is warranted to replicate and extend the present results in a larger sample." (P.256A)

Columbia University Medical Center, Psychiatry Department, New York, NY, 10032, USA ment score (for alcohol, scores ranged from 11 to 15 and 16 to 20; and for the other substances from 4 to 12 and 13 to 20 ).

\section{Participants}

A total of 19 primary care centres $(n=520)$, eight emergency rooms $(n=195)$ and five police stations $(n=91)$ were evaluated. A total of 12217 people aged between 19 and 55 years were screened for moderate alcohol and drug use risk as defined by the ASSIST Chilean version.

A total of 806 non-treatment-seekers were randomised.

Interventions ASSIST-linked BI $(n=400)$ compared with an informational pamphlet on risk associated with substance use $(n=406)$. 
Poblete 2017 (Continued)

Outcomes

Notes
Total ASSIST alcohol (Al) and illicit involvement score (ASSIST-AI), and ASSIST-specific score for alcohol, cannabis and cocaine at baseline and at 3-month follow-up.

We asked the authors about the data for a subsample of primary-care patients who had ASSIST-cocaine positive. The analysis showed no difference between the two groups for the ASSIST- for specific scores alcohol $(\mathrm{MD}=0.18, \mathrm{Cl}=-1.45,1.10)$, or cocaine $(\mathrm{MD}=-0.79, \mathrm{Cl}=-2.89,4.47)$.

$62 \%$ of participants completed 3-month follow-up (38\% study attrition).

\section{Staiger 2011}

Methods

Randomised controlled trial of a brief alcohol intervention programme for adults in residential drug treatment

Participants

$\mathrm{N}=166$ adults, meeting DSM-IV diagnostic criteria for substance dependence in the past 12 months, recruited from 2 Therapeutic Communities (TC) in Victoria; average length of residential stay was 8.7 months (21-974 days)

Most were single, male Australians with some high school education.

- From the table 4 (p28), it would occur that alcohol was the primary problem drug for 22 participants (10 and 12).

- Also, $89 \%$ of the control group, and $90.5 \%$ of the experimental group, reported using alcohol in the 3 months prior to intake (p29).

- Also, 45 had severe alcohol dependency (21 and 24) (p31), as per SADQ (score > 30 indicates severe alcohol dependence).

Interventions

Alcohol intervention group (AIG experimental) vs. Basic education group (EDU control)

1) AIG experimental: Mindfulness-based Relapse Prevention

- Responsible Drinking Program, based on the Alcohol Skills Training Program (ASTP, developed for US college students by Marlatt et al.)

- Designed to progressively build upon a participants' knowledge and skills. Group sessions aimed to equip them to: 1 ) use mindfulness strategies to manage emotional states, to 2) understand motives and expectations about alcohol, to 3) ensure adequate knowledge of the effects of alcohol and to 4) manage personal and social situations in relation to alcohol use;

- Basic principles of Dialectical Behaviour Therapy (Marsha Linehan)

- Mindfulness skills training, comprised a key part of the final 3 sessions of the program;

- A manual guided group facilitators. Facilitators received weekly supervision to monitor and guide their AIG group work. Goups were routinely digitally recorded to ensure fidelity of program content.

- Participants had a workbook to act as a resource and reminder of program content. A mindfulness exercise CD was created which was included in the workbook provided to the AIG group.

- 5 group sessions (weekly; 3-6 weeks after start of residential treatment);

- plus 2 check in calls, (2 weeks apart) after EXIT, reviewed drinking;

- plus 6 therapeutic letters, which were mailed to participants at six weekly intervals, whilst they remained in the residential treatment program, and aimed to minimise the reduction of treatment effect over time, reminding clients of the activities, skills and personal goals.

2) EDU control: basic education

- Semi-structured

- Standard drink

- Effects of alcohol on person

- Low risk drink guidelines 
- Basic alcohol education (which we manualised in order to standardise that component).

- Conducted over 2 group sessions (1 week apart) and was similar in content to a drink driving alcohol education.

- All TC residents were invited to attend the Alcohol Intervention Study as management of the TC did not want those with an alcohol primary problem to be treated differently within a TC setting.

- We designed the interventions to take into account different drinking goals (i.e. abstinence and moderate drinking); however, the primary focus of the program was on those with a dependent drug problem.

- AUDIT
- SADQ/SADQ-C (p.31 of the final project report)
- TLFB- 90 days recall
- SDS (p.32 of the final project report)
- ASI- alcohol (5th edition)
- Social functioning: Index of OTI
- Mental health defined as: number of days with significant psychological problem in past month
(ASI - single item)
- Average standard drinks consumed per drinking day in the 90 days prior to each assessment point
(Table 8 , of the final project report).
- Ave of drinking days in the 90 days prior to each assessment point (Table 9).
Include if authors provide unpublished data for the subsample of AUDIT-positive participants. Final
study report gives results for all participants together, including people with and without alcohol
problems.
Alcohol was used only by 149 of the 166 participants in the 90 days prior to initial presentation. The
full, unpublished report (2010) of this study (Staiger 2009) was considered during the 2017 update
of this review and the study is among studies awaiting classification.

Thapaliya 2017

\begin{tabular}{ll}
\hline Methods & Randomised trial \\
\hline Participants & 43 patients receiving Buprenorphine-Naloxone agonist treatment. \\
& Inclusion criteria: \\
& - ASSIST-alcohol score $>11 ;$ \\
- & male patients, $18-60$ years; \\
- file diagnosis: Opioid Dependence Syndrome; & receiving buprenorphine treatment for at least 3 months; \\
& - receiving buprenorphine from NDDTC pharmacy; \\
& Exclusion criterion: \\
- file diagnosis of comorbidity (other substance abuse or dependence, or psychiatric co-morbidity & on Axis 1, except alcohol and tobacco). \\
Sample characteristics & - $100 \%$ males \\
- Mean age: 41.5 years \\
- Married: $78 \%$ \\
- Urban Residence: $68 \%$
\end{tabular}


Thapaliya 2017 (Continued)

- Employed: $87.5 \%$

- Weekly dispensing of Buprenorphine: $90 \%$

- Mean duration of maintenance treatment: 56 months ( $~ 5$ years)

- Mean dose of Buprenorphine: $\mathbf{1 1 . 5}$ mg/day

Setting: National Drug Dependence Treatment Centre (NDDTC), All-India Institute of Medical Sciences (AlIMS), New Delhi, India

Interventions

(1) ASSIST brief intervention $(n=22)$

(2) Simple advice ( $n=21$, wait list control)
- ASSIST scores (the BI group had mean reduction in ASSIST score $7.7[ \pm 3.67]$ at 3 months)

- bio-markers of change in alcohol use (AST, ALT, GGT, MCV, CDT)

All those who received $\mathrm{SA}$ also received $\mathrm{BI}$ at follow up.

Conference abstract only (Thapaliya 2017); full report not published yet.

Other related abstracts presented at the Lisbon addictions 2017 conference:

- Screening for continued substance use among subjects on buprenorphine maintenance treatment: a cross-sectional study. Suresh Thapaliya, Nepal (poster)

- Screening for moderate/high risk alcohol use among opioid dependent patients on buprenorphine maintenance: a clinical and alcohol-biomarker study. Suresh Thapaliya, Nepal (oral presentation)

HIV+: Human Imunodeficiency Virus positive; MI-only: Motivational Intereviewing-only; BMI: Brief Motivational Interviewing; SD: Standard Deviation; ASSIST: Alcohol, Smoking and Substance Involvement Screening Test; BI: Brief Intervention; MD: Mean Difference; Alcohol intervention group (AIG experimental) vs. Basic education group (EDU control); Alcohol Skills Training Program (ASTP,; OTI: __; SADQ: Substance Abuse Dependence Questionnaire; SDS: Severity of Dependence Scale; ASI: Addiction Severity Index; AUDIT: Alcohol Use Disorders Identification Test; CD: Compact Disc; TLFB: Time Line Follow Back; TC: Therapeutic Communities; DSM-IV: Diagnostic and Statistical Manual Fourth version; SA: Simple Advice; AST: Aspartate Aminotransferase; ALT: Alanine Aminotransferase; GGT: gammaglutamyl transferase; MCV: Mean Corpuscular Volume; CDT: Carbohydrate-deficient transferrin; NDDTC: National Drug Dependence Treatment Centre; AlIMS: All-India Institute of Medical Sciences.

\section{DATA AND ANALYSES}

\section{Comparison 1. Cognitive-behavioural coping skills training (CBCST) versus twelve-step facilitation (TSF) programme}

\begin{tabular}{|c|c|c|c|c|}
\hline Outcome or subgroup title & No. of studies & $\begin{array}{l}\text { No. of partici- } \\
\text { pants }\end{array}$ & Statistical method & Effect size \\
\hline $\begin{array}{l}1 \text { Alcohol abstinence as number achieving } 3 \\
\text { or more weeks of consecutive alcohol absti- } \\
\text { nence during treatment }\end{array}$ & 1 & & $\begin{array}{l}\text { Risk Ratio (M-H, Fixed, } \\
95 \% \mathrm{Cl})\end{array}$ & Subtotals only \\
\hline $\begin{array}{l}2 \text { Alcohol abstinence as maximum number of } \\
\text { weeks of consecutive alcohol abstinence dur- } \\
\text { ing treatment }\end{array}$ & 1 & & $\begin{array}{l}\text { Mean Difference (IV, } \\
\text { Fixed, } 95 \% \mathrm{CI} \text { ) }\end{array}$ & Subtotals only \\
\hline 3 Alcohol abstinence during follow-up year & 1 & & $\begin{array}{l}\text { Risk Ratio (M-H, Fixed, } \\
95 \% \mathrm{Cl})\end{array}$ & Subtotals only \\
\hline
\end{tabular}

Psychosocial interventions to reduce alcohol consumption in concurrent problem alcohol and illicit drug users (Review) 


\begin{tabular}{|c|c|c|c|c|}
\hline Outcome or subgroup title & No. of studies & $\begin{array}{l}\text { No. of partici- } \\
\text { pants }\end{array}$ & Statistical method & Effect size \\
\hline 4 Retention - end of treatment (unpublished) & 1 & & $\begin{array}{l}\text { Risk Ratio (M-H, Fixed, } \\
95 \% \mathrm{Cl})\end{array}$ & Subtotals only \\
\hline $\begin{array}{l}5 \text { Illicit drug abstinence as maximum number } \\
\text { of weeks of consecutive abstinence from co- } \\
\text { caine during treatment }\end{array}$ & 1 & & $\begin{array}{l}\text { Mean Difference (IV, } \\
\text { Fixed, } 95 \% \mathrm{CI} \text { ) }\end{array}$ & Subtotals only \\
\hline $\begin{array}{l}6 \text { Illicit drug abstinence as number achieving } \\
3 \text { or more weeks of consecutive abstinence } \\
\text { from cocaine during treatment }\end{array}$ & 1 & & $\begin{array}{l}\text { Risk Ratio (M-H, Fixed, } \\
95 \% \mathrm{Cl})\end{array}$ & Subtotals only \\
\hline $\begin{array}{l}7 \text { Illicit drug abstinence as abstinence from } \\
\text { cocaine during follow-up year }\end{array}$ & 1 & & $\begin{array}{l}\text { Risk Ratio (M-H, Fixed, } \\
95 \% \mathrm{Cl})\end{array}$ & Subtotals only \\
\hline
\end{tabular}

Analysis 1.1. Comparison 1 Cognitive-behavioural coping skills training (CBCST) versus twelve-step facilitation (TSF) programme, Outcome 1 Alcohol abstinence as number achieving 3 or more weeks of consecutive alcohol abstinence during treatment.

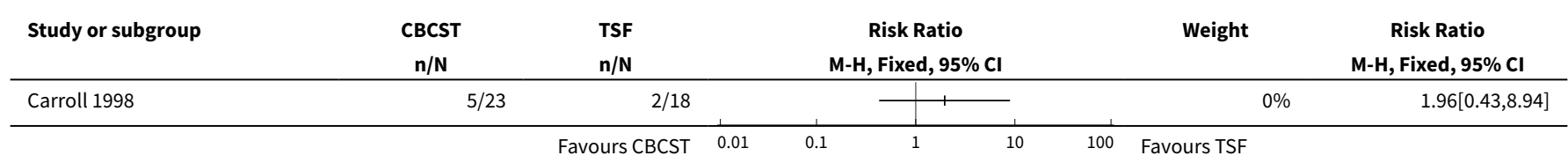

Analysis 1.2. Comparison 1 Cognitive-behavioural coping skills training (CBCST) versus twelve-step facilitation (TSF) programme, Outcome 2 Alcohol abstinence as maximum number of weeks of consecutive alcohol abstinence during treatment.

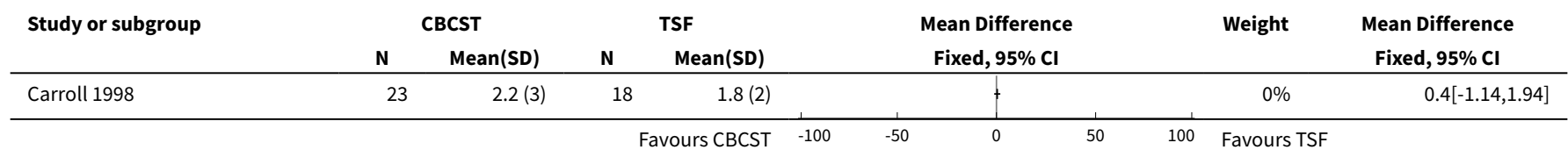

Analysis 1.3. Comparison 1 Cognitive-behavioural coping skills training (CBCST) versus twelvestep facilitation (TSF) programme, Outcome 3 Alcohol abstinence during follow-up year.

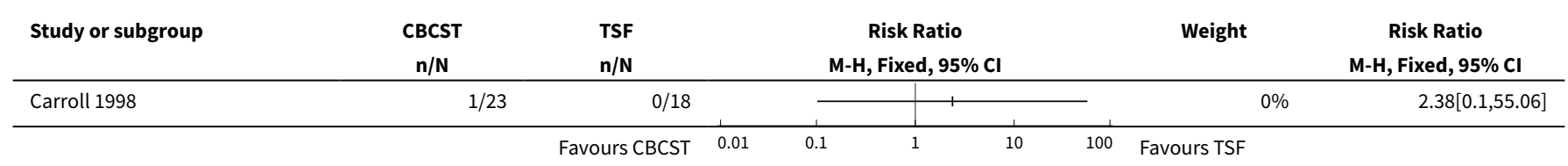


Analysis 1.4. Comparison 1 Cognitive-behavioural coping skills training (CBCST) versus twelvestep facilitation (TSF) programme, Outcome 4 Retention - end of treatment (unpublished).

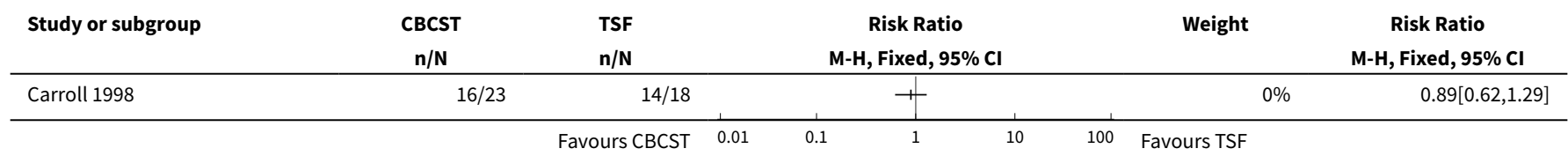

Analysis 1.5. Comparison 1 Cognitive-behavioural coping skills training (CBCST) versus twelve-step facilitation (TSF) programme, Outcome 5 Illicit drug abstinence as maximum number of weeks of consecutive abstinence from cocaine during treatment.

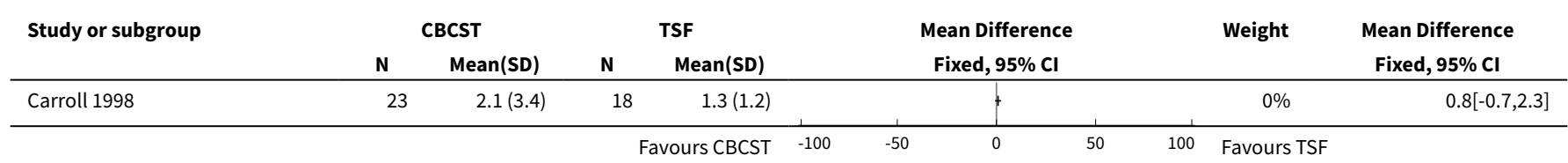

Analysis 1.6. Comparison 1 Cognitive-behavioural coping skills training (CBCST) versus twelve-step facilitation (TSF) programme, Outcome 6 Illicit drug abstinence as number achieving 3 or more weeks of consecutive abstinence from cocaine during treatment.

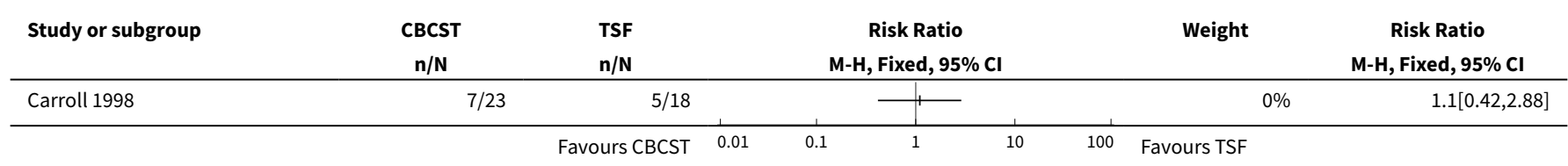

Analysis 1.7. Comparison 1 Cognitive-behavioural coping skills training (CBCST) versus twelve-step facilitation (TSF) programme, Outcome 7 Illicit drug abstinence as abstinence from cocaine during follow-up year.

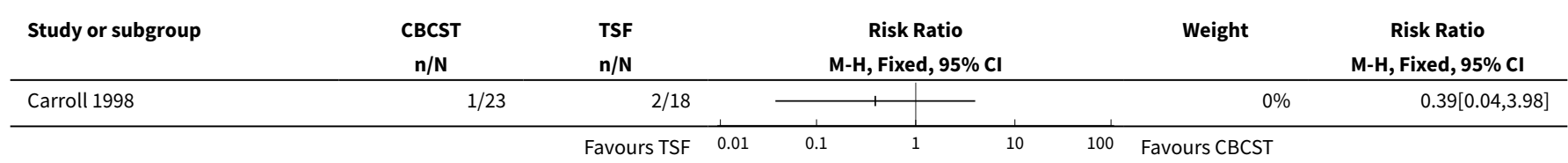

Comparison 2. Brief intervention (BI) versus treatment as usual (TAU)

\begin{tabular}{|c|c|c|c|c|}
\hline Outcome or subgroup title & No. of studies & $\begin{array}{l}\text { No. of partici- } \\
\text { pants }\end{array}$ & Statistical method & Effect size \\
\hline $\begin{array}{l}1 \text { Alcohol use as AUDIT or ASSIST scores } \\
\text { at } 3 \text { months }\end{array}$ & 3 & 170 & $\begin{array}{l}\text { Std. Mean Difference (IV, } \\
\text { Random, 95\% CI) }\end{array}$ & $0.07[-0.24,0.37]$ \\
\hline $\begin{array}{l}2 \text { Alcohol use as AUDIT scores at } 9 \\
\text { months }\end{array}$ & 1 & & $\begin{array}{l}\text { Mean Difference (IV, Fixed, } \\
95 \% \mathrm{CI})\end{array}$ & Subtotals only \\
\hline
\end{tabular}




\begin{tabular}{lllll}
\hline Outcome or subgroup title & No. of studies & $\begin{array}{l}\text { No. of partici- } \\
\text { pants }\end{array}$ & Statistical method & Effect size \\
\hline $\begin{array}{l}\text { 3 Alcohol use as decreased alcohol use } \\
\text { at 3 months }\end{array}$ & 1 & & $\begin{array}{l}\text { Risk Ratio (M-H, Fixed, 95\% } \\
\text { Cl) }\end{array}$ & Subtotals only \\
\hline $\begin{array}{l}4 \text { Alcohol use as number of drinks per } \\
\text { week at 3 months }\end{array}$ & 1 & Mean Difference (IV, Fixed, & Subtotals only \\
\hline $\begin{array}{l}5 \text { Alcohol use as number of drinks per } \\
\text { week at 9 months }\end{array}$ & 1 & Mean Difference (IV, Fixed, & Subtotals only \\
\hline $\begin{array}{l}6 \text { Alcohol use as decreased alcohol use } \\
\text { at } 9 \text { months }\end{array}$ & 1 & $95 \%$ Cl) & $\begin{array}{l}\text { Risk Ratio (M-H, Fixed, 95\% } \\
\text { Cl) }\end{array}$ & Subtotals only \\
\hline $\begin{array}{l}7 \text { Retention at } 3 \text { months (unpublished } \\
\text { and published data) }\end{array}$ & 3 & 190 & $\begin{array}{l}\text { Risk Ratio (M-H, Random, } \\
95 \% \text { Cl) }\end{array}$ & 0.94 [0.78, 1.13]
\end{tabular}

Analysis 2.1. Comparison 2 Brief intervention (BI) versus treatment as usual (TAU), Outcome 1 Alcohol use as AUDIT or ASSIST scores at 3 months.

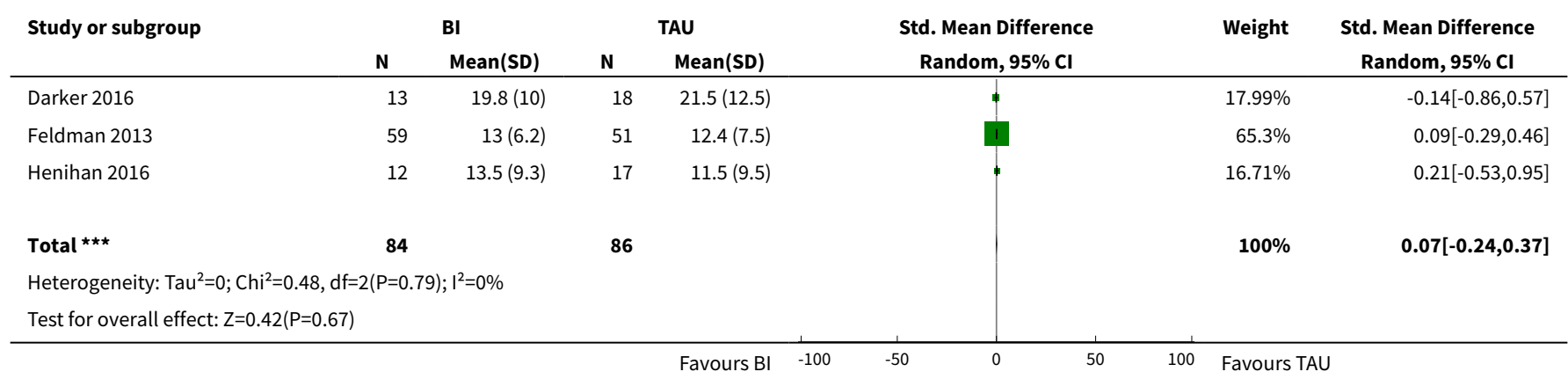

Analysis 2.2. Comparison 2 Brief intervention (BI) versus treatment as usual (TAU), Outcome 2 Alcohol use as AUDIT scores at 9 months.

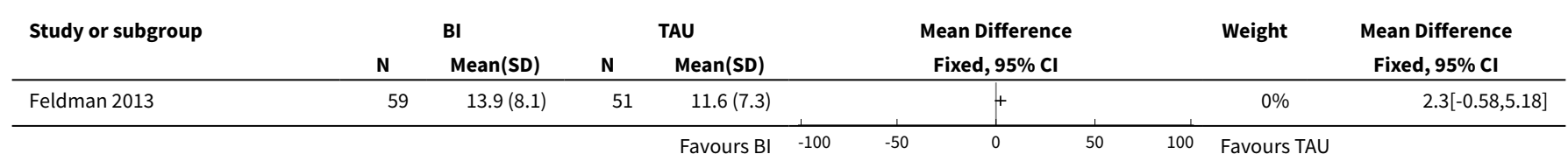

Analysis 2.3. Comparison 2 Brief intervention (BI) versus treatment as usual (TAU), Outcome 3 Alcohol use as decreased alcohol use at 3 months.

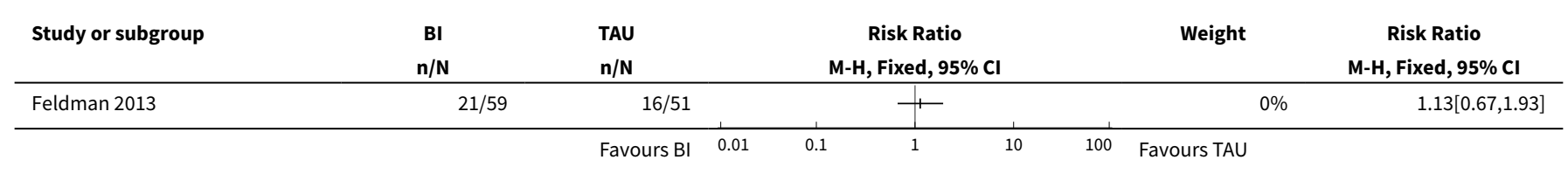


Analysis 2.4. Comparison 2 Brief intervention (BI) versus treatment as usual (TAU), Outcome 4 Alcohol use as number of drinks per week at 3 months.

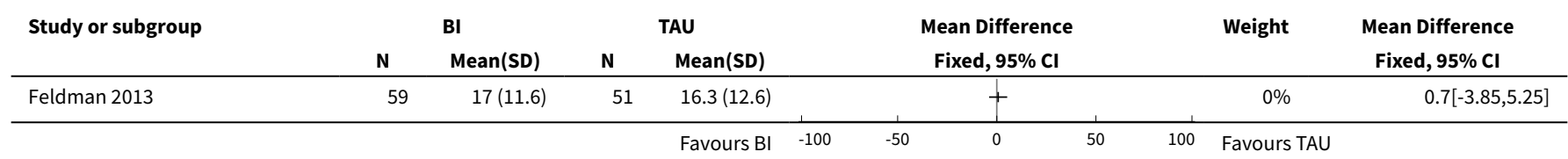

Analysis 2.5. Comparison 2 Brief intervention (BI) versus treatment as usual (TAU), Outcome 5 Alcohol use as number of drinks per week at 9 months.

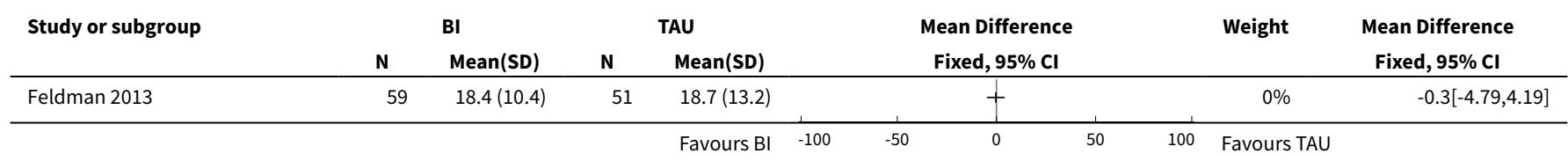

Analysis 2.6. Comparison 2 Brief intervention (BI) versus treatment as usual (TAU), Outcome 6 Alcohol use as decreased alcohol use at 9 months.

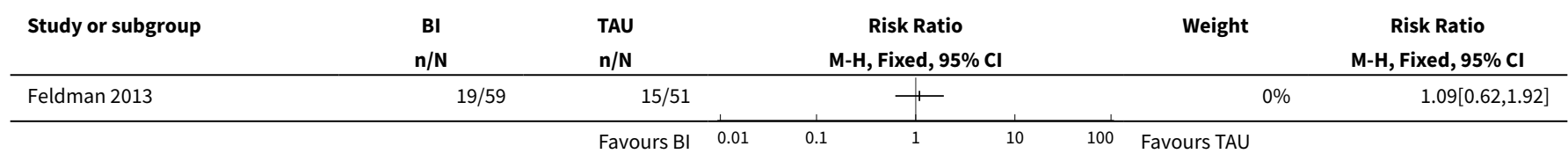

Analysis 2.7. Comparison 2 Brief intervention (BI) versus treatment as usual (TAU), Outcome 7 Retention at 3 months (unpublished and published data).

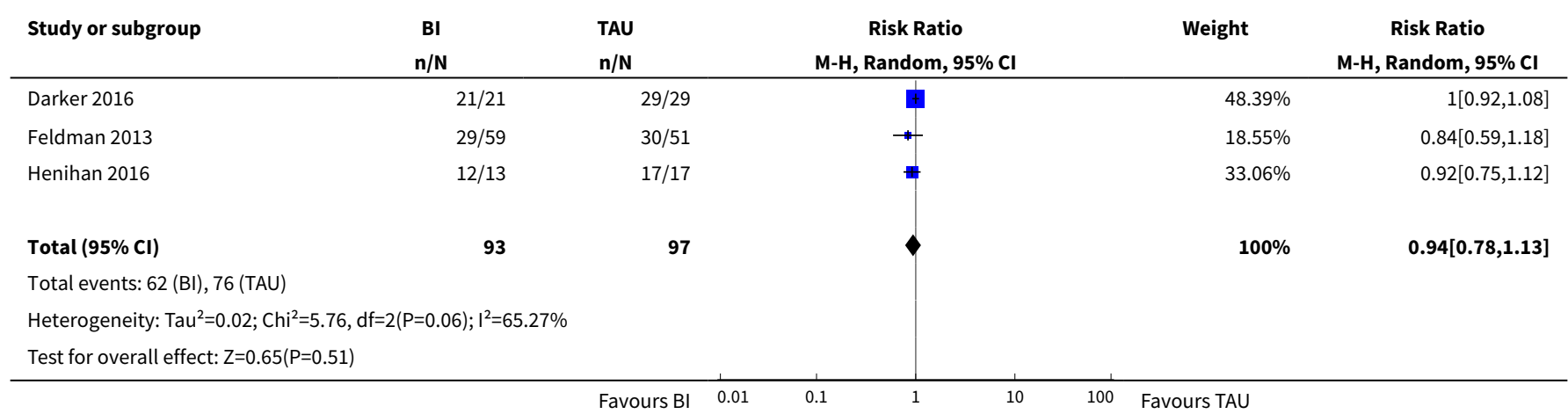


Comparison 3. Motivational interviewing (MI) versus treatment as usual (TAU) or educational intervention only

\begin{tabular}{|c|c|c|c|c|}
\hline Outcome or subgroup title & No. of studies & $\begin{array}{l}\text { No. of partici- } \\
\text { pants }\end{array}$ & Statistical method & Effect size \\
\hline $\begin{array}{l}1 \text { Alcohol use as AUDIT or ASSIST scores at } \\
3 \text { months }\end{array}$ & 2 & 141 & $\begin{array}{l}\text { Std. Mean Difference (IV, } \\
\text { Random, } 95 \% \mathrm{CI} \text { ) }\end{array}$ & $0.04[-0.29,0.37]$ \\
\hline 2 Alcohol use as AUDIT scores at 9 months & 1 & & $\begin{array}{l}\text { Mean Difference (IV, } \\
\text { Fixed, } 95 \% \mathrm{CI} \text { ) }\end{array}$ & Subtotals only \\
\hline $\begin{array}{l}3 \text { Alcohol use as number of standard drinks } \\
\text { consumed per day over the last } 30 \text { days }\end{array}$ & 1 & & $\begin{array}{l}\text { Mean Difference (IV, } \\
\text { Fixed, } 95 \% \mathrm{CI} \text { ) }\end{array}$ & Subtotals only \\
\hline $\begin{array}{l}4 \text { Alcohol use as number of drinks per week } \\
\text { at } 3 \text { months }\end{array}$ & 1 & & $\begin{array}{l}\text { Mean Difference (IV, } \\
\text { Fixed, } 95 \% \mathrm{CI} \text { ) }\end{array}$ & Subtotals only \\
\hline $\begin{array}{l}5 \text { Alcohol use as number of drinks per week } \\
\text { at } 9 \text { months }\end{array}$ & 1 & & $\begin{array}{l}\text { Mean Difference (IV, } \\
\text { Fixed, } 95 \% \mathrm{CI} \text { ) }\end{array}$ & Subtotals only \\
\hline $\begin{array}{l}6 \text { Alcohol use as greater than } 50 \% \text { reduc- } \\
\text { tion in number of standard drinks con- } \\
\text { sumed per day over the last } 30 \text { days }\end{array}$ & 1 & & $\begin{array}{l}\text { Risk Ratio (M-H, Fixed, } \\
95 \% \mathrm{Cl})\end{array}$ & Subtotals only \\
\hline $\begin{array}{l}7 \text { Alcohol abstinence as abstinence from } \\
\text { alcohol over the last } 30 \text { days }\end{array}$ & 1 & & $\begin{array}{l}\text { Risk Ratio }(\mathrm{M}-\mathrm{H}, \text { Fixed, } \\
95 \% \mathrm{Cl})\end{array}$ & Subtotals only \\
\hline $\begin{array}{l}8 \text { Alcohol use as decreased alcohol use at } 3 \\
\text { months }\end{array}$ & 1 & & $\begin{array}{l}\text { Risk Ratio }(\mathrm{M}-\mathrm{H}, \text { Fixed, } \\
95 \% \mathrm{Cl})\end{array}$ & Subtotals only \\
\hline $\begin{array}{l}9 \text { Alcohol use as decreased alcohol use at } 9 \\
\text { months }\end{array}$ & 1 & & $\begin{array}{l}\text { Risk Ratio (M-H, Fixed, } \\
95 \% \mathrm{Cl})\end{array}$ & Subtotals only \\
\hline 10 Retention - end of treatment & 1 & & $\begin{array}{l}\text { Risk Ratio }(\mathrm{M}-\mathrm{H}, \text { Fixed, } \\
95 \% \mathrm{Cl})\end{array}$ & Subtotals only \\
\hline $\begin{array}{l}11 \text { Retention at } 3 \text { months (unpublished } \\
\text { and published data) }\end{array}$ & 2 & 160 & $\begin{array}{l}\text { Risk Ratio (M-H, Random, } \\
95 \% \mathrm{Cl})\end{array}$ & $0.93[0.60,1.43]$ \\
\hline $\begin{array}{l}12 \text { Illicit drug use as frequency of drug use } \\
\text { (as measured by Addiction Severity Index - } \\
\text { ASI drug) }\end{array}$ & 1 & & $\begin{array}{l}\text { Mean Difference (IV, } \\
\text { Fixed, } 95 \% \mathrm{CI} \text { ) }\end{array}$ & Subtotals only \\
\hline $\begin{array}{l}13 \text { Illicit drug use as a composite drug } \\
\text { score (frequency* }{ }^{\star} \text { severity for all drugs tak- } \\
\text { en) }\end{array}$ & 1 & & $\begin{array}{l}\text { Mean Difference (IV, } \\
\text { Fixed, } 95 \% \mathrm{CI} \text { ) }\end{array}$ & Subtotals only \\
\hline
\end{tabular}

Analysis 3.1. Comparison 3 Motivational interviewing (MI) versus treatment as usual (TAU) or educational intervention only, Outcome 1 Alcohol use as AUDIT or ASSIST scores at 3 months.

\begin{tabular}{|c|c|c|c|c|c|c|c|c|}
\hline \multirow{2}{*}{ Study or subgroup } & \multicolumn{2}{|r|}{ MI } & \multicolumn{2}{|c|}{ TAU } & \multirow{2}{*}{\multicolumn{2}{|c|}{$\begin{array}{c}\text { Std. Mean Difference } \\
\text { Random, } 95 \% \mathrm{Cl} \\
\end{array}$}} & \multirow[t]{2}{*}{ Weight } & \multirow{2}{*}{$\begin{array}{l}\text { Std. Mean Difference } \\
\text { Random, } 95 \% \mathrm{CI}\end{array}$} \\
\hline & $\mathbf{N}$ & Mean(SD) & $\mathbf{N}$ & Mean(SD) & & & & \\
\hline Darker 2016 & 13 & $19.8(10)$ & 18 & $21.5(12.5)$ & & $\phi$ & $21.59 \%$ & $-0.14[-0.86,0.57]$ \\
\hline Feldman 2013 & 59 & $13(6.2)$ & 51 & $12.4(7.5)$ & & & $78.41 \%$ & $0.09[-0.29,0.46]$ \\
\hline
\end{tabular}




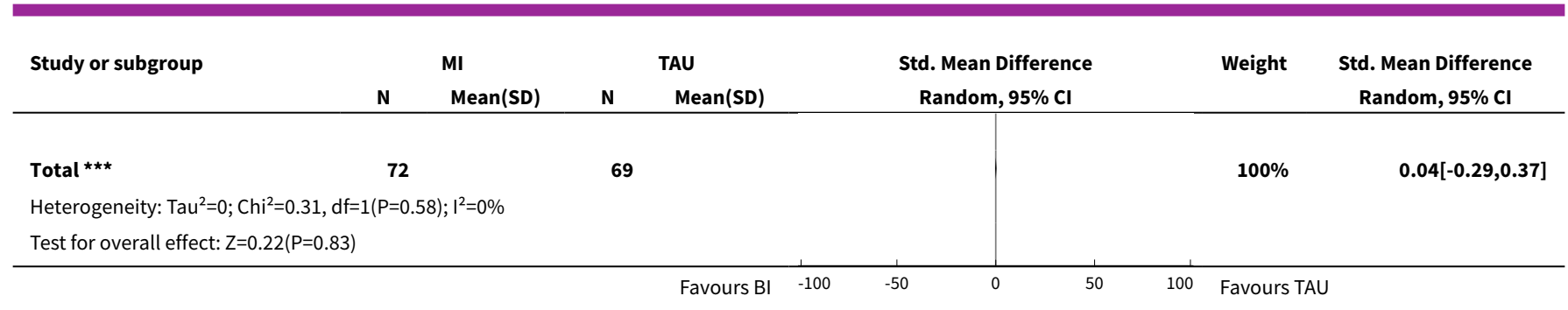

Analysis 3.2. Comparison 3 Motivational interviewing (MI) versus treatment as usual (TAU) or educational intervention only, Outcome 2 Alcohol use as AUDIT scores at 9 months.

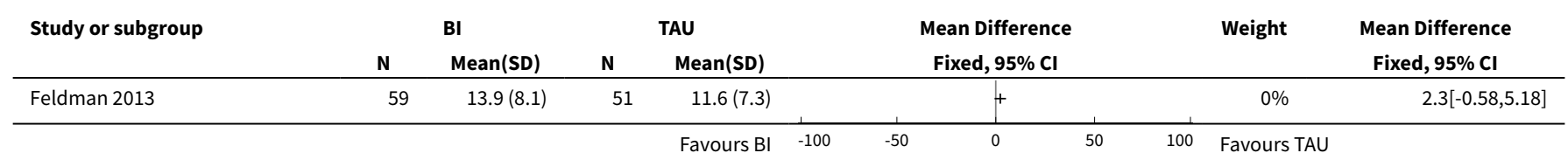

Analysis 3.3. Comparison 3 Motivational interviewing (MI) versus treatment as usual (TAU) or educational intervention only, Outcome 3 Alcohol use as number of standard drinks consumed per day over the last 30 days.

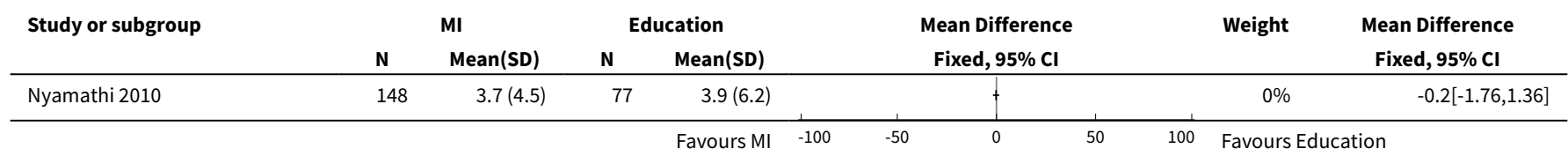

Analysis 3.4. Comparison 3 Motivational interviewing (MI) versus treatment as usual (TAU) or educational intervention only, Outcome 4 Alcohol use as number of drinks per week at 3 months.

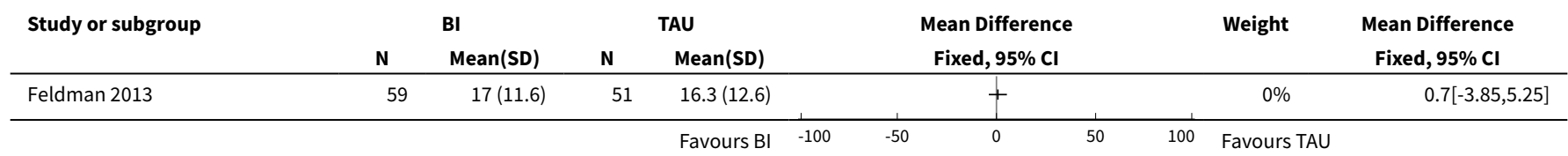

Analysis 3.5. Comparison 3 Motivational interviewing (MI) versus treatment as usual (TAU) or educational intervention only, Outcome 5 Alcohol use as number of drinks per week at 9 months.

\begin{tabular}{|c|c|c|c|c|c|c|c|c|c|c|}
\hline \multirow[t]{2}{*}{ Study or subgroup } & \multicolumn{2}{|r|}{ BI } & \multicolumn{2}{|c|}{ TAU } & \multirow{2}{*}{\multicolumn{3}{|c|}{$\begin{array}{c}\text { Mean Difference } \\
\text { Fixed, } 95 \% \mathrm{Cl}\end{array}$}} & & \multirow[t]{2}{*}{ Weight } & \multirow{2}{*}{$\begin{array}{c}\text { Mean Difference } \\
\text { Fixed, } 95 \% \mathrm{Cl}\end{array}$} \\
\hline & $\mathbf{N}$ & Mean(SD) & $\mathbf{N}$ & Mean(SD) & & & & & & \\
\hline Feldman 2013 & 59 & $18.4(10.4)$ & 51 & $18.7(13.2)$ & & & & & $0 \%$ & $-0.3[-4.79,4.19]$ \\
\hline
\end{tabular}


Analysis 3.6. Comparison 3 Motivational interviewing (MI) versus treatment as usual (TAU) or educational intervention only, Outcome 6 Alcohol use as greater than $50 \%$ reduction in number of standard drinks consumed per day over the last $\mathbf{3 0}$ days.

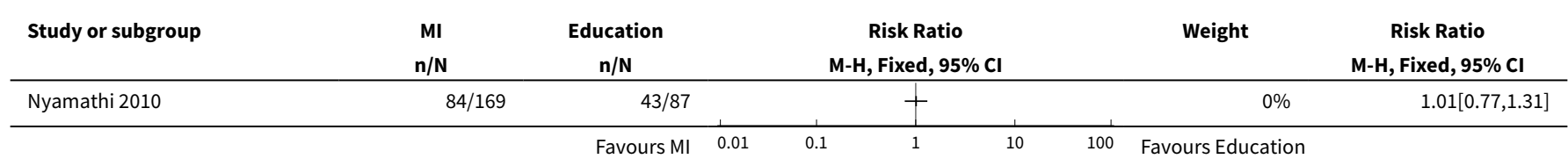

Analysis 3.7. Comparison 3 Motivational interviewing (MI) versus treatment as usual (TAU) or educational intervention only, Outcome $\mathbf{7}$ Alcohol abstinence as abstinence from alcohol over the last $\mathbf{3 0}$ days.

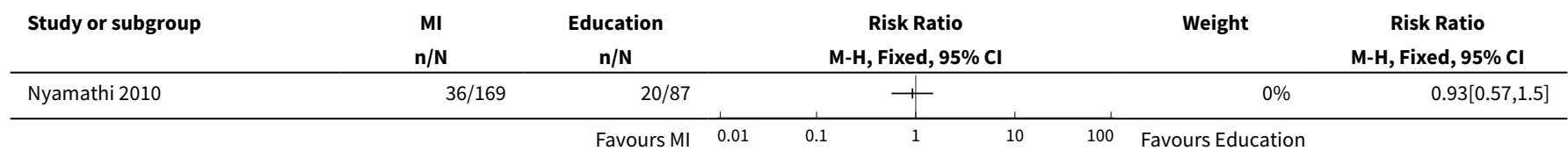

Analysis 3.8. Comparison 3 Motivational interviewing (MI) versus treatment as usual (TAU) or educational intervention only, Outcome 8 Alcohol use as decreased alcohol use at 3 months.

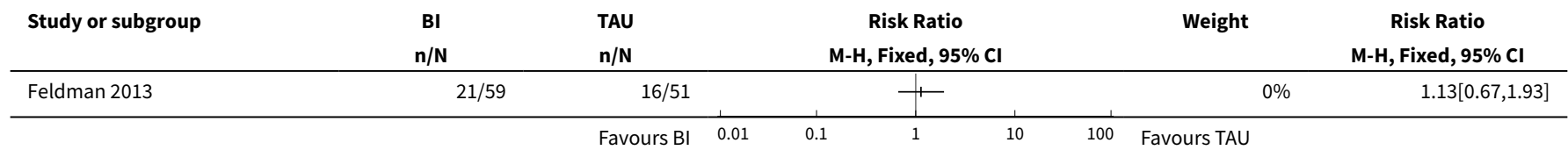

Analysis 3.9. Comparison 3 Motivational interviewing (MI) versus treatment as usual (TAU) or educational intervention only, Outcome 9 Alcohol use as decreased alcohol use at 9 months.

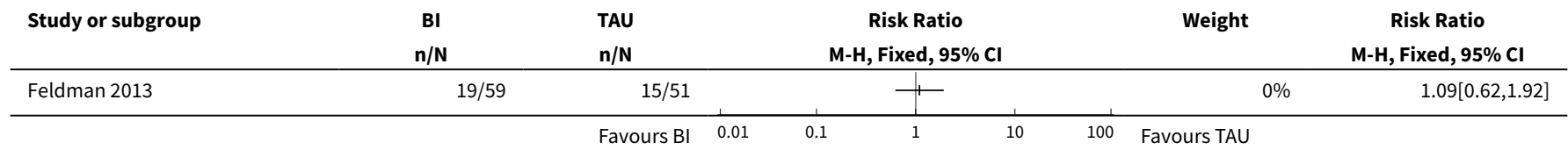

Analysis 3.10. Comparison 3 Motivational interviewing (MI) versus treatment as usual (TAU) or educational intervention only, Outcome 10 Retention - end of treatment.

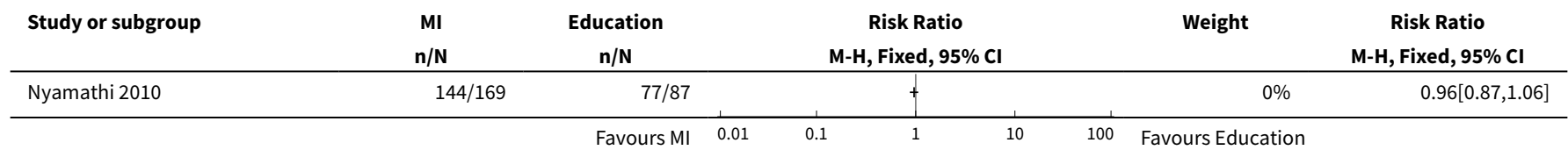


Analysis 3.11. Comparison 3 Motivational interviewing (MI) versus treatment as usual (TAU) or educational intervention only, Outcome 11 Retention at 3 months (unpublished and published data).

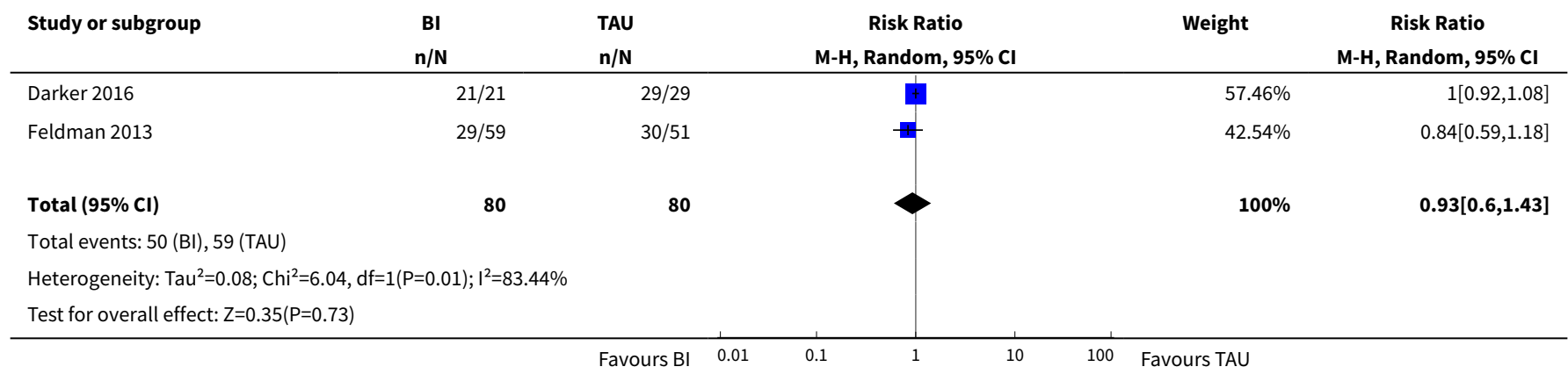

Analysis 3.12. Comparison 3 Motivational interviewing (MI) versus treatment as usual (TAU) or educational intervention only, Outcome 12 Illicit drug use as frequency of drug use (as measured by Addiction Severity Index - ASI drug).

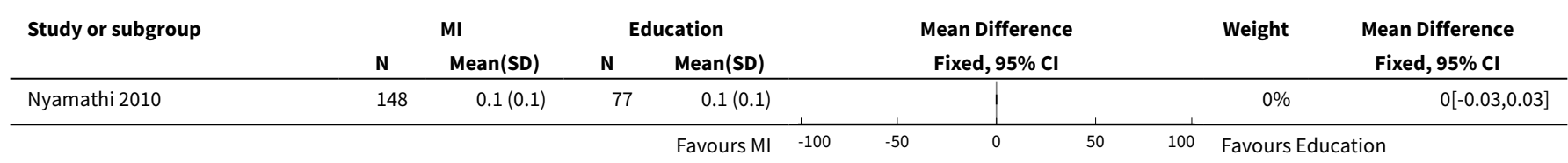

Analysis 3.13. Comparison 3 Motivational interviewing (MI) versus treatment as usual (TAU) or educational intervention only, Outcome 13 Illicit drug use as a composite drug score (frequency*severity for all drugs taken).

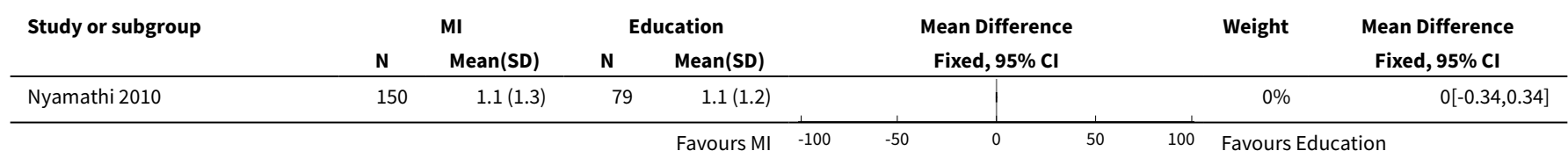

\section{Comparison 4. Brief motivational interviewing (BMI) versus assessment-only}

\begin{tabular}{|c|c|c|c|c|}
\hline Outcome or subgroup title & No. of studies & $\begin{array}{l}\text { No. of partici- } \\
\text { pants }\end{array}$ & Statistical method & Effect size \\
\hline $\begin{array}{l}1 \text { Alcohol use as number of days in the past } \\
30 \text { days with alcohol use at } 1 \text { month }\end{array}$ & 1 & & $\begin{array}{l}\text { Mean Difference (IV, } \\
\text { Fixed, } 95 \% \mathrm{CI} \text { ) }\end{array}$ & Subtotals only \\
\hline $\begin{array}{l}2 \text { Alcohol use as number of days in the past } \\
30 \text { days with alcohol use at } 6 \text { months }\end{array}$ & 1 & & $\begin{array}{l}\text { Mean Difference (IV, } \\
\text { Fixed, } 95 \% \mathrm{CI} \text { ) }\end{array}$ & Subtotals only \\
\hline $\begin{array}{l}3 \text { Alcohol use as } 25 \% \text { reduction of drinking } \\
\text { days in the past } 30 \text { days }\end{array}$ & 1 & & $\begin{array}{l}\text { Risk Ratio (M-H, Fixed, } \\
95 \% \mathrm{Cl})\end{array}$ & Subtotals only \\
\hline $\begin{array}{l}4 \text { Alcohol use as } 50 \% \text { reduction of drinking } \\
\text { days in the past } 30 \text { days }\end{array}$ & 1 & & $\begin{array}{l}\text { Risk Ratio (M-H, Fixed, } \\
95 \% \mathrm{Cl})\end{array}$ & Subtotals only \\
\hline
\end{tabular}




\begin{tabular}{|c|c|c|c|c|}
\hline Outcome or subgroup title & No. of studies & $\begin{array}{l}\text { No. of partici- } \\
\text { pants }\end{array}$ & Statistical method & Effect size \\
\hline $\begin{array}{l}5 \text { Alcohol use as } 75 \% \text { reduction of drinking } \\
\text { days in the past } 30 \text { days }\end{array}$ & 1 & & $\begin{array}{l}\text { Risk Ratio (M-H, Fixed, } \\
95 \% \mathrm{Cl})\end{array}$ & Subtotals only \\
\hline $\begin{array}{l}6 \text { Alcohol use as } 1 \text { or more drinking days' } \\
\text { reduction in the past } 30 \text { days }\end{array}$ & 1 & & $\begin{array}{l}\text { Risk Ratio (M-H, Fixed, } \\
95 \% \mathrm{Cl})\end{array}$ & Subtotals only \\
\hline $\begin{array}{l}7 \text { Alcohol use as } 7 \text { or more drinking days' } \\
\text { reduction in the past } 30 \text { days }\end{array}$ & 1 & & $\begin{array}{l}\text { Risk Ratio (M-H, Fixed, } \\
95 \% \mathrm{Cl})\end{array}$ & Subtotals only \\
\hline 8 Retention - end of treatment & 1 & & $\begin{array}{l}\text { Risk Ratio (M-H, Fixed, } \\
95 \% \mathrm{Cl})\end{array}$ & Subtotals only \\
\hline
\end{tabular}

Analysis 4.1. Comparison 4 Brief motivational interviewing (BMI) versus assessment-only, Outcome 1 Alcohol use as number of days in the past 30 days with alcohol use at 1 month.

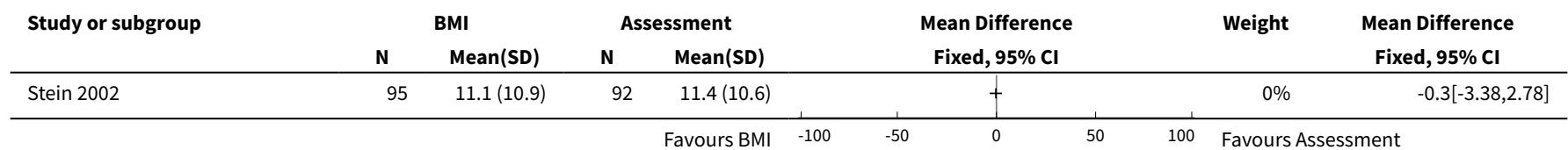

Analysis 4.2. Comparison 4 Brief motivational interviewing (BMI) versus assessment-only, Outcome 2 Alcohol use as number of days in the past 30 days with alcohol use at 6 months.

\begin{tabular}{|c|c|c|c|c|c|c|c|c|c|}
\hline \multirow[t]{2}{*}{ Study or subgroup } & \multicolumn{2}{|c|}{ BMI } & \multicolumn{2}{|c|}{ Assessment } & & \multirow{2}{*}{\multicolumn{2}{|c|}{$\begin{array}{c}\text { Mean Difference } \\
\text { Fixed, } 95 \% \mathrm{Cl}\end{array}$}} & \multirow[t]{2}{*}{ Weight } & \multirow{2}{*}{$\begin{array}{c}\text { Mean Difference } \\
\text { Fixed, } 95 \% \mathrm{Cl}\end{array}$} \\
\hline & $\mathbf{N}$ & Mean(SD) & $\mathbf{N}$ & Mean(SD) & & & & & \\
\hline Stein 2002 & 95 & $7.6(10.3)$ & 92 & $9.1(11)$ & & & & $0 \%$ & $-1.5[-4.56,1.56]$ \\
\hline
\end{tabular}

Analysis 4.3. Comparison 4 Brief motivational interviewing (BMI) versus assessmentonly, Outcome 3 Alcohol use as $25 \%$ reduction of drinking days in the past 30 days.

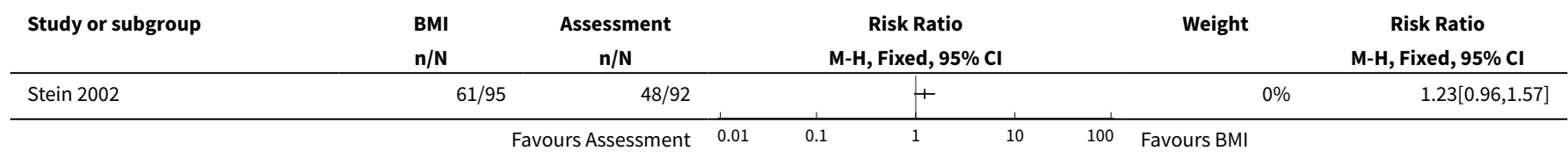


Analysis 4.4. Comparison 4 Brief motivational interviewing (BMI) versus assessmentonly, Outcome 4 Alcohol use as $\mathbf{5 0 \%}$ reduction of drinking days in the past $\mathbf{3 0}$ days.

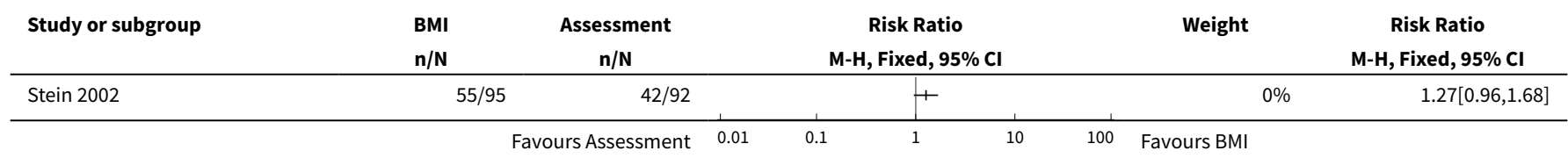

Analysis 4.5. Comparison 4 Brief motivational interviewing (BMI) versus assessmentonly, Outcome 5 Alcohol use as $\mathbf{7 5 \%}$ reduction of drinking days in the past 30 days.

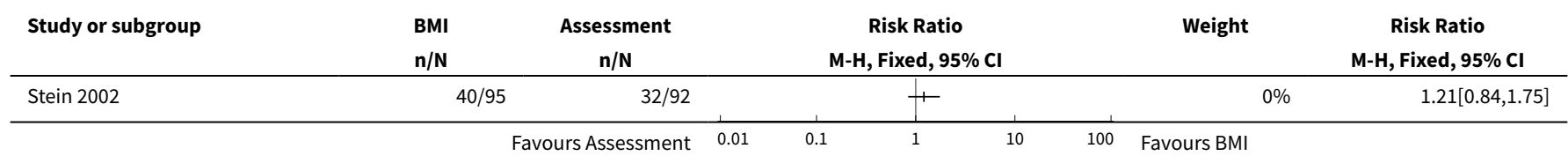

Analysis 4.6. Comparison 4 Brief motivational interviewing (BMI) versus assessmentonly, Outcome 6 Alcohol use as 1 or more drinking days' reduction in the past 30 days.

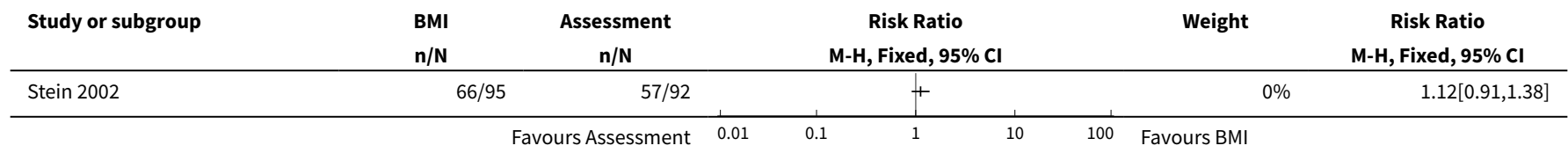

Analysis 4.7. Comparison 4 Brief motivational interviewing (BMI) versus assessmentonly, Outcome 7 Alcohol use as 7 or more drinking days' reduction in the past 30 days.

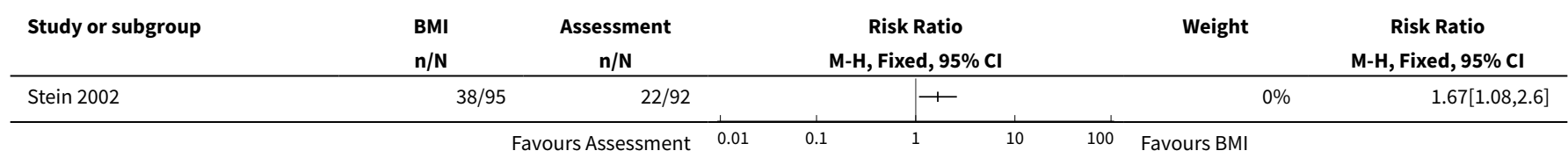

Analysis 4.8. Comparison 4 Brief motivational interviewing (BMI) versus assessment-only, Outcome 8 Retention - end of treatment.

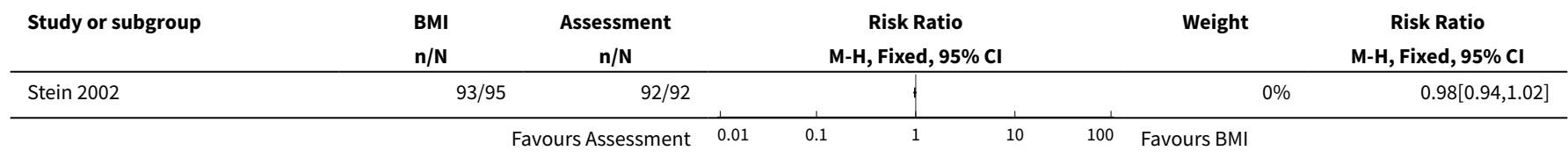


Comparison 5. Motivational interviewing intensive (MII) versus motivational interviewing (MI)

\begin{tabular}{|c|c|c|c|c|}
\hline Outcome or subgroup title & No. of studies & $\begin{array}{l}\text { No. of partici- } \\
\text { pants }\end{array}$ & Statistical method & Effect size \\
\hline $\begin{array}{l}1 \text { Alcohol addiction severity as ASI alco- } \\
\text { hol score at } 2 \text { months }\end{array}$ & 1 & & $\begin{array}{l}\text { Mean Difference (IV, Fixed, } \\
95 \% \mathrm{Cl})\end{array}$ & Subtotals only \\
\hline $\begin{array}{l}2 \text { Alcohol addiction severity as ASI alco- } \\
\text { hol score at } 4 \text { months }\end{array}$ & 1 & & $\begin{array}{l}\text { Mean Difference (IV, Fixed, } \\
95 \% \mathrm{Cl})\end{array}$ & Subtotals only \\
\hline $\begin{array}{l}3 \text { Alcohol addiction severity as ASI alco- } \\
\text { hol score at } 6 \text { months }\end{array}$ & 1 & & $\begin{array}{l}\text { Mean Difference (IV, Fixed, } \\
95 \% \mathrm{CI})\end{array}$ & Subtotals only \\
\hline $\begin{array}{l}4 \text { Retention - end of treatment (unpub- } \\
\text { lished) }\end{array}$ & 1 & & $\begin{array}{l}\text { Risk Ratio (M-H, Fixed, } \\
95 \% \mathrm{Cl})\end{array}$ & Subtotals only \\
\hline $\begin{array}{l}5 \text { Drug abstinence as } \% \text { days metham- } \\
\text { phetamine abstinent in the last } 6 \text { months } \\
\text { (TLFB) }\end{array}$ & 1 & & $\begin{array}{l}\text { Mean Difference (IV, Fixed, } \\
95 \% \mathrm{CI} \text { ) }\end{array}$ & Subtotals only \\
\hline
\end{tabular}

Analysis 5.1. Comparison 5 Motivational interviewing intensive (MII) versus motivational interviewing (MI), Outcome 1 Alcohol addiction severity as ASI alcohol score at 2 months.

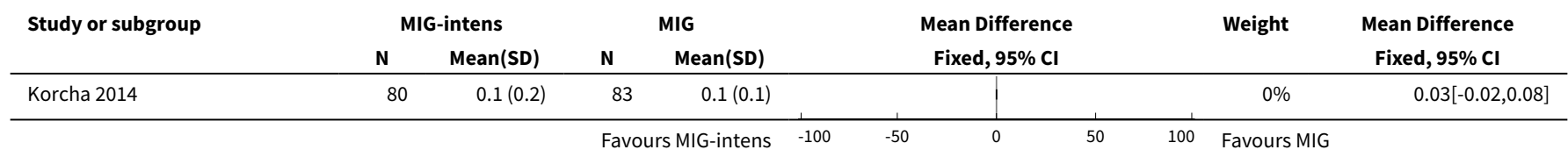

Analysis 5.2. Comparison 5 Motivational interviewing intensive (MII) versus motivational interviewing (MI), Outcome 2 Alcohol addiction severity as ASI alcohol score at 4 months.

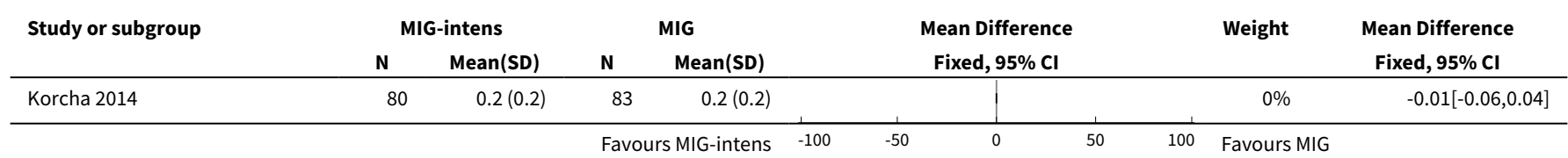

Analysis 5.3. Comparison 5 Motivational interviewing intensive (MII) versus motivational interviewing (MI), Outcome 3 Alcohol addiction severity as ASI alcohol score at 6 months.

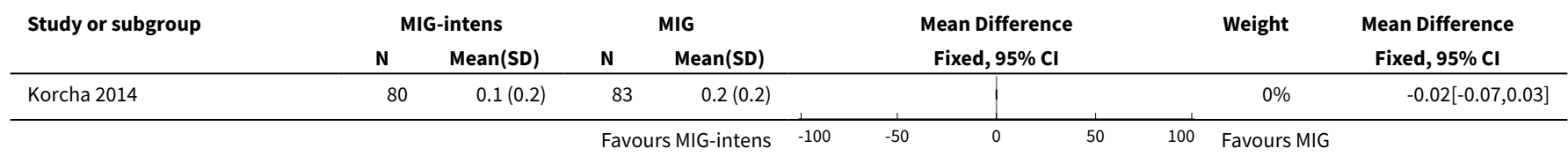


Analysis 5.4. Comparison 5 Motivational interviewing intensive (MII) versus motivational interviewing (MI), Outcome 4 Retention - end of treatment (unpublished).

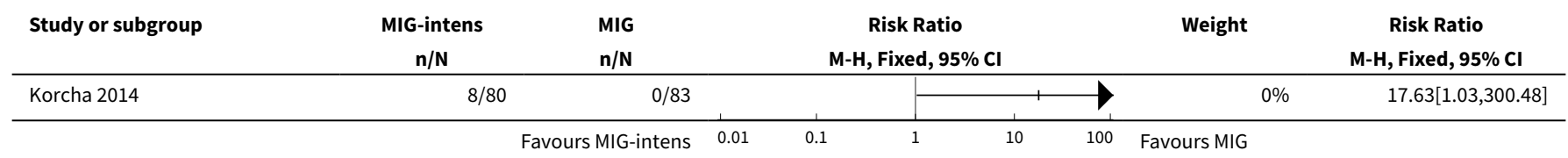

Analysis 5.5. Comparison 5 Motivational interviewing intensive (MII) versus motivational interviewing (MI), Outcome 5 Drug abstinence as \% days methamphetamine abstinent in the last 6 months (TLFB).

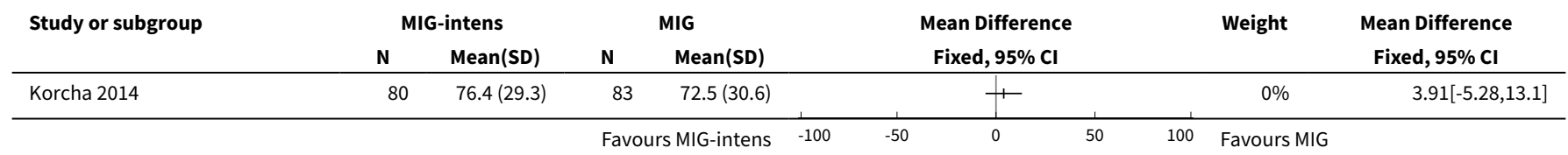

\section{APPENDICES}

\section{Appendix 1. MEDLINE search strategy}

MEDLINE (via PubMed)

Thursday, August 3, 2017 (726 hits):

\section{Search terms to locate drug abuse:}

1. "Substance-Related Disorders"[MeSH]

2. addict* [tiab] OR overdose[tiab] OR intoxicat*[tiab] OR abstin*[tiab] OR abstain*[tiab] OR withdrawal*[tiab] OR abuse*[tiab] OR use*[tiab] OR misuse[tiab] OR disorder ${ }^{\star}[$ tiab] OR dependen*[tiab]

\section{3. \#1 or \#2}

\section{Search terms to identify drugs:}

4. "heroin"[mh] OR heroin[tiab]

5. narcotic* $[$ tiab]

6. drug[tiab] OR polydrug[tiab] OR substance[tiab] OR opioid[tw] OR opiate[tw] OR hallucinogen[tiab] OR cocaine[tw] OR benzodiazepine*[tw] OR amphetamine*[tw] OR "anti-anxiety-agents"[tiab] OR barbiturate*[tiab] OR "lysergic acid"[tiab] OR ketamine[tiab] OR cannabis[tiab] OR marihuana[tiab] OR hashish[tiab] OR opium[tiab] OR inhalant*[tiab] OR solvent[tiab] OR steroid*[tiab] OR methadone[tiab] OR morphine[tiab] OR ecstasy[tiab] OR MDMA[tiab]

7. "Street Drugs"[MeSH]

8. "Designer Drugs"[MeSH]

9. \#4 or \#5 or \#6 or \#7 or \#8

\section{Search terms to identify alcohol:}
10. alcohol*[tiab]
11. binge[tiab] OR drink ${ }^{\star}[$ tiab]
12. alcoholism[MeSH]
13. alcoholic Intoxication [MeSH]
14. "Drinking behavior" [MeSH]
15. \#10 or \#11 or \#12 or \#13 or \#14

Search terms to locate interventions: 
16. psychotherapy $[\mathrm{MeSH}]$

17. incentive* $\left[\right.$ tiab] OR voucher[tiab] OR psychotherap*[tiab] OR psychosocial* ${ }^{\star}$ tiab] OR "behaviour therapy" [tiab] OR "behavior therapy"[tiab] OR reinforcement[tiab] OR motivation*[tiab] OR contingent*[tiab] OR advice[tiab] OR biofeedback[tiab] OR community[tiab] OR stimulation[tiab] OR education*[tiab]

18. "brief intervention"[tiab]

19. "early intervention"[tiab]

20. "minimal intervention" [tiab]

21. "counselling"[MeSH] or counsel[tiab]

22. "cognitive therapy" [tiab]

23. "family therapy" [tiab]

24. "social skill"[tiab]

25. "stress management training" [tiab]

26. "supportive expressive therapy" [tiab]

27. neurobehavioral ${ }^{\star}[$ tiab]

28. "coping skill"[tiab]

29. "self-control training"'[tiab]

30. "social support"'[MeSH]

31. "relaxation techniques"[MeSH]

32. "case management"[MeSH]

33. \#16 or \#17 or \#18 or \#19 or \#20 or \#21 or \#22 or \#23 or \#24 or \#25 or \#26 or \#27 or \#28 or \#29 or \#30 or \#31 or \#32

\section{Search terms to locate randomised controlled trials}

34. randomised controlled trial [pt]

35. controlled clinical trial [pt]

36. random^[tiab]

37. placebo [tiab]

38. drug therapy [sh]

39. trial [tiab]

40. groups [tiab]

41. \#34 or \#35 or \#36 or \#37 or \#38 or \#39 or \#40

42. Animals [mh] NOT Humans [mh]

43. \#41 NOT \#42

44. \#3 AND \#9 AND \#\#15 AND \#33 AND \#43

\section{Appendix 2. CENTRAL (CLIB) search strategy}

\section{The Cochrane Library}

\section{Issue 7, July 2017 (613 hits)}

\#1. MeSH descriptor Substance-Related Disorders explode all trees

\#2. ((stimulant* or polydrug* or drug* or substance) near/3 (abuse* or abusing or depend ${ }^{\star}$ or addict ${ }^{\star}$ or disorder $^{\star}$ or intoxicat $^{\star}$ or misus ${ }^{\star}$ or use $\left.e^{\star}\right): t i, a b$

\#3. (\#1 OR \#2)

\#4. (abuse* or abusing or depend ${ }^{\star}$ or addict ${ }^{\star}$ or depend ${ }^{\star}$ or overdos ${ }^{\star}$ or withdraw ${ }^{\star}$ or abstain* or abstinen ${ }^{\star}$ or disorder ${ }^{\star}$ or intoxicat ${ }^{\star}$ or misus $\left.^{\star}\right): t i, a b, k w$

\#5. use $:$ ti, ab

\#6. (\#4 OR \#5)

\#7. MeSH descriptor Narcotics explode all trees

\#8. (heroin or morphine* or diamorphine or diacetylmorphine or morfin* or narcotic* or methadone):ti,ab,kw

\#9. MeSH descriptor Methadone explode all trees

\#10. (Opioid* or opiate* or opium):ti,ab,kw

\#11. MeSH descriptor Amphetamine explode all trees

Psychosocial interventions to reduce alcohol consumption in concurrent problem alcohol and illicit drug users (Review) 
\#12. (amphetamine $e^{\star}$ or dextroamphetamine ${ }^{\star}$ or methamphetamine or Methylamphetamine $\left.e^{\star}\right): t i, a b, k w$

\#13. MeSH descriptor Methamphetamine explode all trees

\#14. (ecstasy or MDMA or hallucinogen $\left.{ }^{\star}\right): t i, a b, k w$

\#15. MeSH descriptor Hallucinogens explode all trees

\#16. MeSH descriptor Street Drugs explode all trees

\#17. MeSH descriptor Cocaine explode all trees

\#18. (crack or cocaine):ti,ab,kw

\#19. MeSH descriptor Cannabis explode all trees

\#20. (cannabis or marijuana or marihuana or Hashish):ti,ab,kw

\#21. (Lysergic NEXT Acid):ti,ab,kw

\#22. (LSD):ti,ab,kw

\#23. (benzodiazepine ${ }^{\star}$ or barbiturate* or ketamine or solvent or inhalant):ti,ab,kw

\#24. (\#7 OR \#8 OR \#9 OR \#10 OR \#11 OR \#12 OR\#13 OR\#14 OR\#15 OR \#16 OR \#17 OR \#18 OR\#19 OR \#20 OR\#21 OR \#22 OR \#23)

\#25. (\#6 AND \#24)

\#26. (\#3 OR \#25)

\#27. (alcohol*):ti,ab,kw

\#28. (binge or drink ${ }^{\star}$ ):ti,ab

\#29. MeSH descriptor Drinking Behavior explode all trees

\#30. MeSH descriptor Alcoholism explode all trees

\#31. MeSH descriptor Alcoholic Intoxication explode all trees

\#32. (\#27 OR \#28 OR \#29 OR \#30 OR \#31)

\#33. MeSH descriptor Psychotherapy explode all trees

\#34. (psychotherap* or psychosocial or voucher or reinforcement or motivation* or contingent* or biofeedback or community or stimulation or education* or counsel $\left.^{\star}\right):$ ti,ab,kw

\#35. (social near/2 skill*):ti,ab

\#36. (coping near/2 skill):ti,ab

\#37. MeSH descriptor Counseling explode all trees

\#38. (behavi ${ }^{\star}$ near/2 therap $\left.{ }^{\star}\right): t i, a b$

\#39. MeSH descriptor Reinforcement (Psychology) explode all trees

\#40. (brief near intervention):ti,ab

\#41. (early near intervention):ti,ab

\#42. (minimal near intervention):ti,ab

\#43. (cognitive near therapy):ti,ab

\#44. (family near therapy):ti,ab

\#45. (stress near management near training):ti,ab 
\#46. (supportive near expressive near therapy):ti,ab

\#47. MeSH descriptor Social Support explode all trees

\#48. MeSH descriptor Case Management explode all trees

\#49. (self near control near training):ti,ab

\#50. neurobehavioral ${ }^{*}: a b, t i$

\#51. (\#33 OR \#34 OR \#35 OR \#36 OR \#37 OR \#38 OR \#39 OR \#40 OR \#41 OR \#42 OR \#43 OR \#44 OR \#45 OR \#46 OR \#47 OR \#48 OR \#49 OR \#50)

\#52. (\#26 AND \#32 AND \#51)

\#53. "\#26 AND \#32 AND \#51) in Cochrane Central Register of Controlled Trials"

\section{Appendix 3. Embase search strategy}

\section{Embase (via embase.com)}

\section{Thursday, August 3, 2017 (695 hits)}

\#1. 'addiction'/exp

\#2. dependen*:ab,ti OR addict*:ab,ti OR overdos*:ab,ti OR intoxicat*ab,ti OR abstin*:ab,ti OR abstain:ab,ti OR withdraw*:ab,ti OR abus*:ab,ti OR use*:ab,ti OR misus*:ab,ti OR disorder*:ab,ti

\#3. \#1 OR \#2

\#4. 'diamorphine'/exp

\#5. diamorphine:ab,ti OR heroin:ab,ti OR narcotic*:ab,ti OR drug*:ab,ti OR polydrug:ab,ti OR substance:ab,ti OR opioid:ab,ti OR opiate:ab,ti OR hallucinogen:ab,ti OR cocaine:ab,ti OR benzodiazepine:ab,ti OR amphetamine:ab,ti OR 'anti-anxiety-agents':ab,ti OR barbiturate:ab,ti OR 'lysergic acid':ab,ti OR ketamine:ab,ti OR cannabis:ab,ti OR marihuana:ab,ti OR marijuana:ab,ti OR hashish:ab,ti OR opium:ab,ti OR inhalant:ab,ti OR solvent:ab,ti OR steroid:ab,ti OR methadone:ab,ti OR morphine:ab,ti OR ecstasy:ab,ti OR mdma:ab,ti

\#6. 'designer drug'/exp

\#7. 'street drug'/exp

\#8. \#5 OR \#6 OR \#7

\#9. alcohol*:ab,ti OR binge:ab,ti OR drink* ${ }^{*}$ ab,ti

\#10. 'alcohol intoxication'/exp

\#11. drinking behavior'/exp

\#12. 'alcohol abuse'/exp

\#13. \#9 OR \#10 OR \#11 OR\#12

\#14. 'psychotherapy'/exp

\#15. incentive*:ab,ti OR voucher:ab,ti OR psychotherap*:ab,ti OR psychosocial*:ab,ti OR reinforcement:ab,ti OR motivation*:ab,ti OR contingent ${ }^{\star}: a b, t i$ OR advice:ab,ti OR biofeedback:ab,ti OR community:ab,ti OR stimulation:ab,ti OR education*:ab,ti

\#16. 'behaviour therapy':ab,ti OR 'behavior therapy':ab,ti

\#17. counsel*:ab,ti

\#18. 'counseling'/exp

\#19. 'cognitive therapy':ab,ti OR 'family therapy':ab,ti OR 'social skill':ab,ti OR 'stress management training':ab,ti OR 'supportive expressive therapy':ab,ti

\#20. 'coping skill':ab,ti OR 'social skill':ab,ti

Psychosocial interventions to reduce alcohol consumption in concurrent problem alcohol and illicit drug users (Review) 
\#21. 'social support'/exp

\#22. 'case management'/exp

\#23. 'relaxation therapy':ab,ti

\#24. 'self-control training':ab,ti

\#25. neurobehavioral*:ab,ti

\#26. \#9 OR \#10 OR \#11 OR \#12 OR \#13 OR \#14 OR \#15 OR \#16 OR \#17 OR \#18 OR \#19 OR \#20 OR \#21 OR \#22 OR \#23 OR \#24 OR \#25

\#27. 'crossover procedure'/exp

\#28. 'double blind procedure'/exp

\#29. 'single blind procedure'/exp

\#30. 'controlled clinical trial'/exp

\#31. 'clinical trial'/exp

\#32. placebo:ab,ti OR 'double blind':ab,ti OR 'single blind':ab,ti OR assign*:ab,ti OR allocat*:ab,ti OR volunteer*ab,ti

\#33. random*:ab,ti OR factorial*:ab,ti OR crossover:ab,ti OR (cross:ab,ti AND over:ab,ti)

\#34. 'randomized controlled trial'/exp

\#35. \#27 OR \#28 OR \#29 OR \#30 OR \#31 OR\#32 OR \#33 OR \#34

\#36. \#3 AND \#8 AND \#13 AND \#26 AND \#35 AND [humans]/lim AND [embase]/lim

\section{Appendix 4. CINAHL search strategy}

\section{CINAHL (via EBSCO)}

\section{Thursday, August 3, 2017 (278 hits)}

S01. MH "Substance Use Disorders"

S02. TX(drug N3 addict ${ }^{\star}$ ) or TX(drug N3 dependen ${ }^{\star}$ ) or TX(drug N3 abuse ${ }^{\star}$ ) or TX(drug N3 misus $\left.{ }^{\star}\right)$ or TX(drug N3 use $\left.{ }^{\star}\right)$

S03. TX(substance N3 addict*) or TX(substance N3 dependen*) or TX(substance N3 abuse*) or TX(substance N3 misus*)

S04. S1 or S2 or S3

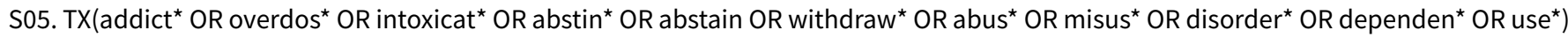

S06. MH "Heroin"

S07. MH "Narcotics"

S08. MH "Designer Drugs"

S09. TX(polydrug or opioid or opiate or opium or hallucinogen or cocaine or benzodiazepine* or amphetamine*or "anti-anxiety-agents" or barbiturate* or "lysergic acid" or ketamine or cannabis or marihuana or hashish or inhalant* or solvent or steroid* or methadone or morphine)

S10. TI ecstasy or TI mdma or AB ecstasy or AB mdma

$\mathrm{S} 11 . \mathrm{S} 6$ or $\mathrm{S} 7$ or $\mathrm{S} 8$ or $\mathrm{S} 9$ or $\mathrm{S} 10$

S12. S5 and S11

S13. S4 or S12

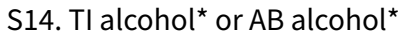

S15. Tl drink* or Tl binge or AB drink* or AB binge

Psychosocial interventions to reduce alcohol consumption in concurrent problem alcohol and illicit drug users (Review) 
S16. MH "Alcoholism"

S17. MH "Alcoholic Intoxication"

S18. (MH "Drinking Behavior+")

S19. S14 or S15 or S16 or S17 or S18

S20. MH "Clinical Trials+"

S21. PT Clinical trial

S22. TI clinic ${ }^{\star}$ N1 trial ${ }^{*}$ or AB clinic* N1 trial ${ }^{\star}$

S23. TI ( singl ${ }^{\star}$ or doubl* or trebl* or tripl ${ }^{\star}$ ) and TI ( blind ${ }^{\star}$ or mask ${ }^{\star}$ )

S24. $A B$ ( singl ${ }^{\star}$ or doubl ${ }^{\star}$ or trebl ${ }^{\star}$ or tripl ${ }^{\star}$ ) and AB ( blind $^{\star}$ or mask ${ }^{\star}$ )

S25. TI randomi?ed control ${ }^{\star}$ trial $^{*}$ or AB randomi?ed control ${ }^{\star}$ trial $^{*}$

S26. MH "Random Assignment"

S27. TI random* allocat* or AB random* allocat*

S28. MH "Placebos"

S29. TI placebo* or AB placebo*

S30. MH "Quantitative Studies"

$\mathrm{S} 31 . \mathrm{S} 20$ or $\mathrm{S} 21$ or $\mathrm{S} 22$ or $\mathrm{S} 23$ or $\mathrm{S} 24$ or $\mathrm{S} 25$ or $\mathrm{S} 26$ or $\mathrm{S} 27$ or $\mathrm{S} 28$ or $\mathrm{S} 29$ or $\mathrm{S} 30$

S32. S13 and S19 and S31

S33. S13 and S19 and S31

Limiters - Exclude MEDLINE records; Human

\section{Appendix 5. PsycINFO search strategy \\ PsycINFO (via EBSCO)}

\section{July, Week 4, 2017 (947 hits)}

1. (((psychotherap*) OR TI(psychosocial*) OR TI("behaviour therapy") OR TI("behavior therapy") OR TI(reinforcement) OR TI(motivation*) OR TI(contingent*) OR TI(advice) OR TI(biofeedback) OR TI(community) OR TI(stimulation) OR TI(education*) OR TI(incentive*) OR $\mathrm{TI}($ voucher)) OR ((psychotherap*) OR AB(psychosocial*) OR AB("behaviour therapy") OR AB("behavior therapy") OR AB(reinforcement) OR AB (motivation*) OR AB(contingent*) OR AB(advice) OR AB(biofeedback) OR AB(community) OR AB(stimulation) OR AB(education*) OR MJ("psychotherapy") OR AB(incentive*) OR AB(voucher)))

2. ((TI(alcohol $\left.{ }^{\star}\right)$ OR TI(binge) OR TI(drink $\left.\left.{ }^{\star}\right)\right)$ OR (AB(alcohol $\left.{ }^{\star}\right)$ OR AB(binge) OR AB(drink $\left.\left.{ }^{\star}\right)\right)$ OR (KW(alcohol $\left.{ }^{\star}\right)$ OR KW(binge) OR KW(drink $\left.\left.{ }^{\star}\right)\right)$ OR DE(Alcoholism) OR DE("Alcohol intoxication") OR DE("Alcohol drinking patterns"))

3. ((KW("heroin") OR KW("morphine")) OR KW("narcotics") OR (TI(drug) OR AB(drug) OR TI(polydrug) OR AB(polydrug) OR TI(substance) OR AB(substance) OR TI(opioid) OR AB(opioid) OR TI(opiate) OR AB(opiate) OR TI("hallucinogenic drugs") OR AB("hallucinogenic drugs") OR KW("psychedelic drugs") OR KW("Lysergic Acid Diethylamide") OR TI(LSD) OR AB(LSD) OR TI(cocaine) OR AB(cocaine) OR TI(benzodiazepine*) OR AB(benzodiazepine*) OR TI("amphetamine") OR AB("amphetamine") OR TI("anti-anxiety-agents") OR AB("antianxiety-agents") OR TI(barbiturate*) OR AB(barbiturate*) OR TI(ketamine) OR AB(ketamine) OR TI("cannabis") OR AB("cannabis") OR TI("marihuana") OR AB("marihuana") OR TI(hashish) OR AB(hashish) OR TI(opium) OR AB(opium) OR TI("inhalant abuse") OR $A B$ ("inhalant abuse") OR TI(solvent) OR AB(solvent) OR TI(steroid*) OR AB(steroid*) OR TI("methadone") OR AB("methadone") OR $\mathrm{TI}$ (ecstasy) OR AB(ecstasy) OR TI("methylenedioxyamphetamine") OR AB("methylenedioxyamphetamine")) OR (KW(street drug*) OR $\mathrm{KW}($ designer drug*)))

4. (SU("drug abuse") OR (KW(addict* OR abus* OR dependen*)) OR TX(overdose) OR TX(intoxicat*) OR TX(abstin*) OR TX(abstain) OR TX(withdrawal) OR TX(abuse) OR TX(use) OR TX(misuse) OR TX(disorder ${ }^{\star}$ ) OR KW("drug addiction"))

5. $\mathrm{DE}$ (treatment effectiveness evaluation)

Psychosocial interventions to reduce alcohol consumption in concurrent problem alcohol and illicit drug users (Review) 


\section{6. $\mathrm{DE}($ clinical trials)}

7. $\mathrm{DE}$ (mental health program evaluation)

8. DE(placebo)

9. $\mathrm{TI}\left(\right.$ placebo $\left.^{\star}\right)$ OR AB(placebo*)

10. $A B$ (randomly)

11. $\mathrm{TI}\left(\right.$ randomi*ed) OR AB(randomi $\left.{ }^{\star} e d\right)$

12. $\mathrm{TI}$ (trial) OR AB(trial)

13. $\mathrm{TI}\left(\left(\right.\right.$ singl $l^{\star}$ OR doubl* OR trebl* OR tripl*) W3 (blind ${ }^{\star}$ OR mask ${ }^{\star}$ OR dummy)) OR AB((singl* OR doubl* OR trebl* OR tripl*) W3 (blind OR mask $^{\star}$ OR dummy))

14. TI((control $\left.{ }^{\star}\right)$ W3 (trial ${ }^{\star}$ OR study OR studies OR group $\left.\left.{ }^{\star}\right)\right)$ OR AB $\left(\left(\right.\right.$ control $\left.^{\star}\right)$ W3 (trial ${ }^{\star}$ OR study OR studies OR group $\left.\left.{ }^{\star}\right)\right)$

15. $\mathrm{TI}\left(\right.$ factorial $\left.^{\star}\right)$ OR AB $($ factorial*)

16. $\mathrm{TI}\left(\right.$ allocat $\left.^{\star}\right) \mathrm{OR} A B\left(\right.$ allocat $\left.^{\star}\right)$

17. $\mathrm{TI}\left(\operatorname{assign}^{\star}\right) \mathrm{OR} A B\left(\operatorname{assign}^{\star}\right)$

18. $\mathrm{TI}_{\left(\text {volunteer }^{\star}\right)} \mathrm{OR} \mathrm{AB}\left(\right.$ volunteer $\left.^{\star}\right)$

19. 5 AND 6 AND 7 AND 8 AND 9 AND 10 AND 11 AND 12 AND 13 AND 14 AND 15 AND 16 AND 17 AND 18

20. 1 AND 2 AND 3 AND 4 AND 19

21. 20 AND (Population Group: Human)

Appendix 6. Criteria for risk of bias in RCTs and CCTs

\begin{tabular}{lll}
\hline Item & Judgement & Description \\
\hline $\begin{array}{l}\text { 1. Random sequence } \\
\text { generation (selection } \\
\text { bias) }\end{array}$ & Low risk & $\begin{array}{l}\text { The investigators describe a random component in the sequence generation } \\
\text { process such as: random number table; computer random number generator; } \\
\text { coin tossing; shuffling cards or envelopes; throwing dice; drawing of lots; min- } \\
\text { imisation }\end{array}$ \\
\hline
\end{tabular}

High risk

The investigators describe a non-random component in the sequence generation process such as: odd or even date of birth; date (or day) of admission; hospital or clinic record number; alternation; judgement of the clinician; results of a laboratory test or a series of tests; availability of the intervention

Unclear risk

Insufficient information about the sequence generation process to permit judgement of low or high risk

2. Allocation conceal- Low risk
ment (selection bias)

Investigators enrolling participants could not foresee assignment because one of the following, or an equivalent method, was used to conceal allocation: central allocation (including telephone, web-based, and pharmacy-controlled, randomisation); sequentially numbered drug containers of identical appearance; sequentially numbered, opaque, sealed envelopes cause one of the following method was used: open random allocation schedule (e.g. a list of random numbers); assignment envelopes without appropriate safeguards (e.g. if envelopes were unsealed or nonopaque or not sequentially numbered); alternation or rotation; date of birth; case record number; any other explicitly unconcealed procedure 
(Continued)

Unclear risk Insufficient information to permit judgement of low or high risk This is usually the case if the method of concealment is not described or not described in sufficient detail to allow a definite judgement

\begin{tabular}{|c|c|c|}
\hline $\begin{array}{l}\text { 3. and 4. Blinding of } \\
\text { outcome assessor (de- }\end{array}$ & Low risk & $\begin{array}{l}\text { No blinding of outcome assessment, but the review authors judge that the out- } \\
\text { come measurement is not likely to be influenced by lack of blinding }\end{array}$ \\
\hline Objective outcomes. & & $\begin{array}{l}\text { Blinding of outcome assessment ensured, and unlikely that the blinding could } \\
\text { have been broken }\end{array}$ \\
\hline
\end{tabular}

Subjective outcomes.

High risk

No blinding of outcome assessment, and the outcome measurement is likely to be influenced by lack of blinding

Blinding of outcome assessment, but likely that the blinding could have been broken, and the outcome measurement is likely to be influenced by lack of blinding

5. Incomplete outcome
data (attrition bias)
For all outcomes except
retention in treatment
or drop-out

Unclear risk

Insufficient information to permit judgement of low or high risk

Low risk

Lew risk

High risk
No missing outcome data

Reasons for missing outcome data unlikely to be related to true outcome (for survival data, censoring unlikely to be introducing bias)

Missing outcome data balanced in numbers across intervention groups, with similar reasons for missing data across groups

For dichotomous outcome data, the proportion of missing outcomes compared with observed event risk not enough to have a clinically relevant impact on the intervention effect estimate

For continuous outcome data, plausible effect size (difference in means or standardised difference in means) among missing outcomes not enough to have a clinically relevant impact on observed effect size

Missing data have been imputed using appropriate methods

All randomised participants are reported/analysed in the group they were allocated to by randomisation irrespective of non-compliance and co-interventions (intention to treat)

Reason for missing outcome data likely to be related to true outcome, with either imbalance in numbers or reasons for missing data across intervention groups

For dichotomous outcome data, the proportion of missing outcomes compared with observed event risk enough to induce clinically relevant bias in intervention effect estimate

For continuous outcome data, plausible effect size (difference in means or standardised difference in means) among missing outcomes enough to induce clinically relevant bias in observed effect size

'As-treated' analysis done with substantial departure of the intervention received from that assigned at randomisation

Unclear risk Insufficient information to permit judgement of low or high risk (e.g. number randomised not stated, no reasons for missing data provided; number of dropout not reported for each group) 
WHAT'S NEW

\begin{tabular}{lll}
\hline Date & Event & Description \\
\hline 14 June 2018 & $\begin{array}{l}\text { New citation required but conclusions } \\
\text { have not changed }\end{array}$ & $\begin{array}{l}\text { Clinical implications downgraded to: "no reliable conclusions } \\
\text { can be drawn regarding the effectiveness of different types of } \\
\text { psychosocial interventions for the target condition". }\end{array}$ \\
\hline
\end{tabular}

3 August $2017 \quad$ New search has been performed

\begin{abstract}
We updated the searches and included three new studies, with a total of 231 participants. The new 'Risk of bias' assessment introduced "Selective reporting" as a domain. Also, we think that lack of blinding of participants and personnel did not introduce bias and we did not assess the risk of performance bias.
\end{abstract}

Feldman et al. 2011 was rated as having unclear risk of bias due to the lack of information on randomisation (selection bias).

Clinical implications downgraded to: "no reliable conclusions can be drawn regarding the effectiveness of different types of psychosocial interventions for the target condition"

\section{H I S T ORY}

Protocol first published: Issue 8, 2011

Review first published: Issue 11, 2012

\begin{tabular}{lll}
\hline Date & Event & Description \\
\hline 14 November 2014 & Amended & Amended typo in the PLS \\
\hline 14 November 2014 & $\begin{array}{l}\text { New citation required but conclusions } \\
\text { have not changed }\end{array}$ & No new studies included. \\
\hline 23 June 2014 & New search has been performed & Searches updated \\
\hline
\end{tabular}

\section{CONTRIBUTIONS OF AUTHORS}

JK: designed and co-ordinated the review, wrote and re-drafted the protocol and full review.

$\mathrm{ChF}$ and HT: double-screened titles, abstracts and full texts, carried out double data extraction and commented on draft updates. WC, CAF, CSMOG: contributed to design of the first version of this review and commented on drafts.

LGG, JS: provided methodological advice and commented on review drafts.

$\mathrm{GB}, \mathrm{EK}, \mathrm{CD}$ : commented on review drafts.

\section{DECLARATIONS OF INTEREST}

Jan Klimas: none known

Christopher Fairgrieve: none known

Helen Tobin: none known

Catherine-Anne Field: none known

Clodagh SM O'Gorman: none known 
Liam G Glynn: none known

Eamon Keenan: none known

Jean Saunders: none known

Gerard Bury: none known

Colum Dunne: none known

Walter Cullen: none known

\section{SOURCES OF SUPPORT}

\section{Internal sources}

- No sources of support supplied

\section{External sources}

- Cochrane Training Fellowship (No. CTF/2010/9) from Health Research Board, Ireland.

- PINTA feasibility study (No. HRA_HSR/2012/14) grant from Health Research Board, Ireland.

- Medical Emergency Responders: Integration and Training (MERIT) grant from Department of Health, Ireland.

- Irish Research Council, Ireland.

Salary stipend ELEVATEPD/2014/6

- European Commission, Belgium.

Salary stipend 701698

\section{DIFFERENCES BETWEEN PROTOCOLANDREVIEW}

According to the protocol we intended to exclude studies comparing psychosocial with pharmacological treatments. However, we exempted trials with two psychosocial arms in addition to pharmacological arms from this rule in the review. We did not conduct the subgroup/sensitivity analyses planned in the protocol owing to the lack of studies identified. We simplified the wording of the primary and secondary outcome measures from those in the protocol for ease of presentation, as follows:

1. reduction and/or stabilisation of alcohol use = alcohol use or abstinence;

2. illicit drug use outcomes (changes in illicit drug use) = illicit drug use or abstinence.

We have added new references to the Background sections 'Description of the condition' and 'Why is it important to do this review', to reflect recent developments in the field. We reduced the text in the sections 'Experimental interventions' and 'Types of participants' so as to exclude examples. We removed mention of the Newcastle-Ottawa scale for assessing the quality of non-randomised studies from the review as it was not used in any of the studies (observational studies were not included in the review).

We have assessed the risk of selective reporting bias.

We have renamed and moved the secondary outcome "Engagement in further treatment (i.e. drop-out rates)" among primary outcomes as "retention in treatment (measured as number of people completing all treatment sessions or retained at three months - for studies of brief interventions)."

\section{INDEX TERMS}

\section{Medical Subject Headings (MeSH)}

Adaptation, Psychological; Alcohol Drinking [ ${ }^{*}$ prevention \& control] [psychology]; Alcoholics Anonymous; Cocaine-Related Disorders [complications] [therapy]; Drug Users [ ${ }^{\star}$ psychology]; Hepatitis C [prevention \& control]; Motivational Interviewing [ ${ }^{\star}$ methods]; Psychotherapy [ ${ }^{\star}$ methods]; Psychotherapy, Brief; Randomized Controlled Trials as Topic; Self-Help Groups; Substance-Related Disorders [ ${ }^{\star}$ complications] [therapy]; Temperance [statistics \& numerical data]; Time Factors

\section{MeSH check words}

Adult; Humans 